Distribution

SAND94-2872

Category UC-721

Unlimited Release

Printed January 1995

\title{
SNL/NM Weapon Hardware Characterization Process Development Report
}

\author{
E. W. Graff \\ Air Delivered Weapons Department 5111 \\ W. B. Chambers \\ Chemical \& X-Ray Analysis Department 1824 \\ Sandia National Laboratories \\ Albuquerque, NM 87185
}

\begin{abstract}
This report describes the process used by Sandia National Laboratories, New Mexico to characterize weapon hardware for disposition. The report describes the following basic steps: (1) the drawing search process and primary hazard identification; (2) the development of Disassembly Procedures (DPs), including demilitarization and sanitization requirements; (3) the generation of a "disposal tree"; (4) generating RCRA waste disposal information; and (5) documenting the information. Additional data gathered during the characterization process supporting hardware grouping and recycle efforts is also discussed.




\section{Acknowledgment}

The Weapon Hardware Inventory Reduction Effort Project and the New Mexico Weapon Systems Dismantlement and Process Development Project have been successful due to the hard work of personnel from a wide spectrum of Sandia organizations. Personnel from 1824, 2222, 2481, 2483, $2652,2653,2671,2709,5111,6625,7572,7573,7711,13214$, and 13316 have made significant contributions. The authors wish to thank in particular Ruth Burger (5111); Paul Salazar (Pantex, formerly 5111); Carmel Chavez (7573); Donna Eaton and Timothy Meeks (13316); Larry Friday and Rosemarie Renn (2709); David Van Ornum (2481-2); and Jack Trodden (retired, formerly 13214) for their support. This report also makes use of data generated by the WeDID project, supported primarily by Pat Neiswander, Jim Lutz, and Ted Wheelis (6625). 


\section{DISCLAIMER}

This report was prepared as an account of work sponsored by an agency of the United States Government. Neither the United States Government nor any agency thereof, nor any of their employees, make any warranty, express or implied, or assumes any legal liability or responsibility for the accuracy, completeness, or usefulness of any information, apparatus, product, or process disclosed, or represents that its use would not infringe privately owned rights. Reference herein to any specific commercial product, process, or service by trade name, trademark, manufacturer, or otherwise does not necessarily constitute or imply its endorsement, recommendation, or favoring by the United States Government or any agency thereof. The views and opinions of authors expressed herein do not necessarily state or reflect those of the United States Government or any agency thereof. 


\title{
DISCLAIMER
}

\author{
Portions of this document may be illegible \\ in electronic image products. Images are \\ produced from the best available original \\ document.
}




\section{CONTENTS}

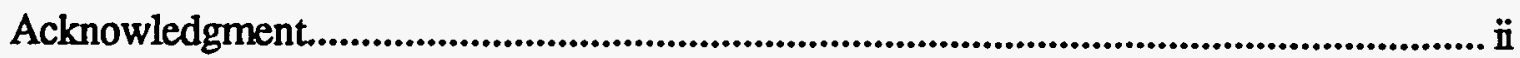

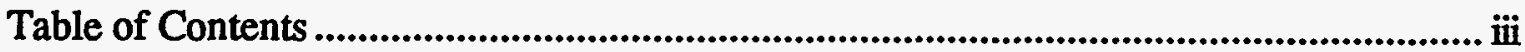

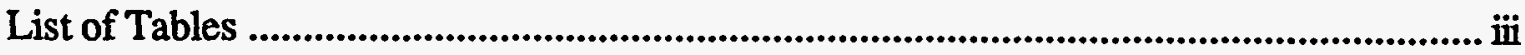

List of Figures ....................................................................................................................ii

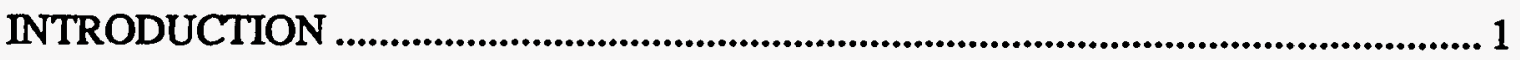

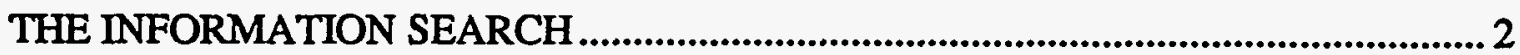

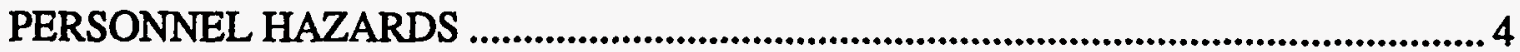

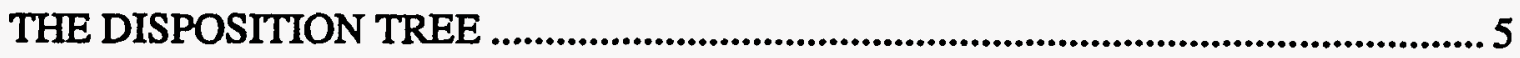

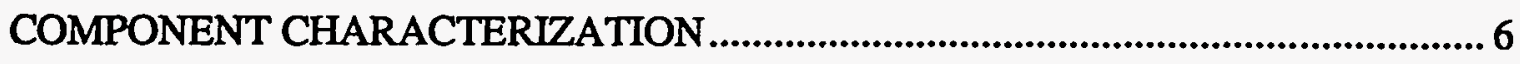

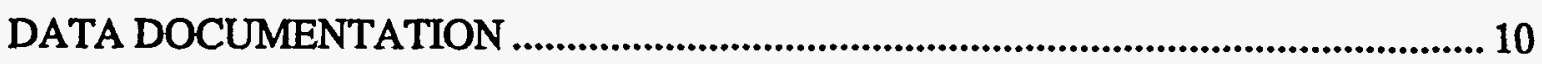

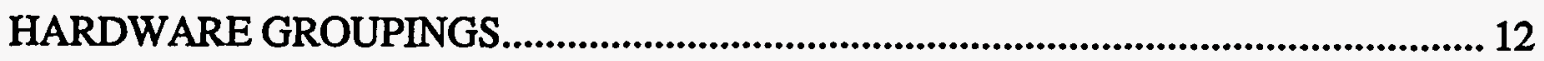

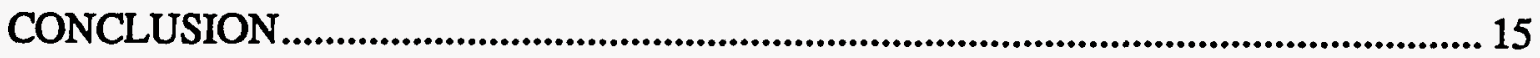

Appendix A, Disassembly Procedure, MC1187 .......................................................... 17

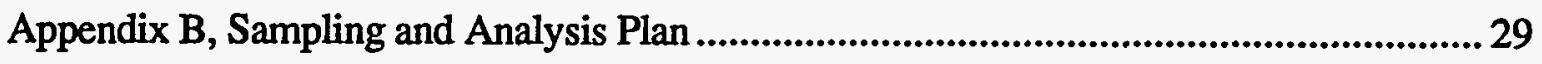

Appendix C, Analysis of Weapon Component Electronic Hardware by the TCLP ........... 47

Appendix D, Summary of TCLP Data on Weapon Component Electronic Hardware ...... 61

Appendix E, Air Gravity Separation Demonstration ......................................................6 65

\section{List of Tables}

Table 1. Semi-quantitative XRF Analysis of Components............................................... 3

Table 2. Maximum Concentration of Contaminants for The Toxicity Characteristic......... 7

Table 3. Average Composition of Electronic Components Analyzed ............................... 13

Table 4. Precious Metal Reclaimed from Electronic Components (1060 lbs. test)........... 14

\section{List of Figures}

Figure 1. Typical Disposition Tree..................................................................................

Figure 2. Toxicity Characteristic Leaching Procedure ................................................. 8

Figure 3. Material Characterization Database............................................................ 11 
This page intentionally left blank. 


\section{SNL/NM Weapon Hardware Characterization Process Development Report}

\section{INTRODUCTION}

The purpose of this report is to document the process developed as part of the New Mexico Weapon Systems Dismantlement and Process Development Project to characterize weapon hardware for disposition. The process is described as a series of steps to be accomplished in order to properly identify hazards, process the hazards, characterize the hardware for disposition and document the information.

The process consists of five basic steps:

1. Perform information searches to identify personnel hazards.

2. Determine processing required to minimize the personnel hazards.

3. Develop a disposition tree for the component.

4. Characterize the component for disposal.

5. Document the information generated.

Each of the steps is described in detail in separate sections of this report. This does not mean to imply that the steps must be accomplished serially. On the contrary, the steps are best accomplished in parallel with data flowing into each step as it is generated.

Also included is a discussion of the information gathered to date that supports grouping electronic components and hardware for waste characterization as well as for recycle and precious metals recovery.

The process described is a further development and implementation of a process proposed by a special projects team headed by W. D. Ulrich in early 1992. This baseline process is documented in SAND92-0302, Sandia National Laboratories Process Development Report Weapon Hazardous Material Identification, printed March 1992. The process proposed by this special projects team evolved into the Weapon Hardware Inventory Reduction Effort (WHIRE) Project, which concentrated on characterizing and processing excess weapon parts owned by Department 5111. Through this effort, thousands of excess weapon parts were characterized and dispositioned.

Use of this or a similar process is a requirement for weapon component disposal at Sandia National Laboratories/New Mexico. Components must be characterized and processed for personnel hazards before they will be accepted by the Waste Operations Department for disposal. 


\section{THE INFORMATION SEARCH}

There are numerous sources of information that can be used to identify potential hazards in excess weapon hardware. One of the best places to start is "process knowledge". If the Design Agency (DA) engineers who designed the parts are still around, they probably have a treasure trove of information stored in memory on potential personnel hazards that may be present, such as radioactive materials, reactive or explosive materials, gases or liquids under pressure, stored electrical or mechanical energy, and so on. They may also know what materials might be present including toxic metals such as lead, cadmium, mercury, barium, selenium, silver, chromium, or arsenic; other regulated substances such as asbestos or PCB containing oils; and reclaimable metals such as, copper, aluminum, steel, gold or other precious materials. Another useful source of process knowledge may be the Production Agency (PA) personnel who actually built the part. They should have a pretty good idea of what materials or parts were actually used. Even if these sources do not have all of the information, they can usually provide enough initial information to help you know what hazards you should be looking for during the characterization process.

Design definitions or drawings are a primary source of component hazard and material information. Usually the drawings contain information on how the part is constructed and what it is made from. For "newer" parts, we have Automated Material Lists which allow computer listings of all the subparts (including materials in a lot of cases). This speeds up the characterization process since you can usually determine from the computer generated list which subparts require additional characterization and which are simple parts that are already adequately characterized. For the "older" parts that were designed and built prior to the Automated Material List system, characterization requires obtaining copies of the drawings and performing the characterization "by hand". This is a time consuming process, but necessary in order to fully identify any potential personnel or disposal hazards. The drawing search alone, although capable of identifying RCRA regulated constituents, cannot be used for RCRA waste determination.

While drawings provide much of the needed information, they cannot always be relied on to supply all of the information. A useful tool in determining the types of material in a complex part or "black box" that contains many subparts is X-ray Fluorescence Spectroscopic (XRF) analysis. A semi-quantitative analysis of a part can be obtained quickly by analyzing a representative sample of the part. (Information on how we process parts to obtain a representative sample is provided in the Component Characterization section.) Table 1 shows typical analysis results for six different electronic components. The materials are divided into categories labeled "Major", "Minor", and "Trace" depending on the percentage (by weight) of the elements that are present in the sample. It is interesting to note that for various electronic type parts (consisting of printed circuit boards, wiring, and sometimes potting and a housing), regardless of function, the percentages of materials typically fall within the noted ranges. Use of this type of data will be discussed further in the Hardware Grouping section. 


\section{Table 1. - Semi-quantitative XRF Analysis of Components}

\begin{tabular}{|c|c|c|c|c|c|c|c|c|c|c|c|c|c|c|c|c|c|c|c|c|c|}
\hline \multirow[b]{3}{*}{ Component } & \multicolumn{4}{|c|}{ Major } & \multicolumn{11}{|c|}{ Minor } & \multicolumn{6}{|c|}{ Trace } \\
\hline & \multicolumn{4}{|c|}{$(10-50 \mathrm{wh} . \%)$} & \multicolumn{11}{|c|}{ (1-10 wt. \%) } & \multicolumn{6}{|c|}{$(<1 \mathrm{wL} \%)$} \\
\hline & Al & $\mathrm{Fe}$ & $\mathrm{Cu}$ & $\mathrm{Ni}$ & $\mathbf{Z n}$ & Si & $\mathrm{Ba}$ & $\mathrm{Ca}$ & $\mathrm{Ti}$ & $\mathrm{Ag}$ & So & Po & Sb & $\mathrm{Br}$ & Pd & $\mathbf{z}$ & $\mathbf{s r}$ & $\mathrm{Mn}$ & Cd & $\mathrm{Cr}$ & Mo \\
\hline $\begin{array}{l}\text { Signal Conditioner } \\
\text { Boards }\end{array}$ & $\mathbf{x}$ & $\mathbf{x}$ & $\mathrm{x}$ & $\mathbf{x}$ & $\mathbf{x}$ & $\mathbf{x}$ & $\mathbf{x}$ & $\mathbf{x}$ & $\mathbf{x}$ & $\mathrm{x}$ & $\mathbf{x}$ & $\mathbf{x}$ & $\mathbf{x}$ & $\mathbf{x}$ & $\mathbf{x}$ & ND & $\mathbf{x}$ & $\mathrm{x}$ & ND & ND & ND \\
\hline $\begin{array}{l}\text { MC3371 Data } \\
\text { Analyzer Boards }\end{array}$ & $x$ & $\mathbf{x}$ & $\mathbf{x}$ & $\mathbf{x}$ & $x$ & $\mathbf{x}$ & $\mathbf{x}$ & $\mathrm{x}$ & $\mathbf{x}$ & $\mathbf{x}$ & $\mathbf{x}$ & $\mathbf{x}$ & $\mathbf{x}$ & $\mathbf{x}$ & $\mathbf{x}$ & ND & $\mathbf{x}$ & $\mathrm{x}$ & ND & $\mathrm{ND}$ & ND \\
\hline $\begin{array}{l}\text { MC2534 Firing } \\
\text { Set }\end{array}$ & $x$ & $\mathbf{x}$ & $\mathrm{x}$ & $\mathbf{x}$ & $\mathbf{x}$ & $\mathrm{x}$ & $\mathbf{x}$ & $\mathbf{x}$ & $\mathbf{x}$ & $\mathbf{x}$ & $\mathbf{x}$ & $\mathbf{x}$ & $\mathbf{x}$ & $\mathbf{x}$ & $\mathrm{x}$ & $\mathrm{ND}$ & $\mathrm{x}$ & $\mathrm{ND}$ & $\mathbf{x}$ & ND & ND \\
\hline \begin{tabular}{|l|} 
MC3097 Power \\
Supply (w/o housing) \\
\end{tabular} & $\mathbf{x}$ & $\mathbf{x}$ & $\mathbf{x}$ & ND & $\mathbf{x}$ & $\mathrm{x}$ & $\mathbf{x}$ & $\mathrm{x}$ & $\mathbf{x}$ & $\mathbf{x}$ & $\mathbf{x}$ & $\mathbf{x}$ & $\mathbf{x}$ & $\mathbf{x}$ & $\mathbf{x}$ & $\mathrm{ND}$ & $\mathbf{x}$ & $\mathrm{ND}$ & $\mathbf{x}$ & ND & ND \\
\hline $\begin{array}{l}\text { MC 3276 Firing } \\
\text { Set (w/o housing) }\end{array}$ & $x$ & $\mathbf{x}$ & $\mathrm{x}$ & $x$ & $\mathbf{x}$ & $\mathbf{x}$ & $\mathbf{x}$ & $\mathrm{x}$ & $\mathbf{x}$ & $\mathbf{x}$ & $\mathrm{x}$ & $\mathbf{x}$ & $\mathrm{x}$ & $\mathbf{x}$ & $x$ & $\mathbf{x}$ & $\mathbf{x}$ & $\mathrm{x}$ & $x$ & ND & $\mathbf{x}$ \\
\hline $\begin{array}{l}\text { MC3276 Firing } \\
\text { Set (w/housing) }\end{array}$ & $\mathbf{x}$ & $\mathbf{x}$ & $\mathbf{x}$ & $\mathrm{x}$ & $\mathbf{x}$ & $\mathbf{x}$ & $\mathbf{x}$ & $\mathbf{x}$ & $\mathbf{x}$ & $\mathbf{x}$ & $\mathbf{x}$ & $\mathbf{x}$ & $\mathbf{x}$ & $\mathbf{x}$ & $\mathrm{x}$ & $\mathbf{x}$ & $\mathbf{x}$ & $\mathbf{x}$ & $\mathbf{x}$ & $x$ & $\mathbf{x}$ \\
\hline
\end{tabular}

$\mathrm{X}=$ Element detected at nominal concentration.

$\mathrm{ND}=$ Element not detected due to low concentration or interfering spectra.

Nominal concentration ranges were determined from the relative intensities of the

$\mathrm{X}$-ray spectra combined with process knowledge of material segregation with particle size.

Actual weight composition of metallic elements will vary with concentration of organic (C, H, N) material, i.e., potting, insulation, etc., but relative amounts ( $\mathrm{Al}>$ $\mathrm{Cd}$ ) tend to maintain the order of abundance shown above.

Chemical analysis is another method of determining material composition, but it is more costly and time consuming. Chemical analysis can also result in additional waste problems due to the chemicals that must be disposed of as hazardous waste. We use chemical analysis only when alternative methods cannot be developed. Additional analysis information that is available will also be discussed further in the Hardware Grouping section. 


\section{PERSONNEL HAZARDS}

Once potential hazards have been identified, procedures should be developed to address them. One method used to document the steps required to remove or eliminate potential hazards is a Disassembly Procedure (DP). We use DPs to document the hazards in weapon parts and to provide the information needed to either process the part to eliminate the hazard (such as firing explosive components) or removing it completely so that the remainder of the part can be recycled (rather than disposed of as radioactive or mixed waste, for example, if the part contained a radioactive source). Appendix A shows an example of a procedure that would be used for a part that contained both explosive and radioactive subparts. Information is provided to tell the person processing the part how to activate the explosive and where the radioactive tube is located and how to process the part to remove it.

Developing the procedures to remove a part are often even more challenging than determining what subparts are incorporated into a component. Drawings are again a good place to start when trying to determine a hazardous component location. They will show you where the part was intended to be located. However, experience tells us that just because the drawing says this is where the part should be, and how it should be oriented, the builder may have varied from the design in order to make it easier to assemble. Parts with flexible leads are very susceptible to variations in location. One way to determine the "as built" location is the use of radiography. X-rays allow you to verify location and orientation so that machining operations can be defined to safely remove the part.

When cut line diagrams for DPs are developed, margins between the part being removed and the actual machine cut line should be defined to maintain a minimum spacing of .5 inches. We typically X-ray or "de-pot" up to 6 of a particular part to find out what maximum variations in location are possible and then move the cut out .5 inches from the worst case location. This provides an adequate safety margin and eliminates the possibility of sawing through the part you want to remove.

The recommended method of demilitarization for explosive parts contained in electronic components is to fire them. In our DPs, we provide the information to fire explosive switches, piston motors, and other self-contained explosive devices when possible. However, in some parts, such as the part described in Appendix A, not all of the explosives can be fired, so removal information is included.

Parts containing mercury, such as tilt switches or mercury wetted contacts on switches or relays, should also be identified and removed using DPs. This will allow the bulk of the material to be processed for precious metals recovery and only the mercury containing parts will need to be disposed of as hazardous waste or recycled if sufficient quantities are present. 


\section{THE DISPOSITION TREE}

The part Disposition Tree should be generated as characterization, demilitarization, sanitization, and waste minimization information is gathered. The disposition tree is a breakdown of a part or assembly that shows which parts are removed for separate processing. For example, the disposal tree for a bomb preflight section would start with the top drawing number for the assembly, and then branch out for the parts that would be removed for separate processing, such as a preflight controller, spin rocket, screws and other hardware, and the preflight case itself. If the preflight controller contained a thermal battery that could be removed so that it could be disposed of as hazardous waste, while the bulk of the controller could be processed for precious metals recovery, the battery would be listed in the tree under the controller. Each part that is removed is characterized to the extent required for final disposition. An example of a disposition tree is shown in Figure 1.

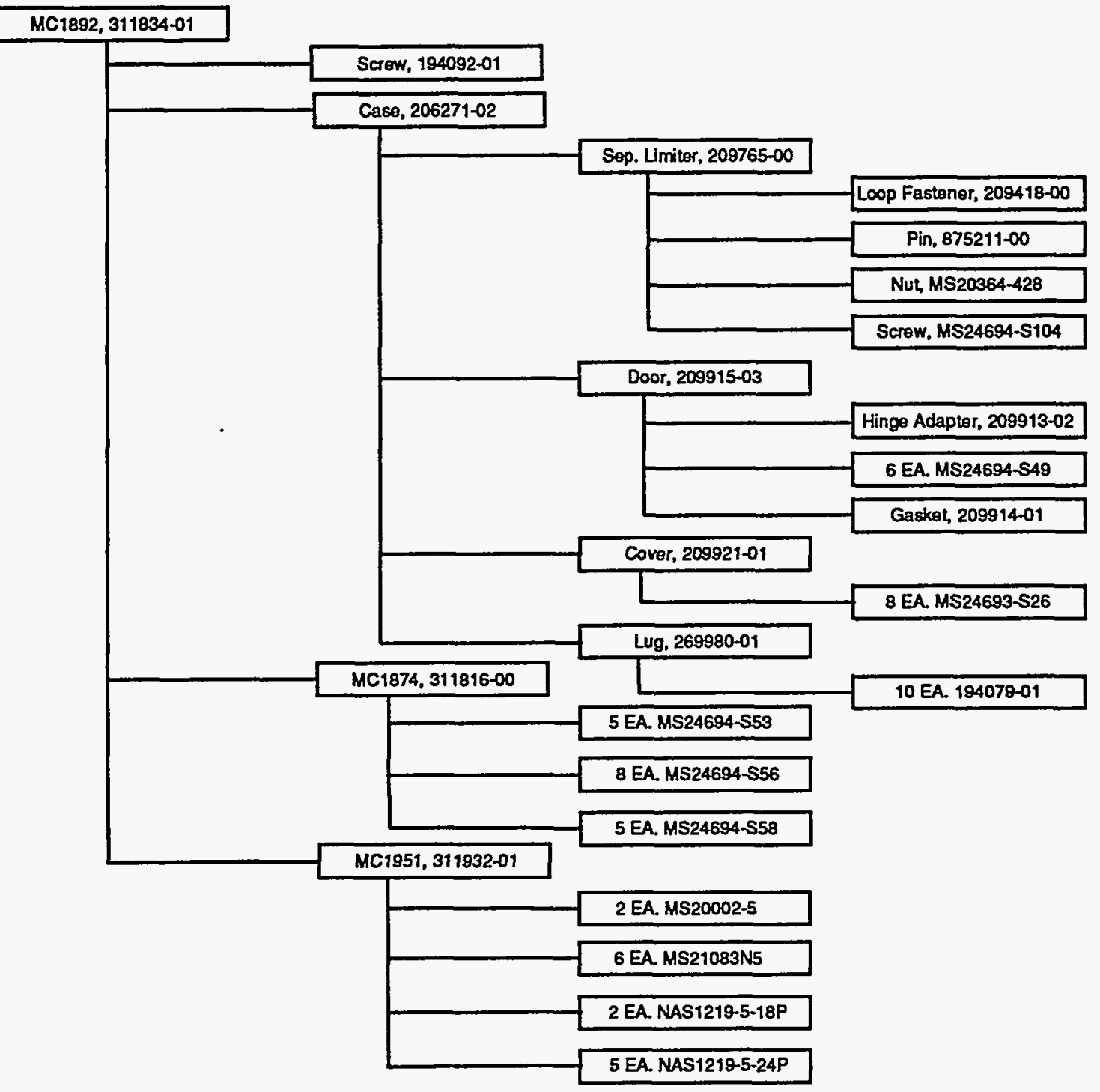

Figure 1. Typical Disposition Tree 


\section{COMPONENT CHARACTERIZATION}

To deal with solid waste management issues, laws such as the Resource Conservation and Recovery Act (RCRA) were passed. This law and similar ones set guidelines for how hazardous materials must be disposed of and at what concentrations materials are considered hazardous. The law also defines four characteristics of hazardous waste: Ignitability, Corrosivity, Reactivity and Toxicity. If waste meets the specified requirements for any of the four characteristics, then it must be disposed of as hazardous waste. A discussion of each characteristic follows.

A solid waste exhibits the characteristic of Ignitability if a representative sample of the waste has any of the following properties:

1. It is a liquid and has a flash point less than $60^{\circ} \mathrm{C}\left(140^{\circ} \mathrm{F}\right)$.

2. It is not a liquid and is capable of causing fire through friction, absorption of moisture or spontaneous chemical changes and when ignited, burns so vigorously and persistently that it creates a hazard.

3. It is an ignitable compressed gas.

4. It is an oxidizer

A solid waste exhibits the characteristic of Corrosivity if a representative sample of the waste has either of the following properties:

1. It is aqueous and has a pH less than or equal to 2 or greater than or equal to 12.5 .

2. It is a liquid and corrodes steel at a rate greater than 6.35 millimeters $(0.250$ inch $)$ per year at a test temperature of $55^{\circ} \mathrm{C}\left(130^{\circ} \mathrm{F}\right)$.

A solid waste exhibits the characteristic of reactivity if a representative sample of the waste has any of the following properties:

1. It is normally unstable and readily undergoes violent change without detonating.

2. It reacts violently with water.

3. It forms potentially explosive mixtures with water.

4. When mixed with water, it generates toxic gases, vapors or fumes in a quantity sufficient to present a danger to human health or the environment.

5. It is a cyanide or sulfide bearing waste which, when exposed to $\mathrm{pH}$ conditions between 2 and 12.5, can generate toxic gases, vapors or fumes in a quantity sufficient to present a danger to human health or the environment.

6. It is capable of detonation or explosive reaction if it is subjected to a strong initiating source or if heated under confinement.

7. It is readily capable of detonation or explosive decomposition or reaction at standard temperature and pressure;

8. It is a forbidden explosive or a Class A or Class B explosive. 
A solid waste exhibits the toxicity characteristic (TC) if, using approved test methods, the extract from a representative sample of the waste contains any of the contaminants listed in Table 2 at a concentration equal to or greater than the respective value given in that Table.

Table 2. - Maximum Concentration of Contaminants for the Toxicity Characteristic

\begin{tabular}{|l|c|l|c|}
\hline \multicolumn{1}{|c|}{ Contaminant } & $\begin{array}{c}\text { Regulatory } \\
\text { Level } \\
(\mathrm{mg} / \mathrm{L})\end{array}$ & \multicolumn{1}{|c|}{ Contaminant } & $\begin{array}{c}\text { Regulatory } \\
\text { Level } \\
(\mathrm{mg} / \mathrm{L})\end{array}$ \\
\hline Arsenic & $\mathbf{5 . 0}$ & Hexachloroethane & 3.0 \\
\hline Barium & $\mathbf{1 0 0 . 0}$ & Lead & $\mathbf{5 . 0}$ \\
\hline Benzene & $\mathbf{0 . 5}$ & Lindane & 0.4 \\
\hline Cadmium & $\mathbf{1 . 0}$ & Mercury & $\mathbf{0 . 2}$ \\
\hline Carbon tetrachloride & 0.5 & Methoxychlor & 10.0 \\
\hline Chlordane & 0.03 & Methyl ethyl ketone & 200.0 \\
\hline Chlorobenzene & 100.0 & Nitrobenzene & 2.0 \\
\hline Chloroform & 6.0 & Pentrachlorophenol & 100.0 \\
\hline Chromium & 5.0 & Pyridine & 5.0 \\
\hline Cresol & 200.0 & Selenium & 1.0 \\
\hline 2,4-D & 10.0 & Silver & 5.0 \\
\hline 1,4-Dichlorobenzene & 7.5 & Tetrachloroethylene & 0.7 \\
\hline 1,2-Dichloroethane & 0.5 & Toxaphene & 0.5 \\
\hline 1,1-Dichloroethylene & 0.7 & Trichloroethylene & 0.5 \\
\hline 2,4-Dinitrotoluene & 0.13 & 2,4,5-Trichlorophenol & 400.0 \\
\hline Endrin & 0.02 & 2,4,6-Trichlorophenol & 2.0 \\
\hline Heptachlor & 0.008 & 2,4,5-TP (Silvex) & 1.0 \\
\hline Hexachlorobenzene & 0.13 & Vinyl chloride & 0.2 \\
\hline Hexachlorobutadiene & 0.5 & & \\
\hline
\end{tabular}

The Toxicity Characteristic Leaching Procedure (TCLP) is designed to determine the mobility of both organic and inorganic analytes present in liquid, solid, and multiphasic wastes. The TCLP test consists of adding an extraction fluid (glacial acetic acid, $\mathrm{CH}_{3} \mathrm{CH}_{2} \mathrm{OOH}$, diluted with reagent water to a $\mathrm{pH}$ of 4.93 or 2.88 , depending on the characteristics of the sample to be analyzed) to a minimum 100 gram representative sample. (Twenty (20) times the weight of the sample determines the weight of extraction fluid to add). The sample and extraction fluid are then placed in a rotary agitation device and rotated at 30 revolutions per minute for eighteen (18) hours. The sample is then filtered and the filtered liquid is analyzed for concentrations of the eight regulated metals. This is a very simplified summary of the TCLP test. A more detailed graphic showing the steps involved in the TCLP test is shown in Figure 2. The portions of the TCLP that are applicable to the analysis of the solid waste we are characterizing is shaded in the Figure. 
Figure 2

\section{TOXICITY CHARACTERISTIC LEACHING PROCEDURE}

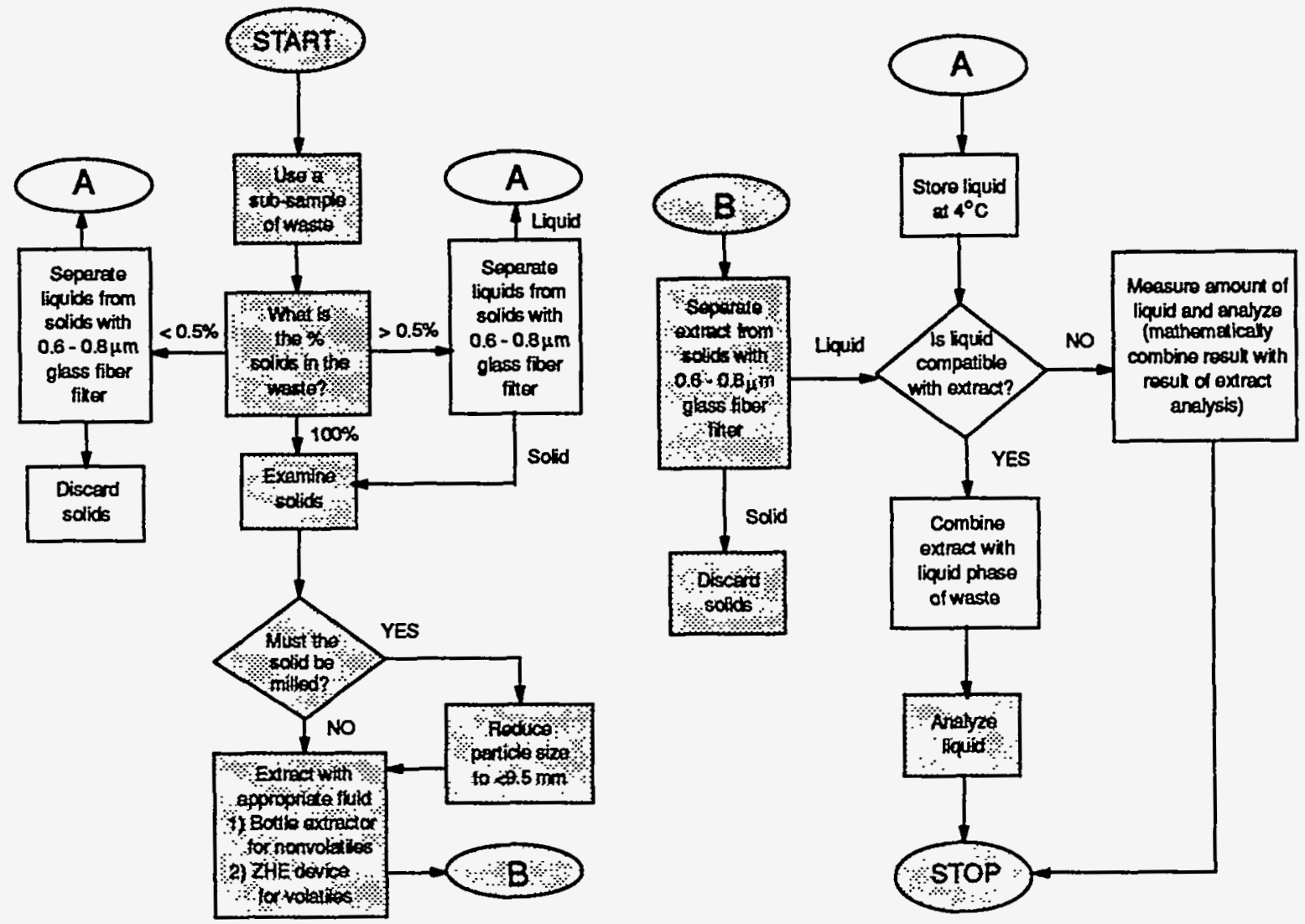

The "tests" for all four characteristics are based on a "representative sample". A representative sample is a smaller sample of the waste that contains all of the constituents in the same proportions as in the whole waste. For liquid and process wastes, fly ash-like waste, crushed, powered, soil or rock-like waste, the sampling protocols are well defined in American Society for Testing and Materials (ASTM) Standards. For electronic components, however, sampling is more difficult since the parts do not typically have equal amounts of materials in every location within the box. The materials tend to be segregated into specific areas - lead/tin solder and copper on printed circuit boards; arsenic, selenium, germanium, in semiconductor devices; silver, gold, on connectors, wire, and contacts; cadmium and chromium on mechanical parts and hardware and so on. A representative sample should contain all of the materials present in the part in the correct proportions. The goal then is to make the part into a homogeneous mixture. We accomplish this by crunching the part in a forge hammer and/or passing it through a hammer mill. 
Process knowledge has shown that, with the exception of some nonexpended explosive devices and thermal batteries, the hazardous waste characteristics of weapon electronic components are limited to the toxicity characteristic.

TCLP analysis of a variety of electronic components to date has shown that of the eight metals in the list - arsenic, barium, cadmium, chromium, lead, mercury, silver, and selenium - only cadmium, lead, barium, and chromium tend to be detectable, and that typically only cadmium and lead approach or exceed the regulatory levels. Preliminary testing has shown that the organic contaminants are not detectable in these parts. The Sampling and Analysis Plan that we used to analyze these components is attached as Appendix B. Included as Appendix C is a tabulation of the TCLP results for 110 components analyzed to date.

When we first began development of this process, the primary disposal method for the types of hardware and material we deal with was land burial. The results of TCLP tests have shown that the majority of components would be considered TC hazardous for lead and cadmium thus requiring stabilization of the hazardous constituents and disposal in an EPA permitted waste facility. During the evolution of this process, it became apparent that there was sufficient precious metals in most of the major components to justify processing for precious metals recovery. This concept allows for "waste minimization" by promoting recycling as discussed in the Hardware Grouping section. 


\section{DATA DOCUMENTATION}

Generating the characterization data for parts, materials, process waste, and so on in order to be able to determine what processing is required and how best to dispose of it is only part of the characterization process. A method of storing the information that makes it readily retrievable and accessible to others who may have the same type of material or part to dispose of is also required. Sifting through file cabinets or stacks of paper is definitely not the quickest and most efficient way of storing and accessing information. Making hard copies of the information and sending it to another person who has the same type of material or part to dispose of may work for a few items, but not hundreds or thousands. That assumes, of course, that the other person even knows you have already generated the characterization data and does not need to do it again.

That is why SNL/NM undertook the task of developing a computer database to store the characterization data that is being generated. The Stockpile Dismantlement Database (SDDB) is intended to provide the user with all of the information about a part that is needed to be able to determine proper disposal methods. The database includes not only the hazards, major constituents, any chemical analysis associated with the part and other characterization data, including how the part would be disposed of locally, but also a list of drawings or other documentation that was used to generate the data. The database thus becomes the auditable data record that justifies why we characterized a part as hazardous or non-hazardous waste and the information needed to support the characterization and disposition method chosen.

The database is based on SUN Sparc 2 workstations using a UNIX operating system in any of three configurations: stand alone workstation, server/client workstations and a network system.

For the stand alone workstation, all of the software and database is loaded on disk drives and is available for the user. Data can be updated or input at the terminal. Data can be exchanged and updated with other workstations using disks or magnetic tapes.

In the server/client configuration, the stand alone workstation acts as a database server using INGRES software (a database management software) and can support three to eight or nine to sixteen client workstations (depending on the version of the INGRES software used), all sharing the same copy of the database.

In the network configuration, a SUN Sparc Server 670MP is used as the data server. This option is used for the "certified" copy of the database which has more than 16 client workstations connected.

The copy of the database supported by the network configuration is called the "record copy". The "record copy" is continually updated from the client workstations connected to it as well as from other locations where data is entered, via disk. Updated copies of the "record copy" of the database are provided to the standalone database servers by disk on a regular basis so that all users have access to the latest information available.

The material characterization database used in this application is menu driven to facilitate data entry. The person doing the data entry can use the menus that are applicable to the type of data they are entering. For example, the design engineer may enter the basic part 
information, such as weight, dimensions, the manufacturer, part number, hazard information and so on; a chemist or materials engineer may enter any chemical analysis data and assign it to a constituent group; a draftsman may enter the document numbers for the information used to generate the characterization data, and so on. Figure 3 is a diagram showing the types of information included in the database.

Figure 3

\section{Stockpile Dismantlement Database}

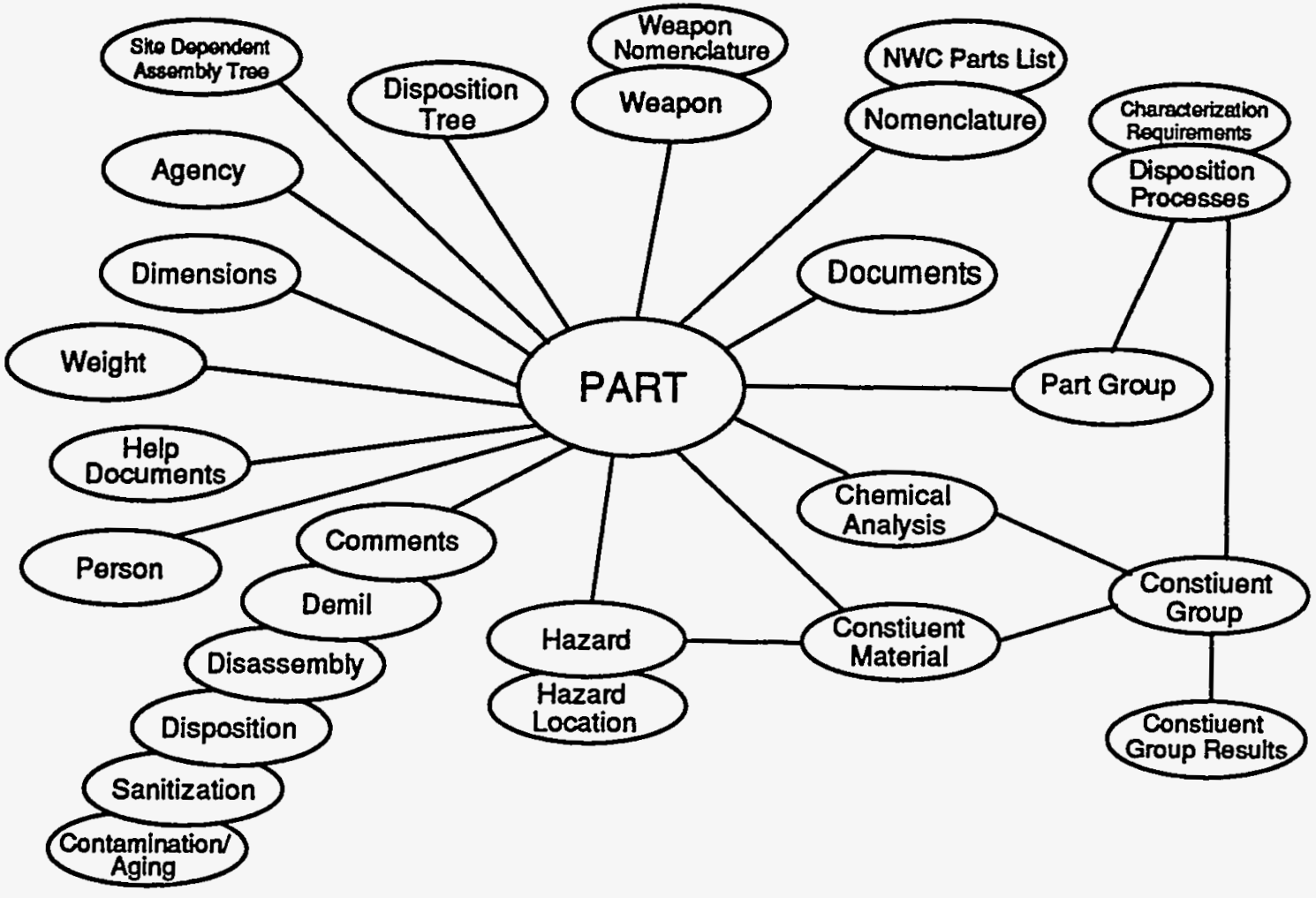

The accuracy of the data contained in any type of database is always an issue. We have tried to eliminate errors in the information by instituting a "Quality Assurance/Quality Control" Plan. We have designated certain qualified personnel to verify specific fields of data for which they could be considered an "expert". For instance, we may have a chemist who is familiar with the chemical analysis data review the data entered in the database to ensure its accuracy. He would "certify" that the specific information is entered correctly. The same chemist would not, however, be the "expert" who would certify the data for personnel hazards, for instance. The goal is to have the data reviewed by personnel who are best qualified for each specific type of data. In addition, the person who certifies the data should not be the same person who entered the data. You have a much higher confidence level in the quality of the data if you use a two person rule - one person to enter the data, and a second person to check and certify the data. All too often, if a single person enters the data incorrectly, he will miss the mistake during the data review. 


\section{HARDWARE GROUPINGS}

One of the things that has been learned as the database and characterization process has matured is that by assigning parts to groups, we can have the database compile reports to track lists of parts and show what parts have the same characteristics and would require the same disposal methods or offer the same recycling opportunities. We typically assign parts to a "Part" Group and/or a "Constituent" Group.

The Part Group categorizes the part according to type of hardware. Screws, bolts, nuts, brackets, and similar parts would go into a "Mechanical Hardware" group. Electronic parts with printed circuit boards, wires, and so on would go into an "Electronics" group. Part groups also are set up for Demilitarization and Sanitization for Disposal (DSD) groups, which break hardware into subgroups such as preflight controllers, batteries, firing sets, Environmental Sensing Devices (ESDs), foams, and so on. Parts within each group have the same or similar requirements for demilitarization and/or sanitization. The Part Group can also be used to track characterization completed for the Army, Navy and Air Force for various lists of base spares and other components that they have and want to disposition.

The original intent of the Constituent Group was to categorize parts according to the types of materials they contained. If a part is primarily aluminum, it could go into an "Aluminum" Group. A part made of steel would go into a "Steel" Group. A part containing gold, silver or platinum would be placed into a "Precious Metals" Group. By dividing parts into constituent groups, you can develop information that can help you decide whether it is economically feasible to recycle materials or recover precious metals. It may not be feasible if you have 100 of one part, but it may be feasible if you have 100 each of 10 different parts with similar materials. The use of the Constituent Group has been expanded to include such things as thermal batteries, which all contain the same basic types of materials, and radioactive parts. The utility of these types of groupings is still to be determined, but are just another example of the flexibility existing within the data base for establishing groups of components or materials to help determine appropriate processing.

Based on the characterization work completed to date, we recommend three basic groupings for hardware and components: Mechanical Hardware, which would primarily be recycled; Electronic Component, which would be a majority of "black box" type components and would primarily be processed for precious metals recovery; and Hazardous Waste, which would be for parts such as expended thermal batteries, mercury contaminated parts, or electronic components that do not contain recycle opportunities or sufficient precious metals to warrant recovery.

Parts grouped in the Electronic Component and Hazardous Waste groups are presumed to fail TCLP testing for lead and cadmium. This grouping is based on TCLP analyses to date which indicate that approximately $96 \%$ of electronic weapon components exceed the RCRA levels of $5 \mathrm{ppm}$ and $1 \mathrm{ppm}$ respectively for either or both of these two constituents. Appendix D provides a summary of the TCLP results to date that supports this conclusion. Parts from both old and new weapon systems have been subjected to TCLP testing, as well as parts from numerous DSD groups, such as firing sets, preflight 
controllers, ESDs, interconnect and junction boxes, ready safe switches, explosive switch packs, and so on, all with similar results.

Components in the Electronic Component group are also relatively consistent in the percentages of various materials that make up the part. As mentioned previously, data has been obtained using X-ray Fluorescence Spectroscopy showing the range of chemical composition of several different electronic components. This same range of composition was quantitatively measured in analyses of samples from $700 \mathrm{lbs}$. of miscellaneous weapon components that were granulated for a "sort-and-recycle" demonstration of alternate disposal technologies. This demonstration was a part of the Weapon Component Waste Disposal Integrated Demonstration (WeDID) project sponsored by the Environmentally Conscious Life Cycle Systems Department (6625). A summary of the analytical results is shown in Table 3. These results show that the metal content of the "average" electronic component accounts for $60 \%$ of the material by weight, with recoverable quantities of aluminum, copper, gold, silver, and palladium. The balance of the material is principally non-hazardous in nature: rubber, plastic, foams, epoxies, and alumina or silica based ceramic and glass. A list of the components processed and the details of how these results were obtained are given in Appendix E. This data is also useful if the material is not going to be processed for metals recovery, because it provides an estimate by weight of additional materials that a particular Treatment, Storage and Disposal (TSD) facility may require knowledge of in order to be able to properly dispose of the material.

Table 3

Average Composition of Electronic Components Analyzed

\begin{tabular}{|c|c|c|c|c|c|c|c|c|c|c|c|c|c|c|c|c|c|c|c|c|c|}
\hline \multicolumn{3}{|c|}{ Major } & \multicolumn{19}{|c|}{ Minor \& Trace } \\
\hline \multicolumn{22}{|c|}{ wt. $\%$ (* indicates oz/hon) } \\
\hline Al & $\mathrm{Fe}$ & $\mathrm{Cu}$ & $\mathrm{Ni}$ & $\mathrm{Zn}$ & $\mathbf{S i}$ & $\mathrm{Bs}$ & $\mathrm{Ca}$ & $\mathrm{Ti}$ & Ag & Sn & $\mathbf{P B}$ & $\mathbf{s b}$ & $\mathrm{Br}$ & Pd & $\mathbf{Z r}$ & $\mathbf{S r}$ & $\mathbf{M n}$ & Cd & $\mathrm{Cr}_{\mathrm{r}}$ & Mo & Au \\
\hline 30 & 10 & 13 & 2 & 2 & ND & $<1$ & $<1$ & $<1$ & $39 *$ & $<1$ & 1 & ND & NA & $2^{*}$ & ND & $<1$ & $<1$ & $<1$ & 1 & $<1$ & $7 *$ \\
\hline
\end{tabular}

The WeDID project also investigated the feasibility of utilizing existing precious metal reclamation technology as a disposition option for electronic components. An additional $1060 \mathrm{lbs}$. of miscellaneous electronic weapon components was shipped to a commercial precious metals recycler for processing (see Appendix E, List 2). The results of that reclamation test are shown in Table 4 . The precious metal values obtained agree reasonably well with the analytical results shown in Table 3. 
Table 4

Precious Metal Reclaimed from Electronic Components (1060 lbs. test)

\begin{tabular}{|l|cccc|c|}
\hline & $\mathrm{Ag}$ & $\mathrm{Au}$ & $\mathrm{Pd}$ & ${ }^{*} \mathrm{Cu}$ & Totals \\
\hline Assay (oz/ton). & 50 & 12 & 2 & 310 & \\
*(lbs./ton) & $\$ 105$ & $\$ 2100$ & $\$ 101$ & $\$ 112$ & $\$ 2418$ \\
Value (1060 lbs.) & $\$ 10$ (10) & \\
Net Return & & &
\end{tabular}

It is reasonable to assume, based on these results, that there is sufficient precious metal content in these electronic components to warrant reclamation as a disposition option. Use of process knowledge about the parts that are grouped into the Electronic Component group and some presorting to remove bulk aluminum, steel, plastics, etc. will help ensure that this disposition method remains a viable option. This option is not only economically viable but environmentally sound as it meets the fundamental goal of RCRA which is to prevent pollution by reducing the quantity of hazardous waste that would end up at a TSD facility for disposal. The break-even point is just under 6 ounces of gold per ton, based on a $\$ 1.00$ per pound processing fee and gold priced at $\$ 350$ per ounce. Any recovery greater than 6 ounces as well as the dollars from the recovered silver, platinum, copper, etc., turns into dollars to help pay for any processing (such as for demilitarization and sanitization) the components may require. The costs of disposing of the material in a TSD facility is also avoided. 


\section{CONCLUSION}

When we started this effort, our first perception was that excess metal parts could be recycled but that electronic components would have to be disposed of as hazardous waste since they contained toxic metals such as lead and cadmium. As the drawing searches and DP development continued, however, we realized that the precious metals present in electronic parts should be recovered, rather than buried in the ground. The WeDID program demonstrated that there was enough precious metal in these components, on average,to pay for the recovery and to help defray the costs of demilitarization and sanitization. As a result, we have reoriented ourselves to the philosophy that the majority of the (metal) mechanical and electronic parts from dismantled weapon systems should be recycled or processed for precious metals recovery.

The activities associated with the NM Weapon Systems Dismantlement and Process Development project have demonstrated a process for characterizing weapon parts, including complex weapon electronic components, and determining an appropriate disposition method. Once personnel hazards are identified and removed, and demilitarization and sanitization activities completed, there is sufficient information available to justify grouping most electronic components into one group and processing them for precious metals recovery. If the disposing site does not have a recycle/recovery/reuse option, then there is sufficient information to conclude that most electronic components will exhibit the Toxicity Characteristic for lead and cadmium and must be disposed of as hazardous waste. Lack of characterization information beyond personnel hazard identification/removal instructions and demilitarization/sanitization requirements should not hinder component disposition.

While this process does not result in "waste minimization" in the strict definition of the term, (based on the idea that all excess material, including recyclables, are solid waste), it does meet the intent of "waste minimization" by reducing the volume of hazardous waste that would require disposal at an EPA approved TSD facility. The market is out there, and it makes a lot more sense to reuse/recycle the material rather than to pay someone to take it out and bury it, with the potential to contaminate the soil and water for future generations. 
This page intentionally left blank. 
CAGE CODE 14213

DP211042

E. Graff 5115

Page 1 of 11

DPMC1187.DOC

\section{Disassembly Procedure, MC1187 (U)}

\section{CHANGE HISTORY}

CONTRQL NUMBER

DP211042-000
ISSUE

A
DATE

$1 / 94$ 
CAGE CODE 14213

E. Graff $\quad 5115$

TABLE OF CONTENTS

1.

GENERAL ...............................

1.1 .

scope. ...............................

1.2

Definitions. 3

1.3

Intent 3

2 . DOCUMENTS . .3

3. INSTRUCTIONS .3

IIST OF ATTACFRENTS

ATTACHMENT A PERSONNEL HAZARD LOCATION AND CUTLINE DIAGRAM 1.6 ATTACHMENT B PERSONNEL HAZARD LOCATION AND CUTLINE DIAGRAM 2.7 ATTACHMENT C PERSONNEL HAZARD LOCATION AND CUTLINE DIAGRAM 3.8 ATTACHMENT D WEAPON COMPONENT SANITIZATION DATA SHEET ......9 ATTACHMENT E HAZARD REMOVAL CERTIFICATION ............... 10 


\section{GENERAL}

\subsection{Scope.}

This disassembly procedure provides instructions for processing the MC1187 Firing Set for disposition. Waste minimization opportunities and sanitization requirements are addressed.

\subsection{Definitions.}

a. Toxicity Characteristic Leaching Procedure (TCLP) -A Resource Conservation and Recovery ACt (RCRA) defined test procedure used to determine whether leachable quantities of lead, barium, silver, arsenic, selenium, cadmium, chromium, and mercury above a preset concentration are present in a representative material sample.

b. Stockpile Dismantlement Data Base (SDDB)--The Sandia developed data base that stores the characterization data for disposition of components and hardware from weapon systems being dismantled throughout the Nuclear Weapon Complex.

\subsection{Intent.}

The intent of this procedure is to provide information about personnel hazards in the MC1187 that must be removed prior to disposition. In addition, opportunities for waste reduction are identified, such as parts that may be removed from the component for reuse, recycling or recovery of precious materials. Sanitization requirements are also included.

2. DOCUMENTS

The following documents form a part of this instruction to the extent specified herein.

$211042 \quad$ MC1187 Firing set

AY211042 Graphic MC1187

\section{INSTRUCTIONS}

a. The MC1187 contains two SA816 and two SA817 radioactive electron tubes. The approximate locations for the four tubes are shown on Attachment $A$. 
b. The MC1187 also contains two MC936 Explosive Tack Switches. The approximate locations for the two switches are shown on Attachment B.

c. Remove the eight non-gold plated connectors/pigtails and other hardware from the brass plate (the two gold connectors will be removed in a later step) using pliers (such as "vice grips") and diagonal cutters or a hammer and chisel as appropriate. Process the connectors for precious metals recovery (gold/silver).

d. Perform the machining operations indicated on Cutline Diagram 1 (see Attachment A). One SA816 and one SA817 tube is located in each of the sections labeled "A" and " $\mathrm{B}$ ". (Note: An alternate machining approach that can be performed using only hand tools begins at step j.)

e. Remove the portions of the brass plate from the cutout sections. The brass plate may be recycled.

E. The tubes may be encased in sleeving and can be removed from the cutout sections by chipping away the surrounding foam and cutting the leads connecting them to the printed circuit boards.

g. The four radioactive electron tubes must be disposed of as low level radioactive waste.

h. If the tubes are left in the cutout sections with the PC boards, they must be disposed of as mixed waste (radioactive and lead).

i. Perform the machining operations indicated on Cutline Diagram 2 (see Attachment B). (Note: If the machining operations utilizing Cutline Diagrams 1 and 2 are performed, proceed to step n.)

j. An alternate cut method is depicted in cutline Diagram 3. These cuts can be performed using hand tools such as a hammer and chisel or on a milling machine. Cut through the housing material (top and edge) and peal it away to expose the areas containing the two MC936 explosive switches and four radioactive tubes. 
k. Remove the two SA817 tubes located as shown on Cutline Diagram 3 by removing the potting material and cutting the four wires connecting them to the PC board.

1. Remove the small PC board immediately under the housing by prying up the edges and cutting the wires soldered to it on the bottom side.

m. Remove the two SA816 tubes by removing the foam and components located in the areas shown on Cutline Diagram 3 and cutting the 2 wires connecting each to the PC board.

n. Remove the two MC936 explosive switches from the remaining section of the firing set if they have not been fired. The switches may be removed by digging out the foam and unscrewing the switch from the end of the capacitor. (Note: Even if the firing set has been operated, some of the four MC935 explosive actuators that are in an MC936 explosive switch may not be fired. Remove all unfired MC936/MC935 explosive components.)

o. Process unfired MC936 explosive switches per DP310655. Process unfired MC935 explosive actuators from a partially fired MC936 per DP310654.

p. Remove the brass plate from the remaining section of the firing set.

q. Remove the lead washer from the back of the brass plate and the two gold plated connectors. Process the connectors for gold recovery. The brass plate may be recycled. Recycle the lead washer.

r. The MC1187 also contains four MC824 fuse switches that may be removed and processed for gold recovery. The approximate location is shown on Attachment B.

s. The remaining section of the firing set is sanitized and meets the requirements of Attachment $C$ once the MC936 explosive switches and the sections containing the radioactive tubes have been removed. 


\section{Appendix A}

CAGE CODE 14213

E. Graff

5115

DP211.042

Issue $\mathrm{A}$

Page 6 of 11

t. The residue from the sanitization activities must be disposed of as hazardous waste if the

disposition method is landfill. The residue fails TCLP for lead and cadmium. Complete TCLP results are documented in the SDDB. 
Appendix A

CAGE CODE 14213

E. Graff

\section{PERSONNEL HAZARD LOCATION AND CUTLINE DIAGRAM 1}

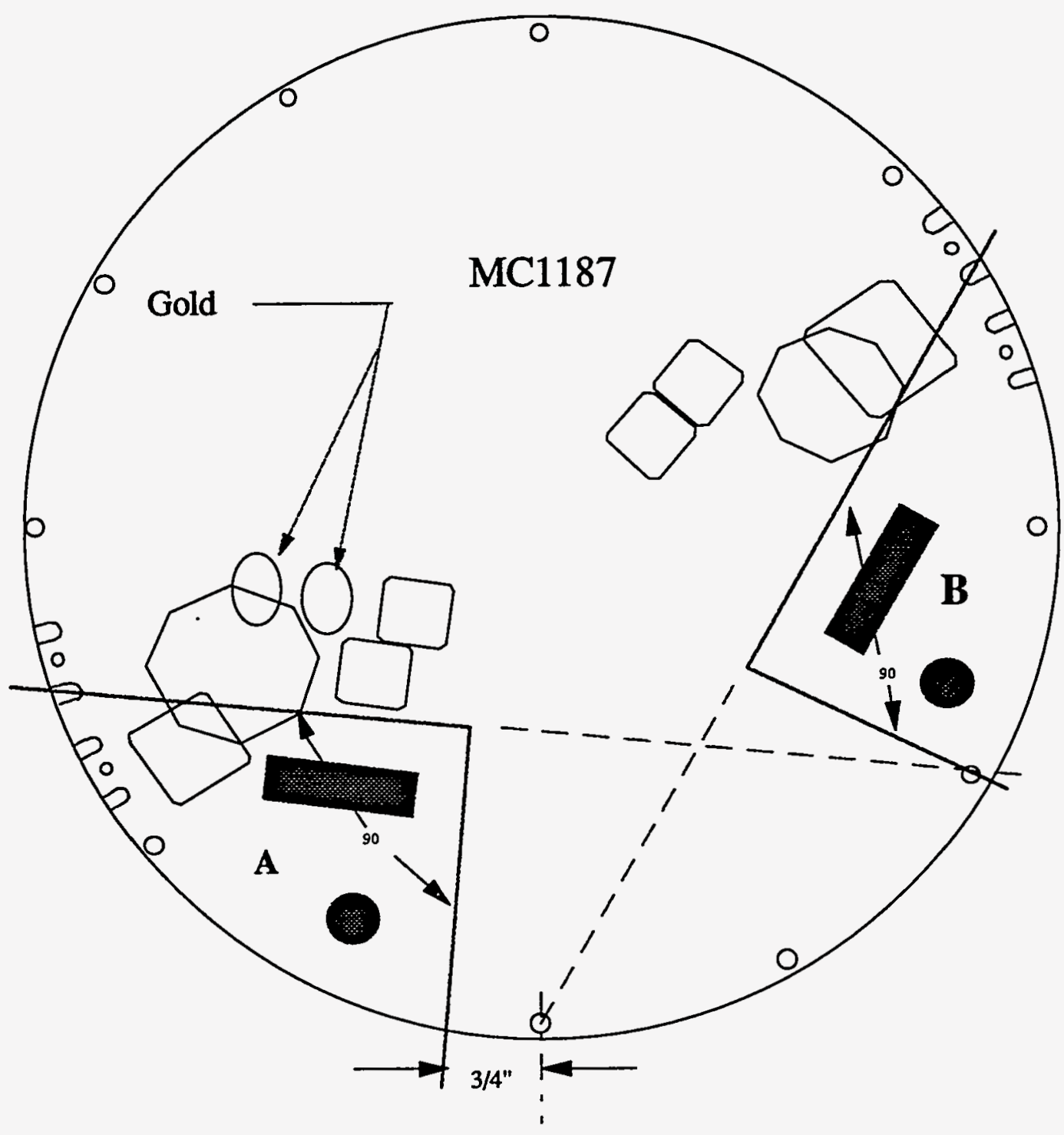

Cut Line 
Appendix A

CAGE CODE 14213

E. Graff

5115

DP211042

Issue A

Page 8 of 11

\section{ATTACHMENT B \\ PERSONNEL HAZARD LOCATION AND CUTLINE DIAGRAM 2}

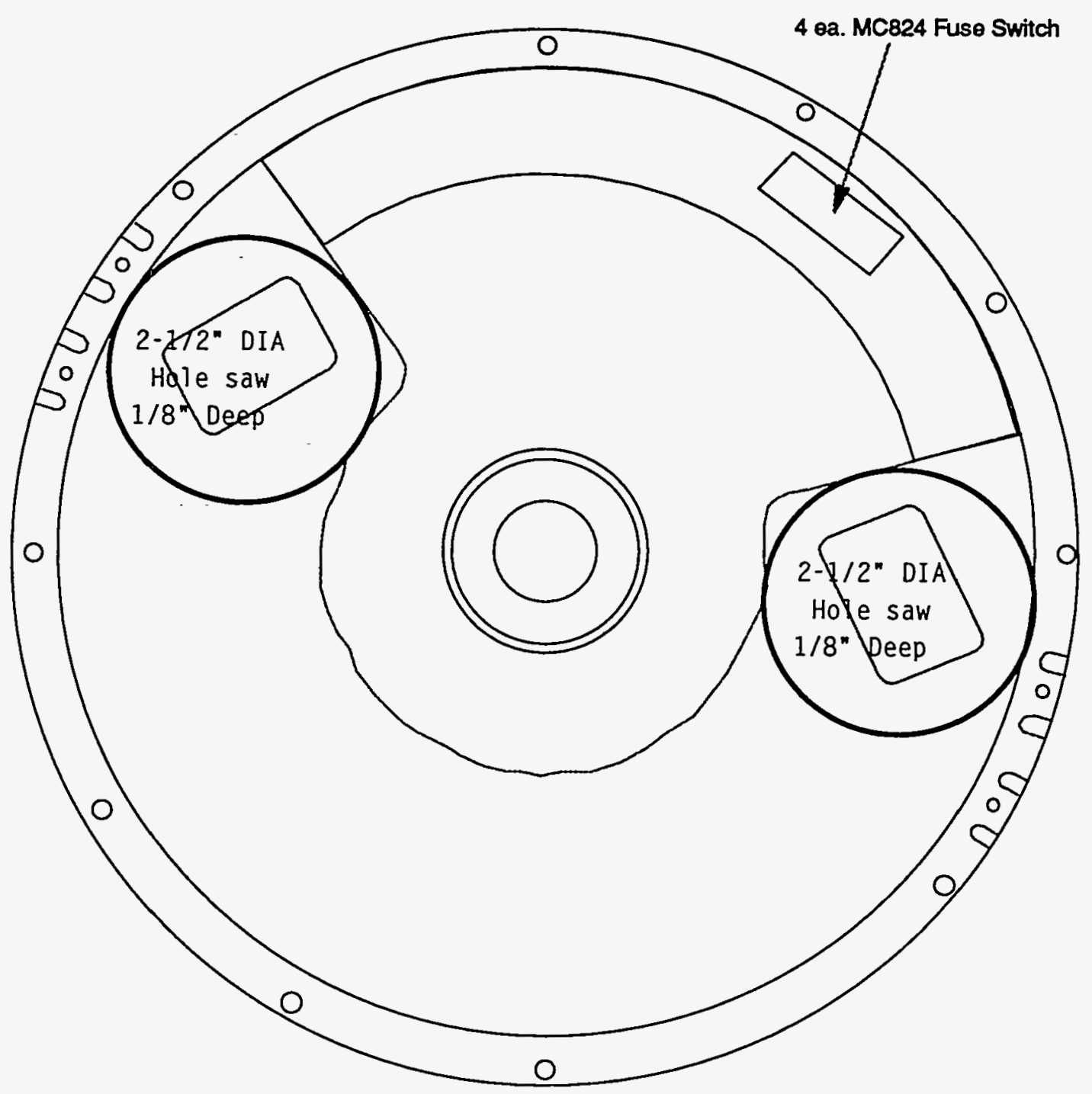

Cut Line 


\section{ATTACHMENT C \\ PERSONNEL HAZARD LOCATION AND CUTLINE DIAGRAM 3}

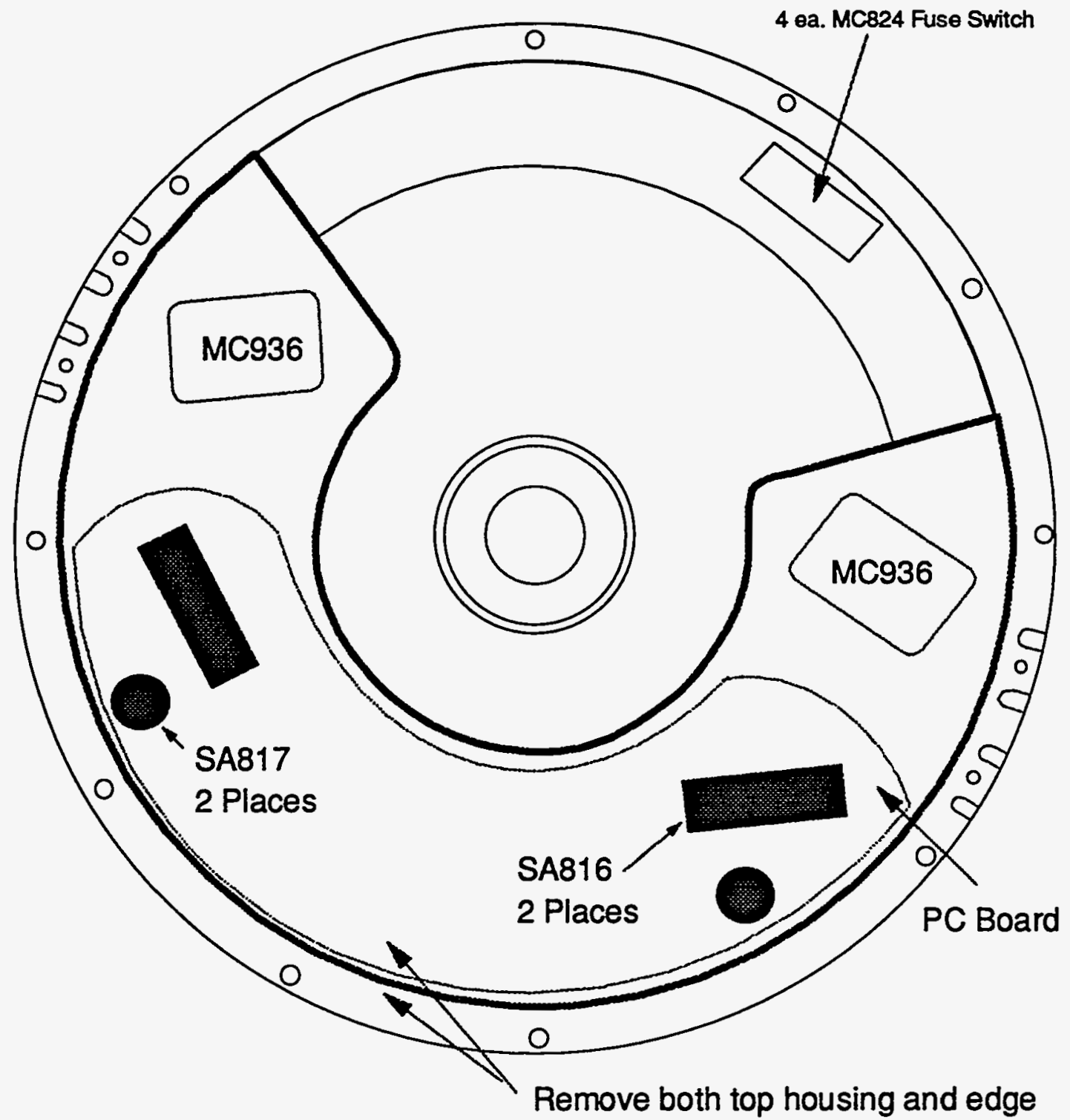

Cut Line 


\section{ATTACHMENT D WEAPON COMPONENT SANITIZATION DATA SHEET}

Part Number/Nomenclature: 211042 MC1187 Firing Set

Classification of Part: $\mathrm{CRD}$ Weapon Program: W45

Type of Product: Mechanical Plastic $\mathrm{XX}$ Electrical Identification of Classified Features and Characteristics:

Configuration Unscaled

Classification Guide Topic: Constituent Material Fact of Use in part Fact of Use in designated weapon Fact of Use in undesignated Weapon

Classification Guide Topic:

$X X \quad$ Electrical Design and Function:

Description of classified design and function:

The electrical design of the high voltage circuit and interconnections, excluding the components involved in that circuit. is classified.

Classification Guide Topic:

Classified by Association

Part to next assembly

Part to weapon program

Part to sub-component

Classification Guide Topic:

Assembly level that contains classified sub-components

List of classified sub-components:

Sanitization Action:

Destruction of the high voltage circuit to the extent that it cannot be reverse engineered. The components involved in that circuit are unclassified.

Completed by: Earl W. Graff

Reviewed by: $\downarrow$ Trodden
Dept. 5115 Date: $6 / 23 / 93$

Dept. 7180 Date: 10/27/93

Authorized Classifier 
CAGE CODE 14213

E. Graff

5115

DP211042

Issue A

Page 11 of 11

\section{ATTACHMENT E \\ HAZARD REMOVAL CERTIFICATION}

\begin{tabular}{|c|c|c|c|c|c|}
\hline $\begin{array}{l}\text { MC1187 } \\
\text { Serial No. }\end{array}$ & \begin{tabular}{|c|}
2 ea. SA816 Tubes \& 2 ea. SA817 \\
Tubes Removed and 2 ea. MC936 \\
Explosive Switches Removed or \\
Verified Fired by:
\end{tabular} & Date & $\begin{array}{l}\text { Tubes disposed of as } \\
\text { Radioactive waste by: }\end{array}$ & Date & $\begin{array}{c}\text { Document } \\
\text { Number }\end{array}$ \\
\hline & & & & & \\
\hline & & & & & \\
\hline & & & & & \\
\hline & & & & & \\
\hline & & & & & \\
\hline & & & & & \\
\hline & & & & & \\
\hline & & & & & \\
\hline & & & & & \\
\hline & & & & & \\
\hline & & & & & \\
\hline & & & & & \\
\hline & & & & & \\
\hline & & & & & \\
\hline & & & & & \\
\hline & & & & & \\
\hline & & & & & \\
\hline & & & & & \\
\hline
\end{tabular}


Appendix A

This page intentionally left blank. 
Procedure: ENV0001.DOC

Revision: A

PAGE 1 of 18

Issue Date: Dec. 94

SAMPLING AND ANALYSIS PLAN FOR DETERMINING THE WASTE CHARACTERISTICS OF EXCESS WEAPON HARDWARE BY THE USEPA TOXICITY CHARACTERISTIC LEACHING PROCEDURE

Approval Recommended by:

Original Signed by W. B. Chambers $12 / 5 / 94$ W. B. Chambers, 1824

Date Author, Project Leader

Original Signed by E. W. Graff, $12 / 7 / 94$ E. W. Graff, 5111 Date Air Delivered Weapons Department

N. A. Durand, 7576

Date

Sample Management Office

J. G. Yeager, 7572

Date

Generator Interface Department

Approved by:

M. R. Keenan, 1824

Date

Chemical and X-Ray Analysis Department 
Procedure: ENV0001.DOC

Revision: A

PAGE 2 of 18

Issue Date: Dec. 94

TABLE OF CONTENTS

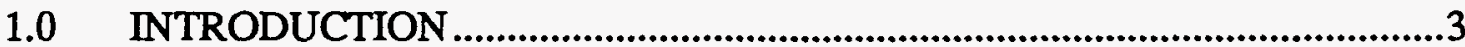

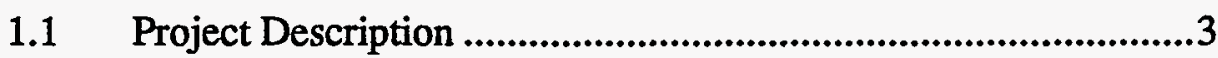

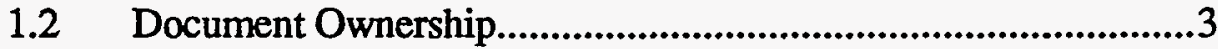

2.0 PROJECT ORGANIZATION AND RESPONSIBILITIES...........................4

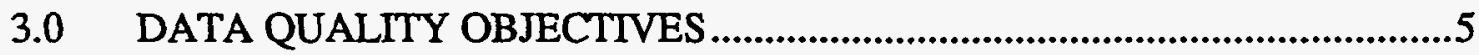

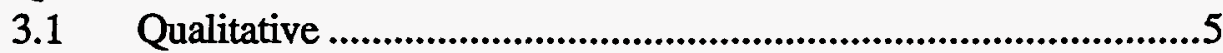

3.2 Quantitative ................................................................6

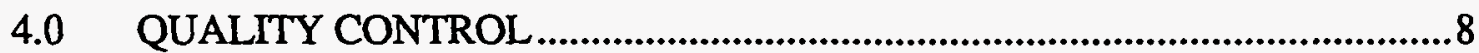

4.1 Sampling QC ................................................................

4.2 Laboratory QC......................................................................8

4.3 Data Quality Assessment......................................................8

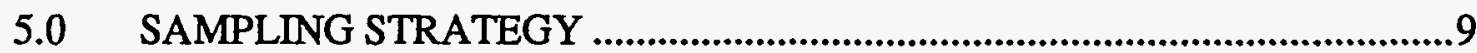

5.1 Sampling Location ..................................................... 10

5.2 Sampling Procedures......................................................10

6.0 SAMPLE DOCUMENTATION AND CUSTODY .................................... 12

6.1 Sampling Laboratory Custody ...........................................13

6.2 Analytical Laboratory Custody ........................................13

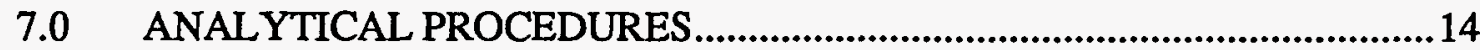

7.1 Instrument Calibration.........................................................14

7.2 Method Detection Limits .................................................14

8.0 DATA REDUCTION, REPORTING, AND VALIDATION..........................15

8.1 Data Reduction .................................................................15

8.2 Data Reporting ................................................................15

8.3 Data Validation...........................................................15

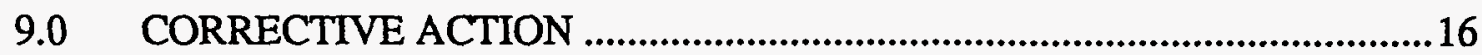

9.1 Analytical Laboratory................................................16

9.2 Sampling Laboratory.................................................17

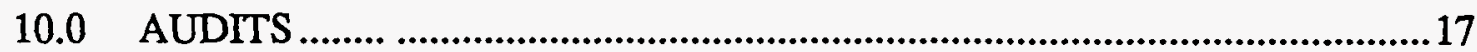

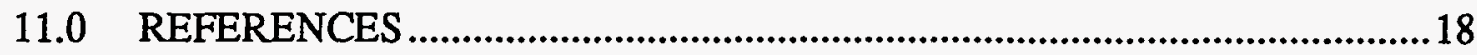


Procedure: ENV0001.DOC

Revision: A

PAGE 3 of 18

Issue Date: Dec. 94

\section{SAMPLING AND ANALYSIS PLAN FOR DETERMINING THE WASTE CHARACTERISTICS OF EXCESS WEAPON HARDWARE BY THE USEPA TOXICITY CHARACTERISTIC LEACHING PROCEDURE}

\subsection{INTRODUCTION}

\subsection{Project Description}

One of the goals of the Dismantlement and Process Development Project at Sandia National Laboratories is to provide for the safe disposal of excess weapon component hardware. Process knowlege and preliminary testing ${ }^{(1)}$ have shown that the hazardous solid yaste characteristics of electronic hardware, as defined in 40-CFR-261 ${ }^{2}$, are generally limited to:

1. Reactivity (D003) - principally a characteristic of self-contained sub-components such as explosive switches and thermal batteries.

2. Toxicity (D004-D011) - the RCRA regulated metals; arsenic, barium, cadmium, chromium, lead, mercury, selenium, and silver.

This procedure describes the methods to be used for sampling excess weapon hardware for purposes of identifying the hazardous waste characteristics by the USEPA Toxicity Characteristic Leaching Procedure (TCLP). These methods are developmental (experimental) and subject to the limitations of existing apparatus for reduction of hardware to the test dimensions required by regulation. Alternate technologies are being evaluated and improvements to this process will be incorporated as they are approved.

This document applies only to the sampling of demilitarized weapon hardware for the Toxicity Characteristic. The sampling and analysis of reactive or radioactive materials are beyond the scope of this plan. Weapon components shall have all reactive and radioactive materials identified and expended/separated by another process prior to sampling for TCLP analyses.

\subsection{Document Ownership}

Department 1824 controls the development, distribution and revision of this document. Written comments and suggestions should be addressed to the author who shall reply in writing regarding the acceptance or rejection of suggested changes. This document shall be reviewed and revised annually to incorporate changes in methodology or regulatory statutes. This document applies to all Dept. 1824 personnel and contractors who engage in sampling of weapon hardware for purposes of analysis by the USEPA TCLP. This document is subordinate to all applicable Center 1800 and SNL Corporate ES\&H and QA policies. 
Procedure: ENV0001.DOC

Revision: A

PAGE 4 of 18

Issue Date: Dec. 94

\subsection{PROJECT ORGANIZATION AND RESPONSIBILITIES}

\section{Air Delivered Weapons Department 5111}

Department 5111 has responsibility for managing the Dismantlement and Process Development Project at SNL/NM and is the principle customer (data requestor) for analytical data generated under this plan.

The data requestor shall:

1. identify personnel hazards which may impact weapon component disassembly and sampling;

2. ensure that weapon components have all reactive and radioactive materials identified and expended/separated prior to sampling for TCLP analysis.

Chemical and X-Ray Analysis Department 1824

Department 1824 is responsible for the sampling and analysis of demilitarized weapon hardware.

The Department Manager has the responsibility to:

1. review the qualifications and training requirements for staff and contract personnel;

2. review and approve the sampling and analysis plan and the activities described therein.

The Project Leader has the responsibility to:

1. coordinate the activities of the sampling and analysis project including sample collection, Quality Control (QC), and contract management for the Analytical Laboratory;

2. develop and revise project specific Operating Procedures as needed;

3. work with the Sample Management Office (SMO) to assure that data generated by the Analytical Laboratory meets the Data Quality Objectives.

\section{Sample Management Office Department 7576}

Department 7576 is contracted to provide sample shipment, tracking, data review and verification, and document control. The contract Statement of Work shall require that the SMO: 
Procedure: ENV0001.DOC

Revision: A

PAGE 5 of 18

Issue Date: Dec. 94

1. review and approve the QA/QC procedures to be used for the project;

2. coordinate sample shipments to/from the Analytical Laboratory and track samples to final disposition;

3. evaluate measurement bias and variability and submit audit samples to aid in the evaluation;

4. review and approve measurement data and reports;

5. maintain records including sample logs, sample custody records, and measurement reports;

6. conduct performance audits and make recommendations when corrective actions are needed.

\section{Analytical Laboratory}

The Analytical Laboratory is contracted to provide sample analysis and under the contract Statement of Work has the responsibility to:

1. document sample receipt and custody;

2. use appropriate analytical methodology and $Q A / Q C$ procedures as specified in this document and in the laboratory's Quality Assurance Plan;

3. document and report measurement data including intemal $Q C$ results.

\subsection{DATA QUALITY OBJECTIVES}

The overall objective of this project is to determine the Toxicity Characteristic of individual weapon system components as a means of evaluating the option for Landfill Disposal of excess and retirement electronic hardware. Sampling and analysis shall be performed in accordance with USEPA QA/QC objectives and approved analytical methods. Based on engineering knowledge, it has been determined that none of the organic constituents listed in 40-CFR-261 ${ }^{(2)}$ will be present in a measurable concentration in weapon component hardware. Therefore, samples will be collected for the purpose of determining the concentration of Toxicity Characteristic metals.

\subsection{Qualitative}

\subsubsection{Representativeness}

Each component selected for sampling and analysis has an identifying part number. All components with the same part number are assumed to be identical in material composition. If sufficient weight of material is available to provide duplicate samples from one component, than a single component shall be selected for rubble-ization and sampling. Otherwise, a sufficient number of same part-numbered components shall be rubble-ized together to provide sufficient material for duplicate sampling. 
Procedure: ENV0001.DOC

Revision: A

PAGE 6 of 18

Issue Date: Dec. 94

\subsubsection{Comparability}

Measurement data shall be reported in units consistent with other organizations reporting similar data to allow comparisons among data bases. For the TCLP analysis those units will be expressed as milligrams of analyte per liter of extraction fluid $(\mathrm{mg} / \mathrm{L})$.

\subsection{Quantitative}

\subsubsection{Analytical Method}

The analytical methodology to be used is described in EPA SW- $846^{(3)}$. Applicable methods include:

Method 1311 - Toxicity Characteristic Leaching Procedure

Method 6010A - Inductively Coupled Plasma-Atomic Emission Spectroscopy

Method 7470 - Mercury in Liquid Waste (TCLP extract)

Method 6010A is an approved procedure for the determination of seven of the eight RCRA regulated Toxicity Characteristic metals: lead $(\mathrm{Pb})$, cadmium $(\mathrm{Cd})$, chromium $(\mathrm{Cr})$, silver ( $\mathrm{Ag})$, barium (Ba), arsenic (As), and selenium (Se). These metals are determined simultaneously in TCLP extracts using a multi-channel inductively coupled plasma-atomic emission spectrometer (ICPAES). Mercury (Hg) can also be determined by ICP-AES although it is not an approved method and the sensitivity is typically at or near the Toxicity Characteristic limit. Based on engineering knowledge, mercury is used in discrete parts which are identified in the Disassembly Procedure (DP) and segregated prior to rubble-ization for sampling and analysis. Therefore it will be acceptable to initially analyze TCLP extracts for $\mathrm{Hg}$ by ICP-AES as a screening technique to supplement the DP. However, if a component does not exhibit the Toxicity Characteristic for $\mathrm{Pb}, \mathrm{Cd}, \mathrm{Cr}, \mathrm{Ag}, \mathrm{Ba}, \mathrm{As}$, or $\mathrm{Se}$, or if the ICP-AES analysis for $\mathrm{Hg}$ exceeds the Toxicity Characteristic limit, then the TCLP extract shall be analyzed by Method 7470 for Mercury.

\subsubsection{Accuracy}

Accuracy of the analytical data shall be assessed by performance evaluation through the use of Laboratory Control Samples (LCS's) and certified reference materials. Reference values and control limits for certified reference materials are established by the issuing agency. The accuracy objective for LCS's analyses shall be to maintain analyte values within $20 \%$ (relative) of the reference value or within 3 standard deviation units of the historical mean. 
Procedure: ENV0001.DOC

Revision: A

PAGE 7 of 18

Issue Date: Dec. 94

\subsubsection{Precision}

Sampling precision is difficult to assess due to the inherent inhomogeneity of the material being sampled. To meet the objectives of this program, the appropriate number of samples needed to characterize each weapon component will be determined using the formula described in Chapter Nine of SW-846 for a simple random sampling strategy ${ }^{(3)}$. A minimum of two samples of each component will be used initially to determine the constituent mean value and variance for each component.

Precision of laboratory measurements shall be determined by the replicate measurement of sample extracts and LCS's. The relative percent difference (RPD) between replicate measurements shall be $\leq 20 \%$.

\subsubsection{Contamination}

Sample contamination in the laboratory will be assessed by the analysis of method blanks. The value for the method blank shall not exceed a factor of 2 times the value of the Method Detection Limit (MDL) without corrective action ( refer to Section 7.2). Contamination of samples by the sampling equipment shall be determined by processing material "blanks" through the component rubble-ization, sampling, and analysis steps. Material blanks shall be made of glass or ceramic filled epoxy resin, similar in composition and density to potting materials used for weapon components but free of RCRA regulated toxic metals. Analytical results for the material blank samples shall not exceed a value such that subtraction of the value from a sample result would impact the waste characterization of the sample.

\subsubsection{Matrix Effect}

Due to the high concentration of metals such as aluminum ( $\mathrm{Al}$ ), iron (Fe), nickel (Ni), and copper $(\mathrm{Cu})$ in these samples, it will be necessary to simultaneously determine the concentration of these and other interfering elements in order to correct for the effect of background and spectral interferences on the RCRA metals analyses. Recommended emission wavelengths and correction procedures are given in Method $6010 \mathrm{~A}^{(3)}$.

The effect of matrix bias on analytical precision and accuracy shall be assessed by the preparation and analysis of matrix spike (MS) and matrix spike duplicate (MSD) samples at the analytical laboratory. The bias for matrix spike analyses shall be limited to $\pm 50 \%$ recovery of the spiked concentration. The precision of MSD analyses shall be within 50\% RPD. 
Procedure: ENV0001.DOC

Revision: A

PAGE 8 of 18

Issue Date: Dec. 94

\subsubsection{Data Completeness}

Completeness is a measure of the relative number of data points that meet the acceptance criteria for accuracy, precision, and bias. $100 \%$ completeness shall be required for those samples with reported values which are equal to or less than the Toxicity Characteristic within the $80 \%$ confidence interval. Those samples for which one or more analytes exceed the Toxicity Characteristic limit will not be included in the completeness calculation.

\subsection{QUALITY CONTROL}

A sufficient number of Quality Control (QC) samples will be collected and analyzed to assure that the Data Quality Objectives are met. The quality control procedures and practices mandated by Chapter One of SW $-846^{(3)}$ and the analytical method will be required as a minimum.

\subsection{Sampling QC}

1. Duplicate samples shall be collected for each weapon component.

2. A minimum of one equipment blank shall be collected with every batch of components rubble-ized and sampled.

3. A minimum of one check sample, of certified composition, shall be included with each batch of samples shipped to the Analytical Laboratory.

\subsection{Laboratory QC}

1. A minimum of one method blank shall be analyzed with each batch of samples.

2. A minimum of one matrix-spike shall be analyzed with each batch of samples.

3. A minium of one Laboratory Control Sample (LCS) and one duplicate LCS shall be analyzed with each batch of samples.

4. A minimum of one sample TCLP extract shall be analyzed in duplicate with each batch of samples.

\subsection{Data Quality Assessment}

\subsubsection{Blank Evaluation}

The most likely source of sample contamination is carry-over in the component rubble-ization step. The forge hammer and hammer-mill equipment are brushed and vacuumed following the rubble-ization of each component however, it would be impracticle and labor-intensive to disassemble and clean the impact surfaces each time. Equipment blanks will be evaluated in terms of the probable effect on sample results. 
Procedure: ENV0001.DOC

Revision: A

PAGE 9 of 18

Issue Date: Dec. 94

\subsubsection{Precision}

Precision shall be expressed as the relative-percent-difference (RPD) between duplicate measurements of the same sample as follows:

$$
\mathrm{RPD}=\left|\frac{v_{1}-v_{2}}{\left(v_{1}+v_{2}\right) / 2}\right| \times 100 \%
$$

where: $v_{1}=$ first sample value, and

$v_{2}=$ duplicate sample value.

\subsubsection{Matrix Bias}

Analytical bias is expressed as the percent recovery of a known amount of analyte (spike) that is added to a sample prior to analysis. For sample TCLP extracts, the percent recovery is determined as:

$$
\% \text { recovery }=\frac{c_{2}-c_{1}}{v} \times 100
$$

where: $c_{2}=$ measured concentration of the spiked sample,

$c_{1}=$ measured concentration of the un-spiked sample, and

$v=$ reference value of spike.

\subsection{SAMPLING STRATEGY}

The sampling strategy has been designed to ensure that samples are representative of the bulk material within the constraints of the mechanical processing techniques and the regulatory requirements for TCLP analysis. The TCLP methodology requires that the material to be characterized be reduced in size such that it will pass through a $9.5 \mathrm{~mm}$ screen prior to the leach test. This is accomplished by the rubble-ization of individual components using a mechanized forge hammer and/or hammermill. The majority of components to be sampled are complex electronic assemblies composed of a mixture of electronic parts, encapsulants, and support materials. The heterogenous nature of the material matrix results in a segregation of material composition with particle size such that the smaller particles $(<9.5 \mathrm{~mm}$ ) consist principally of the brittle and friable electronic materials, and the oversize fraction ( $>9.5 \mathrm{~mm}$ dia.) consists primarily of nonhazardous materials such as aluminum, steel, plastic, and rubber. This segregation tends to bias the composition such that the toxic metals are concentrated in the $<9.5 \mathrm{~mm}$ fraction. Since it is this fraction $(<9.5 \mathrm{~mm})$ that is being sampled, the bias may result in assigning a hazardous characteristic to a component when in fact it should be considered non-hazardous on a per-weight basis. Visual inspection and engineering (material) knowlege shall be used to determine what portion of the oversize fraction is non-hazardous material. As part of the data review process, the weight of non- 
Procedure: ENV0001.DOC

Revision: A

PAGE 10 of 18

Issue Date: Dec. 94

hazardous material can be factored in to determine the concentration of each leachable metal on a per-weight basis.

\subsection{Sampling Location}

Demilitarized components are "rubble-ized" with a mechanized forge hammer on-site at SNL/NM. A hammermill is also used, either alternatively or in succession, for the rubble-ization of small discrete components and subcomponents of larger parts. The rubble from each individual component is collected in a separate container, labeled, and transferred to the Department 1824 Sampling Laboratory. There the rubble-ized material is subdivided and samples are prepared for shipment to the Analytical Laboratory.

\subsection{Sampling Procedures}

\subsubsection{Forge Hammer Operation}

Operation of the forge hammer is described in a separate document ${ }^{(4)}$. Demilitarized components are processed individually and the rubble is contained within an enclosed steel hopper during the hammer cycle. Once the hammering is complete, the hopper is opened and the material is collected in polyethylene containers via an aluminum chute. The hammer surfaces, hopper, and chute are brushed and vacuumed prior to processing the next component to reduce cross-contamination.

\subsubsection{Sample Preparation Method}

Representative samples of the $(<9.5 \mathrm{~mm})$ component rubble are obtained through the use of a simple random sampling procedure. By definition, a random sampling process ensures that every unit (i.e. particle) in the population has an equal chance of being sampled and measured (Chapter 9 $\mathrm{SW}-846)^{(3)}$. This is achieved through the use of a riffle chute splitter which consists of a hopper with altemating directional chutes at the bottom which split the sample feed equally (and randomly) into two collecting trays. The process is then repeated for each of the trays successively, until two samples of appropriate weight are obtained. Figure 1 is a graphical representation of the random sampling process. 
Procedure: ENV0001.DOC

Revision: A

PAGE 11 of 18

Issue Date: Dec. 94

\section{Figure 1. Random Sampling by Riffle Split}

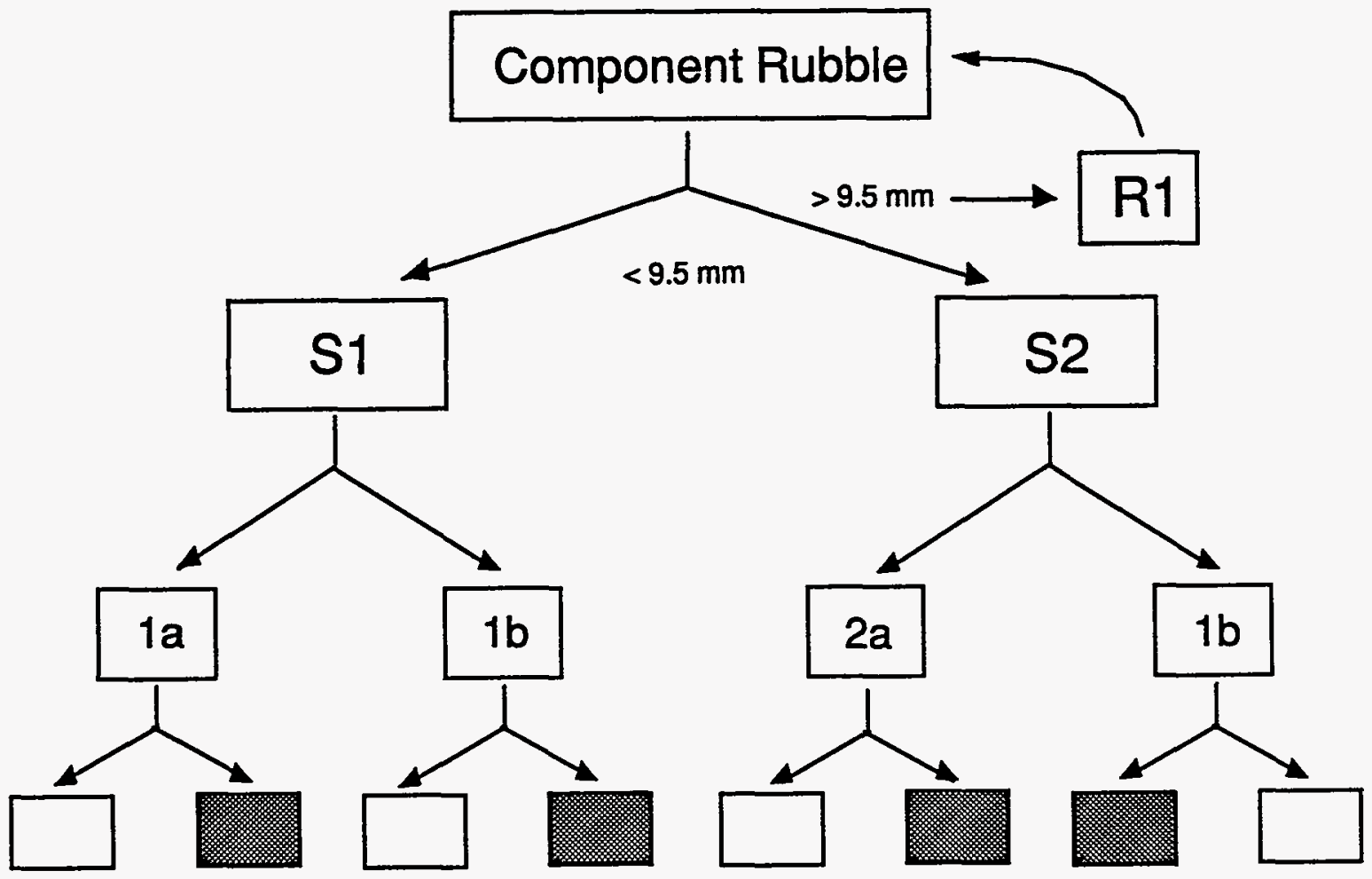

The following steps shall be conducted in a fume hood to avoid worker exposure to hazardous dusts. The appropriate facility training, protective clothing, and health and safety issues are governed by the Department 1824 Facility Operating Procedure(5).

Sample Preparation Steps:

1. Sieve component rubble through a $9.5 \mathrm{~mm}$ wire cloth screen equipped with collection pan.

2. Inspect oversize material $\left(R_{1}>9.5 \mathrm{~mm}\right)$ for known and suspected hazardous materials (e.g. pieces of circuit board with $\mathrm{Pb}$ solder).

3. Reduce any materials suspected of containing toxic metals with hand cutters such that they will pass through the sieve.

4. Weigh the remainder of the oversize material and record the weight.

5. Weigh the amount of sample material which passes through the sieve and record the weight.

6. Split the sample material into two fractions with a riffle chute splitter equipped with collection pans. 
7. Further subdivide by splitting successive fractions, as necessary, until two samples of between 100 and 125 grams are obtained.

8. Record the weights of the two samples in the sample logbook and transfer the samples into pre-cleaned glass jars.

9. Seal the jars with the supplied screw cap and chain-of-custody label.

\subsubsection{Sample Storage and Transportation}

Samples shall be collected and stored in pre-cleaned glass jars which meet the USEPA specification for trace metal contamination(6). Sample preservation is not required for solid samples collected for metals analysis by the TCLP method. Samples are stored at room temperature in a locked laboratory until transfer of custody to the Sample Management Office for shipment to the analytical laboratory. Samples shall be shipped within a period of time such that the analytical laboratory can complete the extraction procedure within an elapsed period of 28 days from the time of sample collection.

The "reject" material that results from successive splits of the component rubble shall be returned to the original polyethylene collection container, labeled, and stored in a locked cabinet until the analytical data has been reviewed. If additional samples are needed they shall be obtained from this material by repeating the steps outlined in the Sample Preparation Method, Section 5.2.2.

\subsubsection{Equipment Calibration}

The analytical balances in Bldg. 805, Room 302, are serviced and calibrated against National Institute of Standards and Technology (NIST) traceable weights every six months. Calibration is verified at time-of-use according to manufacturer's specifications. The $9.5 \mathrm{~mm}$ sieves used in the sampling procedure are manufactured to American Society of Testing and Materials (ASTM) specification E11.

\subsubsection{Equipment Decontamination}

The surfaces of all sampling equipment shall be decontaminated by brushing and vacuuming with a High Efficiency Particulate Air (HEPA) filtered vacuum cleaner following the sampling of each individual component.

\subsection{SAMPLE DOCUMENTATION AND CUSTODY}

Chain-of-custody procedures shall be used to ensure that the possession and handling of samples from the time of collection through shipping and analysis is documented by written record. The chain-of-custody is initiated with the collection and sampling of component rubble and remains in effect until the sample is disposed of by the Analytical Laboratory or returned. 
Procedure: ENV0001.DOC

Revision: A

PAGE 13 of 18

Issue Date: Dec. 94

\subsection{Sampling Laboratory Custody}

The sample preparation steps (Section 5.2.2) for each individual component shall be documented in patent-numbered SNL Laboratory Notebooks. Each sample collected for analysis shall be assigned a unique alphanumeric identifier (sample number) which shall be recorded on the sample label. Sample number, description, and weight, along with date and time of collection shall be recorded in a sample logbook. Standardized, numbered "Analysis Request and Chain of Custody Record" and "Sample Collection Log" forms obtained from the Sample Management Office (SMO) shall be used to document sample collection, transfer, and shipment to the Analytical Laboratory.

\subsection{Analytical Laboratory Custody}

Sample receipt, inspection, custody, and analysis procedures shall be documented by the Analytical Laboratory. A copy of the complete sample chain-of-custody documentation shall be included with the analytical data package (report). Specific custody procedures shall be adhered to as described in the Analytical Laboratory QA plan. As a minimum, the following activities should be documented.

\subsubsection{Sample Inspection}

Upon receipt, the analytical laboratory sample custodian shall inspect sample containers and note the presence of damage or tampering. The custodian shall also identify any discrepancies in the chain-of-custody documentation including labeling and sample identification. Any discrepancies shall be noted on the chain-of-custody form and the Project Leader shall be notified before sample analysis proceeds.

\subsubsection{Sample Tracking and Storage}

Upon completion of inspection, the custodian shall sign and date the custody form to document receipt of samples. Samples shall be logged into the analytical laboratory sample tracking system. Specific storage, holding time, and analytical requirements shall be noted and the appropriate analytical and administrative personnel shall be notified. Samples shall be placed in secure storage prior to analysis. 
Procedure: ENV0001.DOC

Revision: A

PAGE 14 of 18

Issue Date: Dec. 94

\subsection{ANALYTICAL PROCEDURES}

The analytical methods to be used in the evaluation of weapon component hardware for the Toxicity Characteristic are taken from EPA SW-846, "Test Methods for

Evaluating Solid Waste" (3). The applicable methods are listed in Section 3.2.1 of this document. All analytical methods shall be performed as written except where noted in this document or in the contract Analytical Laboratory's Statement of Work (SOW). The Project Leader shall be notified of any additional changes or modifications that may become necessary in the course of analysis.

\subsection{Instrument Calibration}

The analytical instrumentation shall be calibrated, using standard solutions of metals with known concentrations, on the same day and work shift that the samples are scheduled for analysis. Calibration standards shall be prepared from certified reference materials, traceable to NIST standards. The instrument response shall be calibrated using a blank solution and a minimum of two calibration standards. A calibration check standard, made from a different reference material source, shall be used to verify the calibration. Continuous calibration throughout the course of analysis shall be verified by analysis of the check standard at regular intervals as specified in the method.

\subsection{Method Detection Limits}

The method detection limit (MDL) is defined as "the minimum concentration of a substance that can be measured and reported within $99 \%$ confidence that the analyte concentration is greater than zero" (Chapter One, QC, SW-846) (3). The MDL is determined from the variance of a series of replicate analyses of a matrix solution containing the element of interest such that:

$$
\mathrm{MDL}=\mathrm{t}(\mathrm{n}-1, \alpha=0.99)(\mathrm{s})
$$

where, $t(n-1, \alpha=0.99)$ is the one-sided t-statistic appropriate for the number of replicate analyses used to determine the standard deviation (s).

The MDL shall be at least a factor of 10X lower than the Toxicity Characteristic regulatory limit for each metal (except in the case of mercury analysis by ICP-AES as discussed in Section 3.2.1 of this document). 


\subsection{DATA REDUCTION, REPORTING, AND VALIDATION}

Data reduction is defined as those activities involved in the conversion of raw data to reportable units, the computation of summary statistics, and the transcription of data between recording and reporting media. Data validation involves the systemmatic process of reviewing the data against the DQO's to provide assurance that the objectives are met and that the data are adequate for their intended use.

\subsection{Data Reduction}

All calculations which apply to the conversion of raw data to reportable units of concentration shall be completed and reviewed by the analyst. The associated QC data shall be used to verify that the data are within the control limits specified for the analytical method and the DQO's. Calculations shall be performed according to the procedures described in the analytical method and/or the Analytical Laboratory's QA manual. Calculations may be performed manually or electronically if the instrument is interfaced with a microprocessor or computer. All calculations shall be stored in a retrievable form such that the reported values can be reconstructed from the raw data.

\subsection{Data Reporting}

The analytical data shall be delivered in the form of a hard copy data package. The data package shall include a transmittal letter and the following information:

- date of issue;

- contract number and project name;

- copies of the analysis request and chain-of-custody forms;

- laboratory assigned sample identification numbers;

- sample holding times;

- analytical method references and modifications;

- sample analytical results, QC analyses, and control limits;

- technical problems or nonconformances and corrective actions taken.

\subsection{Data Validation}

The analyst has the initial responsibility for verifying the quality of the analytical data. The analyst shall verify that all QC procedures required by the analytical method have been followed and the results of QC sample analyses are within the acceptance criteria for the method. Peer or management review of the data shall be required prior to release of the data. Upon receipt of the data at Sandia, the Sample Management Office (SMO) has the initial responsibility for verifying the quality of the reported data. 
Procedure: ENV0001.DOC

Revision: A

Issue Date: Dec. 94

The data validation process shall include verification that:

- the appropriate procedures were used for sample collection and handling;

- QC samples were collected and analysed;

- analytical QC procedures were performed and documented;

- the QC data meets the established acceptance criteria;

- the analytical report (data package) is complete.

The Project Leader has the responsibility to work with the SMO to verify that the quality of the reported data is adequate for assessing the Toxicity Characteristic of specific weapon components. If the TCLP data is considered valid, it is entered into the Stockpile Dismantlement Database (SDDB). A hardcopy of the analytical report shall be permanently filed with the Environmental Operations Center (7500) Records.

\subsection{CORRECTIVE ACTION}

Corrective action shall be required to correct deficiencies resulting from conditions which could impact the quality of the data. Corrective action shall be initiated when any of the following conditions arise:

- Specific requirements of the analysis method or this procedure are not met;

- DQO's for precision, accuracy, representativeness, and completeness are not achieved;

- data review indicates that the data are incomplete or incorrect or that a miscalculation or instrument malfunction has occured.

\subsection{Analytical Laboratory Corrective Action}

The Analytical Laboratory has responsibility for maintaining the quality of analytical procedures and instrumentation. The Analytical Laboratory shall investigate and determine the cause of any deficiences and determine the corrective action necessary to eliminate the deficiency.

Corrective action may include any of the following activities:

- verify integrity of calibration standards, laboratory control samples, and analytical reagents;

- review instrument operating conditions and parameters;

- check calculations and data transcription;

- re-analyze samples. 
Procedure: ENV0001.DOC

Revision: A

PAGE 17 of 18

Issue Date: Dec. 94

\subsection{Sampling Laboratory Corrective Action}

A review of the analytical data should determine if any of the data are incomplete, inconclusive, or indicative of a sampling strategy deficiency. Examples of sampling deficiencies include:

- large variations in duplicate sample results which would impact waste characterization;

- results which would fall below the Toxicity Characteristic Limit if diluted by the weight fraction of oversize material ( $>9.5 \mathrm{~mm}$ ) not sampled;

- contamination levels in the material blank samples which would impact waste characterization.

Corrective action shall be documented in the Sampling Laboratory records and may include any of the following activities:

- resampling of the component rubble for repeat analysis;

- resampling of the material blank rubble for repeat analysis;

- resizing and sampling of the oversize material for analysis;

- rubble-ize and sample another component for analysis.

\subsection{AUDITS}

A technical performance audit of the Analytical Laboratory shall be conducted on an annual basis. The audit team will include a representative from the SMO and the Project Leader or designated altemative. The audit will evaluate, at a minimum, the laboratory's performance on the following activities:

- implementation and adherence to the laboratory QA Plan;

- sample custody, tracking, and handling procedures;

- sample preparation and analytical methodology;

- instrument calibration;

- data reduction and validation;

- documentation.

A self-assessment audit of the Sampling Laboratory procedures shall also be conducted on an annual basis. The audit team will include a representative from the SMO and the Project Leader or designated alternate. The audit will evaluate, at a minimum, the laboratory's implementation and adherence to this sampling and analysis plan. 
Procedure: ENV0001.DOC

Revision: A

PAGE 18 of 18

Issue Date: Dec. 94

\subsection{REFERENCES}

1. W. D. Ulrich, et. al., Process Development Report - Weapon Hazardous Material Identification, SAND92-0302, (Sandia National Laboratories, 1992).

2. U. S. Environmental Protection Agency, Code of Federal Regulations, Chapter 40, Part 261.23 \& 261.24, (1990).

3. U. S. Environmental Protection Agency, Test Methods for Evaluating Solid Waste, SW-846, 3rd edition, Rev. 1, (1992).

4. P. G. Neiswander, Operation of the Chambersburg Power Forging Hammer as a Rubblizing Device, ES\&H SOP \#SP473054, (Sandia National Laboratories, 1993).

5. W. B. Chambers, Operating Procedure for Analytical Chemistry Laboratory Operations, OP1820-006, (Sandia National Laboratories, 1991).

6. U. S. Environmental Protection Agency, Specifications and Guidance for Contaminant Free Sample Containers, OSWER Directive \#9240.0-05A (1992). 


\section{Analysis of Weapon Component Electronic Hardware by the Toxicity Characteristic Leaching Procedure (TCLP)}

The attached tables show the results of TCLP analysis of 100 electronic components that were analyzed in support of the SNL/NM Weapon Systems Dismantlement and Process Development Project. Components were prepared for sampling and analysis in batches according to the procedure described in Appendix B. The size of the batch was dependent on the number of samples that could be "rubble-ized" in a day. The data is shown in spreadsheet format, 3 pages to a sample batch.

The first page, of each 3 page set, contains a description of the part, the date the part was prepared for analysis, the part weight, and any disassembly information that may apply. The "Process Weight" is the weight of material that was introduced to the forge hammer or other size reducing equipment or process. The "Rubble Weight" is the weight of rubble-ized material that was collected for sampling and analysis. The "Loss Weight" is the difference between the process weight and the rubble weight. The rubble-ized material was sieved through a $9.5 \mathrm{~mm}$ screen, and duplicate samples for TCLP analysis were collected from the $<9.5 \mathrm{~mm}$ material. In a few cases, there was insufficient material for duplicate 100 gram samples.

The second and third pages of each 3 page set show the results of the TCLP analysis - for eight metals: silver $(\mathrm{Ag})$, chromium $(\mathrm{Cr})$, selenium $(\mathrm{Se})$, mercury $(\mathrm{Hg})$, lead $(\mathrm{Pb})$, cadmium (Cd), barium (Ba), and arsenic (As). All samples were analyzed by the Analytical Sciences Department, Allied Signal Aerospace, Kansas City Division (ASKCD). Also referenced, is the Chain-of-Custody Record Number under which the samples were shipped to ASKCD. A hard copy of the analytical data report supplied by ASKCD for each batch of samples is on file in the Records Center for the Waste Management and Regulatory Projects Department at SNL/NM. The analytical data report is filed by Record Number and includes all laboratory Quality Assurance and Quality Control data relative to the sample batch analysis. Data for the internal Quality Control samples are included in the attached spreadsheets (pp.57-59). "ALOX" samples are material blanks that are processed, sampled, and analyzed by the same procedure as the component samples for purposes of monitoring equipment contamination (see Appendix B). Also shown are the results for certified reference materials, included in each sample shipment as control samples for analysis with the sample batch.

Nearly every component tested ( 96 of 100) exhibits the Toxicity Characteristic for either $\mathrm{Pb}, \mathrm{Cd}$, or both, even when the weight of oversize material $(>9.5 \mathrm{~mm})$ is factored in and the sample data is corrected for contamination or control sample variance. The exceptions are primarily electro-mechanical devices, with little or no $(\mathrm{Pb})$ soldered circuitry and which have no (Cd) plated parts associated with them. The Toxicity Characteristic test data is summarized in Appendix D. 
SDDB Data Entry Chemical Analysis

\begin{tabular}{|c|c|c|c|c|c|c|c|c|c|c|c|c|}
\hline $\begin{array}{l}\text { MCSA } \\
\text { Number ext }\end{array}$ & $\begin{array}{l}\text { Weapon } \\
\text { System }\end{array}$ & $\begin{array}{c}\text { Part } \\
\text { Number }\end{array}$ & $\begin{array}{c}\text { Serial } \\
\text { Number }\end{array}$ & $\begin{array}{l}\text { Process } \\
\text { Date }\end{array}$ & $\begin{array}{c}\text { Part } \\
\text { Wt. (g) }\end{array}$ & $\begin{array}{c}\text { Plomoved } \\
\text { Wt (g) }\end{array}$ & $\begin{array}{c}\text { Rernoved } \\
\text { (Description) }\end{array}$ & $\begin{array}{l}\text { Procoss } \\
\text { We }(g)\end{array}$ & $\begin{array}{l}\text { Rubble } \\
\text { Wt. (g) }\end{array}$ & \begin{tabular}{|c|} 
Loss \\
Wt (g)
\end{tabular} & $\begin{array}{l}>0.5 \mathrm{~mm} \\
\text { Wt (q) }\end{array}$ & $\begin{array}{l}9.5 \mathrm{~mm} \\
\text { Wt. (a) }\end{array}$ \\
\hline MC 1187 & 45 & 211042 & BBN-1152-11 & 16-jun-92 & 5742.0 & \begin{tabular}{c|}
2627.0 \\
21.0 \\
62.0 \\
528.5
\end{tabular} & $\begin{array}{l}\text { Hardware } \\
\text { Rad Tubes (4) } \\
\text { Expl. Switch } \\
\text { Foam, etc. }\end{array}$ & 2503.5 & 2482.3 & 21.2 & 1189.5 & 1292.8 \\
\hline MC 1187 & 45 & $211042-12$ & BBN-1712-H2 & 16-jun-92 & 5733.0 & $\begin{array}{c}2642.0 \\
22.0 \\
541.1\end{array}$ & $\begin{array}{c}\text { Hardware } \\
\text { Rad Tubes (4) } \\
\text { Foam, otc. }\end{array}$ & 2527.0 & 2482.7 & 35.2 & 992.2 & 1500.5 \\
\hline MC 1187 & 45 & $211042-13$ & BBN-2125-H3 & 16-jun-82 & 5744.0 & $\begin{array}{c}2655.0 \\
22.0 \\
63.0 \\
367.2\end{array}$ & $\begin{array}{l}\text { Handware } \\
\text { Rad Tubes (4) } \\
\text { Expl. Switch } \\
\text { Foam, otc. }\end{array}$ & 2634.8 & 2599.0 & 35.8 & 1089.4 & 1509.6 \\
\hline MC 1187 & 45 & 211042 & BBN-2587-J4 & 07-jul-92 & 5729.0 & $\begin{array}{c}2636.0 \\
22.0 \\
63.0 \\
522.4\end{array}$ & $\begin{array}{l}\text { Hardware } \\
\text { Rad Tubes (4) } \\
\text { Expl. Switch } \\
\text { Foam, etc. }\end{array}$ & 2485.6 & 2454.1 & 31.5 & 806.2 & 1647.9 \\
\hline MC 3289 A & 80 & 318765.00 & $\begin{array}{l}\text { BBN-2137-B84 } \\
\text { BBN-3273-H87 }\end{array}$ & 29-jul-92 & $\begin{array}{l}834.4 \\
845.0\end{array}$ & $\begin{array}{l}242.2 \\
254.6\end{array}$ & $\begin{array}{l}\text { Connectors } \\
\text { Connectors }\end{array}$ & 1182.6 & 1166.7 & 15.9 & 0.0 & 1166.7 \\
\hline MC 3268 & 80 & $316562-00$ & $\begin{array}{l}\text { BBN-X536-D80 } \\
\text { BBN-1707-H83 }\end{array}$ & 29-juł-92 & $\begin{array}{l}252.1 \\
231.3\end{array}$ & $\begin{array}{l}10.2 \\
10.3\end{array}$ & $\begin{array}{l}\text { Connectors } \\
\text { Connectors }\end{array}$ & 462.9 & 456.0 & 6.9 & 2.5 & 453.5 \\
\hline MC 3269 & 80 & $316563-00$ & $\begin{array}{l}B B N-1030-K 83 \\
B B N-1102-A B 5\end{array}$ & 29-jut-92 & $\begin{array}{l}234.1 \\
237.4\end{array}$ & $\begin{array}{l}11.2 \\
11.3\end{array}$ & $\begin{array}{l}\text { Connectors } \\
\text { Connectors }\end{array}$ & 471.5 & 445.4 & 26.1 & 0.0 & 445.4 \\
\hline MC 3371 & 80 JTA & 317644-00 & $\begin{array}{l}\text { BBN-X010-D80 } \\
\text { BBN-1005- } 182 \\
\text { BBN-X021-K82 }\end{array}$ & 30-oct-92 & $\begin{array}{l}795.0 \\
795.0 \\
795.0\end{array}$ & $\begin{array}{l}404.9 \\
435.6 \\
430.9\end{array}$ & $\begin{array}{l}\text { Al Case } \\
\text { Al Case } \\
\text { Al Case }\end{array}$ & 1113.6 & 1098.8 & 14.8 & 0.0 & 1098.8 \\
\hline MC 2907 & MANY & \begin{tabular}{|l|}
$314689-102$ \\
$314689-103$
\end{tabular} & $\begin{array}{l}\text { BBN-01105-J77 } \\
\text { BBN-01424-J79 }\end{array}$ & $30-$ oct-92 & $\begin{array}{l}50.5 \\
50.1\end{array}$ & - & - & 100.6 & 96.0 & 4.6 & 0.0 & 96 \\
\hline SA $2747-1$ & $80 \mathrm{JTA}$ & $316890-00$ & $\begin{array}{l}\text { CFU-27020-178 } \\
\text { CFU27912-G78 }\end{array}$ & $30-$ oct -92 & $\begin{array}{l}290.4 \\
290.3\end{array}$ & - & - & $\begin{array}{l}290.4 \\
290.3\end{array}$ & $\begin{array}{l}281.0 \\
289.4\end{array}$ & $\begin{array}{l}9.4 \\
0.8\end{array}$ & $\begin{array}{l}156.3 \\
134.2\end{array}$ & $\begin{array}{l}124.7 \\
155.2\end{array}$ \\
\hline MC 3276 & 80 & $316590-00$ & $B B N-\times 320-\sqrt{78}$ & 11-nov-92 & 3788.5 & $\begin{array}{c}\text { No Potting } \\
1641.0 \\
913.9\end{array}$ & $\begin{array}{l}\text { SS Cover } \\
\text { Baseplate }\end{array}$ & 1233.6 & 1204.0 & 29.6 & 547.1 & 656.9 \\
\hline MC 3276 & 80 & 316590-04 & BBN-X456-F79 & 11 -nov-92 & 5648.0 & -1 & & 5648.0 & 4910.9 & & 3293.2 & 1617.7 \\
\hline MC 3097 & 28 & $315779-00$ & |BBN-X201-H81 & $1-92$ & 4522.0 & $\begin{array}{c}\text { No Potting } \\
1576.1 \\
970.0 \\
459.0\end{array}$ & $\begin{array}{l}\text { SS Cover } \\
\text { Baseplate } \\
\text { Cables }\end{array}$ & 1516.9 & 1436.6 & 80.3 & 686.3 & 750.3 \\
\hline MC 3097 & 28 & $315779-00$ & BBN-X202-K81 & 11-nov-92 & 5022.0 & 301.2 & Connectors & 4720.8 & 4647.6 & 73.2 & 3298.1 & 1349.5 \\
\hline MC 2534 & 69 & 312834-03 & BBN-1031-D71 & 11-nov-92 & 3566.0 & 2.0 & Rad Tubo & 3564.0 & 3552.9 & 11.1 & 1474.6 & 2078.3 \\
\hline $\begin{array}{l}\text { MC } 1510 \\
\text { MC } 1821\end{array}$ & $\begin{array}{l}57 \\
43\end{array}$ & $\begin{array}{l}311299-01 \\
311770-01\end{array}$ & $\begin{array}{l}\text { MAM-6027-K4 } \\
\text { BBN-1472-B5 }\end{array}$ & $\begin{array}{l}11 \text {-nov-92 } \\
11 \text {-nov-92 }\end{array}$ & $\begin{array}{c}498.7 \\
2438.2\end{array}$ & $\begin{array}{l}44.7 \\
260.7 \\
30.0\end{array}$ & $\begin{array}{l}\text { Hartware } \\
\text { A Baseplate } \\
\text { Hartware }\end{array}$ & 454.0 & $\begin{array}{c}451.3 \\
1706.4\end{array}$ & 2.7 & $\begin{array}{c}285.6 \\
1075.8\end{array}$ & $\begin{array}{l}165.7 \\
630.6\end{array}$ \\
\hline MC 4067 & 53 & 411381-00 & BBN-X114-G87 & 11-nov-92 & 892.6 & $\begin{array}{l}371.4 \\
202.0 \\
32.7\end{array}$ & $\begin{array}{c}\text { A Baseplate } \\
\text { Cover } \\
\text { Hardware }\end{array}$ & 386.5 & 369.2 & 17.3 & 99.7 & 269.5 \\
\hline $\begin{array}{l}\text { MC } 1212 \\
\text { MC } 2248\end{array}$ & $\begin{array}{c}44 \\
61 / 28\end{array}$ & $\begin{array}{l}311037-03 \\
312246-00\end{array}$ & $\begin{array}{l}\text { BBN-2260-H5 } \\
8 B N-1092-A 9-05\end{array}$ & $\begin{array}{l}11 \text {-nov-92 } \\
11-\text { nov-92 }\end{array}$ & $\begin{array}{l}360.6 \\
353.5\end{array}$ & 1650 & Cables & $\begin{array}{l}360.6 \\
188.5\end{array}$ & $\begin{array}{l}355.0 \\
177.8\end{array}$ & $\begin{array}{r}5.6 \\
107\end{array}$ & 32.3 & 322.7 \\
\hline MC 2969 & MANY & 315225-00 & UNKNOWN & 11-nov-92 & 640.0 & - & - & 640.0 & 637.1 & 2.9 & 357.3 & 279.8 \\
\hline MC 2935 & MANY & 314965-00 & UNKNOWN & 11-nov-92 & 282.0 & - & - & 282.0 & 273.7 & 8.3 & 92.7 & 181 \\
\hline SA $2477-9$ & $80 \mathrm{JTA}$ & 316488-00 & $\begin{array}{l}\text { APR-112-B78 } \\
\text { APR-106-A78 } \\
\text { APR-130-E78 }\end{array}$ & 11-nov-92 & $\begin{array}{l}57.8 \\
57.2 \\
61.7\end{array}$ & $\begin{array}{l}- \\
-\end{array}$ & $\dot{-}$ & 176.7 & 168.5 & 8.2 & 94.8 & 73.7 \\
\hline
\end{tabular}


Appendix C

SDDB Data Entry Chemical Analysis

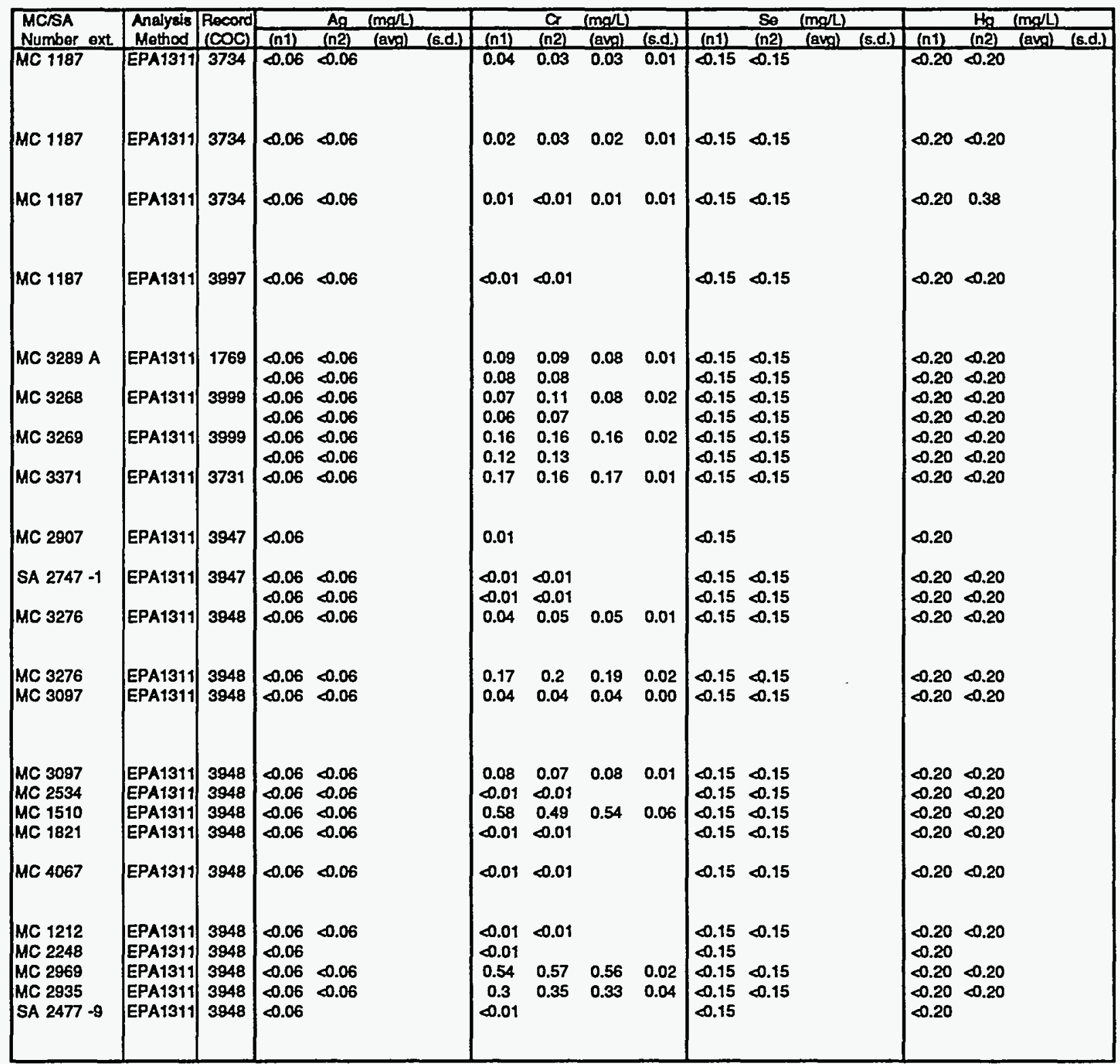


SDDB Data Entry Chemical Analysis

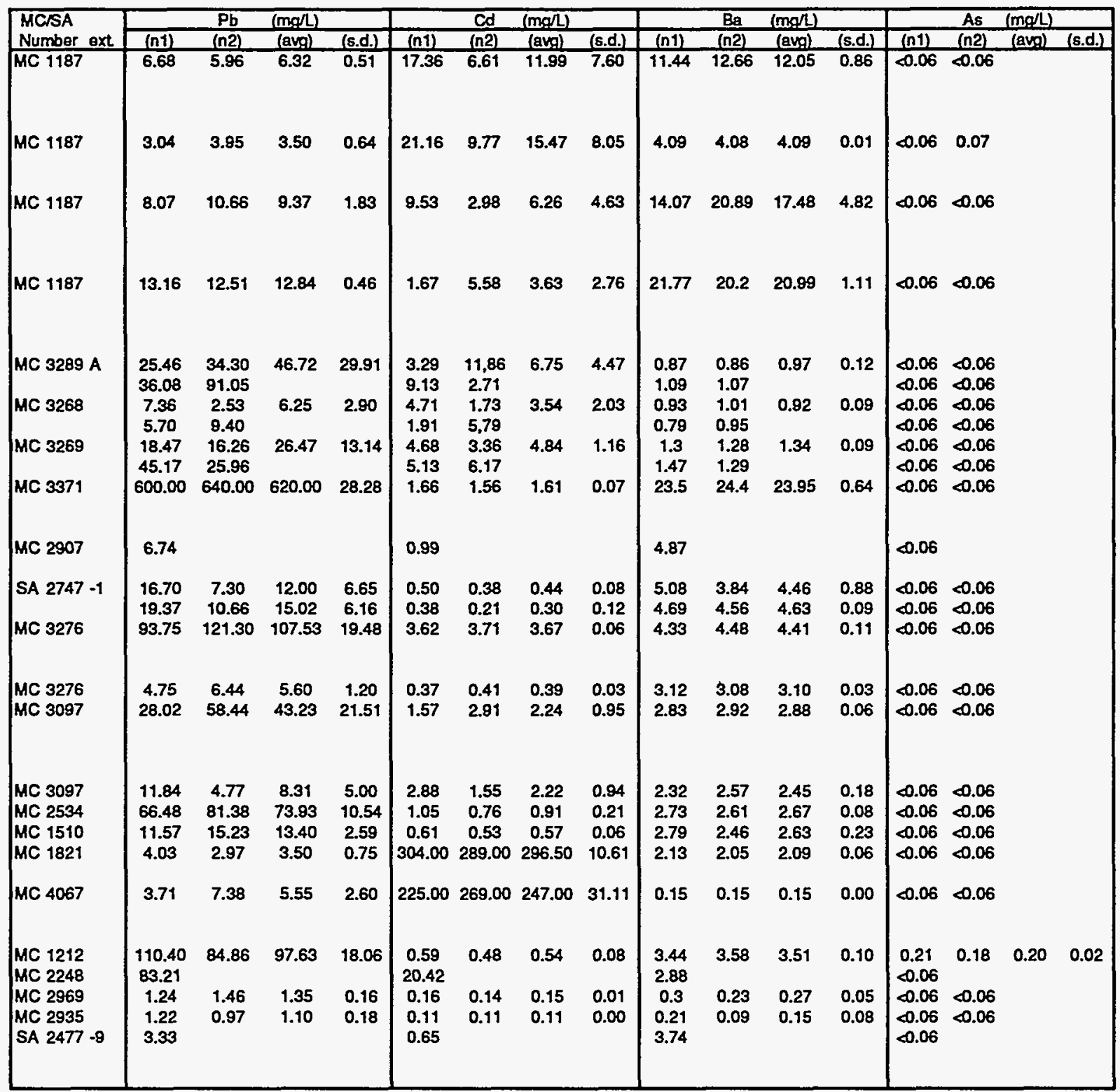


SDDB Data Entry Chemical Analysis

\begin{tabular}{|c|c|c|c|c|c|c|c|c|c|c|c|c|}
\hline$\overline{\mathrm{AC} / \mathrm{SA}}$ & & Part & & & Part & & & & Rubble & Loss & $>9.5 n$ & 1 \\
\hline oxt. & & & & & & & & & & & & $L(a)$ \\
\hline 808 & 28 & $\begin{array}{l}310414-02 \\
310414-02\end{array}$ & $\begin{array}{l}-59053-A B \\
-59263-B 8\end{array}$ & 25-mar-93 & $\begin{array}{l}813.6 \\
815.0\end{array}$ & $\bullet$ & - & 1628.6 & 552.1 & 76.5 & 185.0 & 1367.1 \\
\hline & 43 & $722-09$ & & $-\operatorname{mar}-93$ & 5650.8 & 1313.8 & Cables (U) & 37.0 & 3.0 & 4.0 & 17.1 & 775.9 \\
\hline & 57 & -03 & & & & - & - & & & $\begin{array}{l}20.2 \\
44.4\end{array}$ & $\begin{array}{c}0.0 \\
670.7\end{array}$ & $\begin{array}{l}691.1 \\
490.1\end{array}$ \\
\hline & $\begin{array}{l}57 \\
57\end{array}$ & & $\mid \begin{array}{l}\text { SAF-3577-B5 } \\
\text { BBN-1676-G3 }\end{array}$ & & 3414.5 & 1352.3 & Cables (U) & 62.2 & 2018.5 & 43.7 & 9.0 & 1549.5 \\
\hline & & & & & 1897.0 & . & 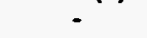 & 97.0 & 832.3 & 64.7 & 53.8 & 1078.5 \\
\hline & 57 & $\begin{array}{l}11164-03 \\
11164-03\end{array}$ & $\mid \begin{array}{l}\text { BBN-2035-K3 } \\
\text { BBN-2016-K3 }\end{array}$ & -93 & $\begin{array}{l}238.9 \\
239.0\end{array}$ & - & - & 77.9 & 431.3 & 46.6 & .5 & 420.8 \\
\hline 1380 & 57 & $311188-00$ & BBN-1577-E3 & $\operatorname{mar}-83$ & 3075.0 & $\begin{array}{l}87.0 \\
178.0\end{array}$ & $\begin{array}{l}\text { Rad Part (5) } \\
\text { Hardware }\end{array}$ & |2810.0 & 2617.5 & 192.5 & 466.5 & 2151.0 \\
\hline IC 1588 & 61 & \begin{tabular}{|l|}
$311397-04$ \\
$311397-02$
\end{tabular} & $\begin{array}{l}\text { MAM-4873 } \\
\text { UAV-2813-F8 }\end{array}$ & $-\operatorname{mar}-83$ & $\begin{array}{l}295.3 \\
299.7\end{array}$ & - & - & 95.0 & 568.4 & 26.6 & 60.1 & 508.3 \\
\hline IC 1612 & 57 & $\begin{array}{l}311466-00 \\
311466-00\end{array}$ & $\begin{array}{l}\text { BBN-4653-A5 } \\
\text { BBN-4634-A5 }\end{array}$ & $-\operatorname{mar}-83$ & $\begin{array}{l}358.0 \\
353.0\end{array}$ & - & ( & 11.0 & 681.2 & 29.8 & 107.5 & 573.7 \\
\hline 101804 & 57 & $311751-03$ & BBN-2129-D8-15 & $-\operatorname{mar}-83$ & 4715.0 & $\begin{array}{l}50.0 \\
257.2\end{array}$ & $\begin{array}{l}\text { Plad Part } \\
\text { Hardware }\end{array}$ & 395.0 & 239.0 & 68.8 & 456.0 & 1783.0 \\
\hline & 43 & -02 & BBN- & -83 & 790.0 & 50.0 & Rad Part & 15.0 & 532.7 & 207.3 & 882.8 & 849.9 \\
\hline & 57 & & BBN & & 3592.0 & 97.7 & $\operatorname{los}(U)$ & & 1.2 & & 66.7 & 944.5 \\
\hline & 57 & & BBN & & 405.2 & - & & & & 34.3 & 0.0 & $\begin{array}{l}370.9 \\
688.7\end{array}$ \\
\hline & 61 & & $\begin{array}{l}\text { BBN } \\
\text { BBN }\end{array}$ & & $\begin{array}{l}1.2 \\
3.3\end{array}$ & 47.9 & & $\begin{array}{l}+1.2 \\
30.4\end{array}$ & $\begin{array}{c}480.0 \\
979.8\end{array}$ & 61.2 & 91.3 & $\begin{array}{l}1688.7 \\
2541.1\end{array}$ \\
\hline $\begin{array}{l}74 \\
38\end{array}$ & $\begin{array}{l}11 / 28 \\
57\end{array}$ & $2-00$ & $\begin{array}{l}\text { BBN-X-192-K6 } \\
\text { BBN-1368-J4-05 }\end{array}$ & $a r-93$ & $\begin{array}{l}178.3 \\
350.0\end{array}$ & $\begin{array}{l}647.9 \\
50.0 \\
262.8\end{array}$ & $\begin{array}{l}\text { Cables (U) } \\
\text { Rad Part } \\
\text { Hartware }\end{array}$ & \begin{tabular}{|l|}
4530.4 \\
2532.0
\end{tabular} & $\begin{array}{l}4279.8 \\
2406.5\end{array}$ & $\begin{array}{l}50.6 \\
30.7\end{array}$ & $\begin{array}{l}738.7 \\
339.7\end{array}$ & $\begin{array}{l}2541.1 \\
2066.8\end{array}$ \\
\hline & $\begin{array}{l}57 \\
69\end{array}$ & & $\begin{array}{l}\text { BBN. } \\
\text { RBN } \\
\text { RBN }\end{array}$ & -93 & $\begin{array}{l}793.0 \\
449.0 \\
450.0\end{array}$ & $:$ & - & $\begin{array}{l}33.0 \\
39.0\end{array}$ & $\begin{array}{l}762.7 \\
886.6\end{array}$ & $\begin{array}{l}30.3 \\
12.4\end{array}$ & $\begin{array}{c}62.0 \\
150.5\end{array}$ & $\begin{array}{l}700.7 \\
736.1\end{array}$ \\
\hline 334 & 69 & $9-09$ & BBN-2523 & ar -93 & 3567.0 & 1174.0 & $\begin{array}{l}\text { Rad Part } \\
\text { ESD. Cable }\end{array}$ & 2393.0 & 2330.9 & 62.1 & 721.5 & 1609.4 \\
\hline $\begin{array}{l}M C: \\
M C:\end{array}$ & $\begin{array}{l}61 \\
61\end{array}$ & $\begin{array}{r}315698-00 \\
318359-00\end{array} \mid$ & $\begin{array}{l}\text { BBN-X2C } \\
\text { BBN-X2C }\end{array}$ & & $\begin{array}{l}1205.0 \\
3139.0\end{array}$ & 314.0 & Harciware & $\begin{array}{l}05.0 \\
15.4\end{array}$ & $\begin{array}{l}157.3 \\
742.2\end{array}$ & $\begin{array}{l}47.7 \\
82.8\end{array}$ & $\begin{array}{l}72.6 \\
104.1\end{array}$ & $\begin{array}{c}984.7 \\
1638.1\end{array}$ \\
\hline & : & & & & & - & $\begin{array}{l}- \\
-\end{array}$ & 5.0 & 4.0 & 1.0 & 3.3 & 24.7 \\
\hline 908 & $\begin{array}{c}43 \\
\text { Many }\end{array}$ & $\begin{array}{c}? \\
310615-0\end{array}$ & UNK & & & - & - & 57.0 & $\begin{array}{l}353.0 \\
245.2\end{array}$ & $\begin{array}{l}4.0 \\
6.1\end{array}$ & $\begin{array}{l}0.0 \\
0.0\end{array}$ & $\begin{array}{l}353.0 \\
245.2\end{array}$ \\
\hline & 43 & -02 & $\begin{array}{l}\text { ACG } \\
\text { SAF }\end{array}$ & & $\begin{array}{c}12 \\
12\end{array}$ & . & - & & & E.1 & & 0 \\
\hline $\begin{array}{l}510 \\
515 \mathrm{~A}\end{array}$ & $\begin{array}{l}57 \\
43\end{array}$ & & & & & - & : & & & $\begin{array}{l}10.6 \\
16.6\end{array}$ & & $\begin{array}{l}401.8 \\
347.9\end{array}$ \\
\hline & 61 & $\begin{array}{l}-\infty \\
-\infty\end{array}$ & $\mid \begin{array}{ll}\mathrm{A} \\
\mathrm{B}\end{array}$ & & 84 & - & - & 3 & .6 & 4.3 & .4 & 575.2 \\
\hline & 61 & & & & 94 & & - & 0.0 & & 7.0 & & 98.8 \\
\hline & & & & & $\begin{array}{c}1070.0 \\
(w / 0 \text { Battery) }\end{array}$ & $\begin{array}{c}152.0 \\
?\end{array}$ & $\begin{array}{c}\text { Cables (U) } \\
\text { Battery }\end{array}$ & 8.0 & 2.7 & 4.7 & 11.8 & 310.9 \\
\hline $477-9$ & JTA & & \begin{tabular}{|} 
APR 129- \\
APR 115- \\
APR 110-
\end{tabular} & $08-f e b-93$ & 60.2 & - & $\begin{array}{l}- \\
-\end{array}$ & 80.6 & 70.3 & 10.3 & 5.1 & 125.2 \\
\hline & $\begin{array}{l}\text { JTA } \\
\text { JTA }\end{array}$ & $\begin{array}{l}-00 \\
-01 \\
-01\end{array}$ & $\begin{array}{l}\text { SNN D4 } \\
\text { BBN-1064-F78 } \\
\text { BBN-1063-F78 }\end{array}$ & & $\begin{array}{c}13 \\
1 \\
1\end{array}$ & - & $\begin{array}{l}- \\
-\end{array}$ & $\begin{array}{l}39.8 \\
4.0\end{array}$ & $\begin{array}{c}1317.0 \\
289.0\end{array}$ & $\begin{array}{c}22.8 \\
5.0\end{array}$ & $\begin{array}{c}145.3 \\
32.4\end{array}$ & $\begin{array}{c}1171.7 \\
256.6\end{array}$ \\
\hline & 61 & $\begin{array}{l}9-02 \\
9-02\end{array}$ & $\begin{array}{l}\text { BBA } \\
\text { BBN }\end{array}$ & & & 116.6 & Hardware & & & & & 2481.8 \\
\hline & & 6-02 & $\begin{array}{l}\mathrm{BBN}-1 \\
\mathrm{BBN}-1\end{array}$ & & $\begin{array}{l}3948.2 \\
283.1\end{array}$ & - & . & $\begin{array}{l}8.2 \\
3.1\end{array}$ & $\begin{array}{c}3928.1 \\
269.3\end{array}$ & 13.8 & $\begin{array}{l}446.3 \\
0.0\end{array}$ & $\begin{array}{c}2481.8 \\
269.3\end{array}$ \\
\hline & Ianve & $\begin{array}{r}3-02 \\
3-02 \\
3-02 \\
3-01\end{array}$ & $\begin{array}{l}\text { BBN-6 } \\
\text { BBN-3 } \\
\text { BBN-3 } \\
\text { BBN-2 }\end{array}$ & & $\begin{array}{l}29.0 \\
29.0 \\
29.0 \\
29.0\end{array}$ & - & - & 6.6 & 113.4 & . & 0.0 & 113.4 \\
\hline & & & $\begin{array}{l}\text { HBL-090 } \\
\text { HBL-091 }\end{array}$ & $b-93$ & $\begin{array}{l}34 \\
34\end{array}$ & - & - & 690.0 & 672.0 & 18.0 & 23.0 & 649.0 \\
\hline & $\begin{array}{c}\text { Many } \\
61\end{array}$ & & BBN- & & $\begin{array}{r}637.8 \\
1390.0\end{array}$ & 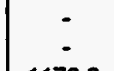 & - & $\begin{array}{l}637.8 \\
1390.0\end{array}$ & $\begin{array}{c}654.0 \\
1108.2\end{array}$ & $\begin{array}{c}? \\
281.8\end{array}$ & $\begin{array}{l}284.8 \\
380.6\end{array}$ & $\begin{array}{l}369.2 \\
727.6\end{array}$ \\
\hline & & & & & & & & & & & 0.0 & 304.7 \\
\hline$M C$ & $\begin{array}{l}80 \\
61\end{array}$ & $\begin{array}{l}192-00 \\
619-00\end{array}$ & $\begin{array}{l}\text { GBV } 5118835 . C 8 \\
\text { BBN-X010-ل } 87\end{array}$ & $\mid \begin{array}{l}08-f a b-93 \\
08-f a b-93\end{array}$ & 3446.0 & 622.8 & $\begin{array}{c}\text { - } \\
\text { Battery } \\
\text { Handware }\end{array}$ & $\begin{array}{c}251.1 \\
2823.2\end{array}$ & \begin{tabular}{c|}
243.8 \\
2777.6
\end{tabular} & $\begin{array}{c}7.3 \\
45.6\end{array}$ & $\begin{array}{c}26.4 \\
1319.5\end{array}$ & $\begin{array}{c}217.4 \\
1458.1\end{array}$ \\
\hline
\end{tabular}


SDDB Data Entry Chemical Analysis

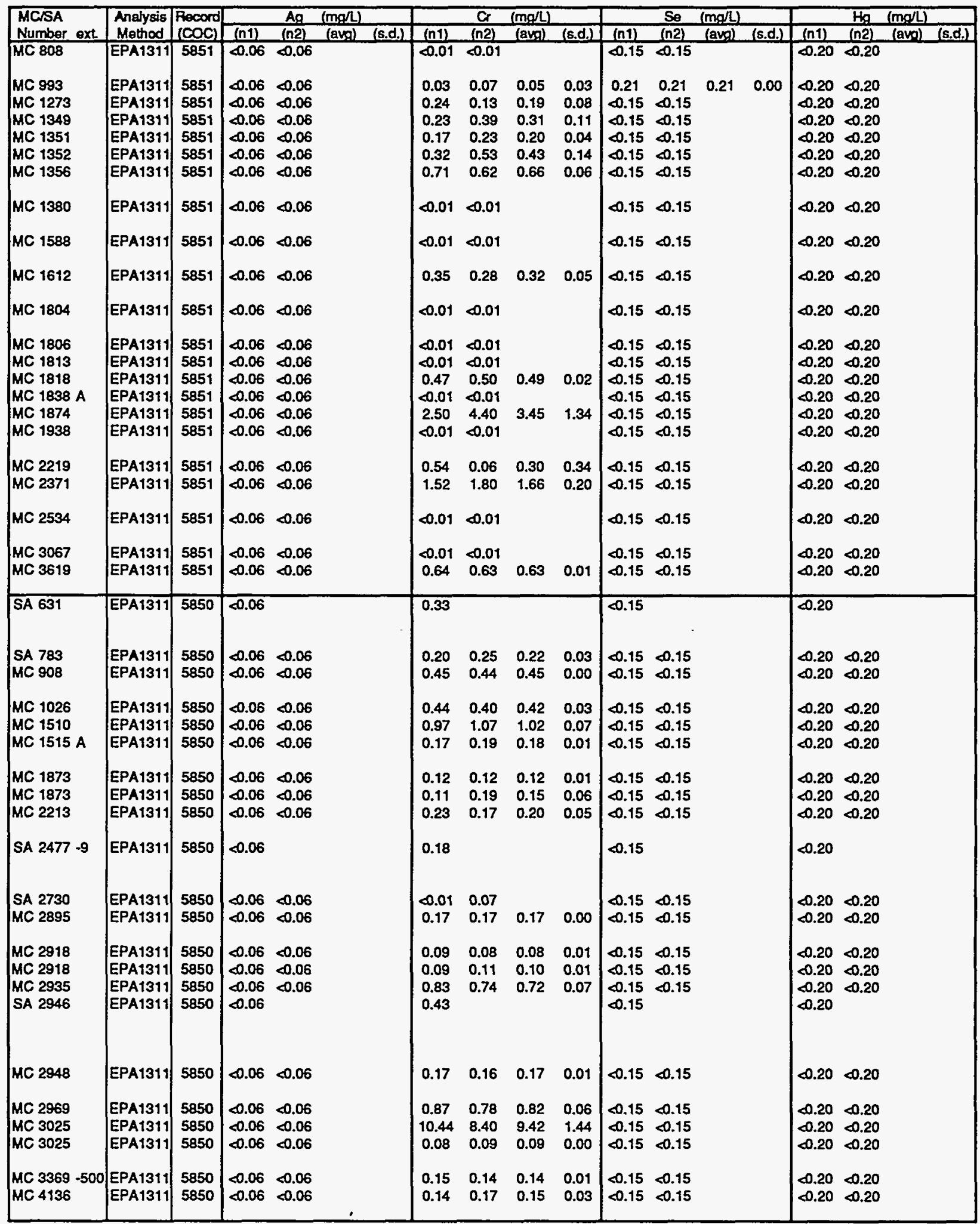


SDDB Data Entry Chemical Analysis

\begin{tabular}{|c|c|c|c|c|c|c|c|c|c|c|c|c|c|c|c|c|}
\hline \multirow{2}{*}{\begin{tabular}{|l|} 
MCSA \\
Number ext
\end{tabular}} & \multicolumn{4}{|c|}{$\mathrm{Pb} \quad(\mathrm{mg} / \mathrm{L})$} & \multicolumn{4}{|c|}{ Cd $(m g / l)$} & \multicolumn{4}{|c|}{$\mathrm{Ba} \quad(\mathrm{mg} / \mathrm{L})$} & \multicolumn{4}{|c|}{ As $(m g / L)$} \\
\hline & (n1) & (n2) & (avg) & (c.d.) & (n1) & (n2) & (avg) & (s.d.) & (n1) & (n2) & (avg) & (s.d.) & (n1) & (n2) & (avg) & (s.d.) \\
\hline MC 808 & 1.86 & 9.29 & 5.63 & 5.18 & 34.12 & 53.50 & 43.81 & 13.70 & 3.69 & 3.70 & 3.70 & 0.01 & $\$ 0.06$ & $\infty .06$ & & \\
\hline MC 993 & 50.63 & 50.79 & 50.71 & 0.11 & 0.48 & 0.30 & 0.39 & 0.13 & 3.12 & 3.66 & 3.39 & 0.38 & 0.22 & 0.20 & 0.21 & 0.01 \\
\hline $\begin{array}{l}M C 1273 \\
M C 1349\end{array}$ & $\begin{array}{c}3.89 \\
18.17\end{array}$ & & 3.79 & 0.29 & 17.06 & 5.69 & 11.38 & 8.04 & 0.39 & 0.44 & 0.42 & 0.04 & $\begin{array}{l}\infty .06 \\
\infty .06\end{array}$ & $\$ .06$ & & \\
\hline $\begin{array}{l}\text { MC } 1349 \\
\text { MC } 1351\end{array}$ & $\begin{array}{c}18.17 \\
154.40\end{array}$ & $\begin{array}{c}9.75 \\
159.00\end{array}$ & $\begin{array}{c}13.96 \\
156.70\end{array}$ & 5.95 & 1.50 & 4.28 & 2.89 & 1.97 & 0.34 & 0.37 & 0.35 & 0.01 & 0.00 & $\begin{array}{l}80.06 \\
40.06\end{array}$ & & \\
\hline $\begin{array}{l}\text { MC } 1351 \\
M C 1352\end{array}$ & 3.49 & 4.03 & $\begin{array}{c}156.70 \\
3.76\end{array}$ & 3.25 & 0.98 & 2.11 & 1.55 & 0.80 & 1.64 & 1.69 & 1.67 & 0.04 & - & $\$ 0.06$ & & \\
\hline $\begin{array}{l}M C 1352 \\
M C 1356\end{array}$ & 6.88 & 18.25 & $\begin{array}{c}3.76 \\
12.57\end{array}$ & 0.38 & 9.05 & 15.59 & 12.32 & 4.62 & 0.47 & 0.53 & 0.50 & 0.05 & $<0.06$ & $\$ 0.06$ & & \\
\hline MC 1356 & & 18.20 & 12.57 & 8.04 & 0.28 & 0.31 & 0.30 & 0.02 & 0.94 & 0.78 & 0.86 & 0.12 & $\infty 0.06$ & $\infty .06$ & & \\
\hline MC 1380 & 9.61 & 9.87 & 9.74 & 0.18 & 0.64 & 0.19 & 0.41 & 0.32 & 16.88 & 16.18 & 16.53 & 0.49 & $\infty 0.06$ & $\infty .06$ & & \\
\hline MC 1588 & 6.03 & 9.08 & 7.56 & 2.16 & 0.11 & 0.29 & 0.20 & 0.13 & 0.50 & 0.61 & 0.55 & 0.07 & $\infty .06$ & $<0.06$ & & \\
\hline MC 1612 & 17.58 & 14.32 & 15.95 & 2.31 & 0.63 & 1.24 & 0.94 & 0.43 & 6.82 & 6.49 & 6.66 & 0.23 & $\varnothing 0.06$ & $<0.06$ & & \\
\hline MC 1804 & 70.24 & 58.40 & 64.82 & 7.67 & 6.67 & 3.14 & 4.91 & 2.50 & 2.45 & 2.55 & 2.50 & 0.07 & $<0.06$ & $\$ 0.06$ & & \\
\hline MC 1806 & 11.80 & 11.70 & 11.75 & 0.07 & 2.45 & 4.05 & 3.25 & 1.13 & 12.68 & 15.40 & 14.04 & 1.92 & $\infty .06$ & $\infty .06$ & & \\
\hline MC 1813 & 159.00 & 110.00 & 134.50 & 34.65 & 0.92 & 3.00 & 1.96 & 1.47 & 1.25 & 1.20 & 1.23 & 0.04 & $<0.06$ & $\varnothing 0.06$ & & \\
\hline MC 1818 & 3.98 & 4.99 & 4.49 & 0.71 & 246.60 & 278.00 & 262.30 & 22.20 & 0.46 & 0.48 & 0.47 & 0.02 & $<0.06$ & $ه 0.06$ & & \\
\hline MC 1838 A & 19.00 & 22.40 & 20.70 & 2.40 & 4.95 & 6.70 & 5.83 & 1.24 & 0.73 & 0.92 & 0.83 & 0.13 & $<0.06$ & $\$ 0.06$ & & \\
\hline MC 1874 & 12.00 & 10.29 & 11.15 & 1.21 & 147.00 & 186.00 & 166.50 & 27.58 & 6.70 & 7.58 & 7.14 & 0.62 & $\infty 0.06$ & $\infty .06$ & & \\
\hline MC 1938 & 5.95 & 6.40 & 6.18 & 0.32 & 3.60 & 0.53 & 2.07 & 2.17 & 24.04 & 26.00 & 25.02 & 1.39 & $<0.06$ & $<0.06$ & & \\
\hline MC 2219 & 27.87 & 36.12 & 32.00 & 5.83 & 14.79 & 20.96 & 17.88 & 4.36 & 5.05 & 4.73 & 4.89 & 0.23 & $\infty .06$ & $<0.06$ & & \\
\hline MC 2371 & 16.45 & 17.44 & 16.95 & 0.70 & 0.65 & 1.25 & 0.95 & 0.42 & 9.79 & 9.89 & 9.84 & 0.07 & $\infty 0.06$ & $\infty .06$ & & \\
\hline MC 2534 & 198.60 & 222.00 & 210.30 & 16.55 & 8.30 & 4.05 & 6.18 & 3.01 & 9.30 & 8.25 & $8.7 B$ & 0.74 & $\infty .06$ & $\infty .06$ & & \\
\hline $\begin{array}{l}\text { MC } 3067 \\
\text { MC } 3619\end{array}$ & $\begin{array}{l}13.47 \\
13.08\end{array}$ & $\begin{array}{c}15.92 \\
5.17\end{array}$ & $\begin{array}{c}14.70 \\
9.13\end{array}$ & $\begin{array}{l}1.73 \\
5.59\end{array}$ & $\begin{array}{l}11.37 \\
79.46\end{array}$ & $\begin{array}{c}6.22 \\
46.46\end{array}$ & $\begin{array}{c}8.80 \\
62.96\end{array}$ & $\begin{array}{c}3.64 \\
23.33\end{array}$ & $\begin{array}{c}30.60 \\
2.07\end{array}$ & $\begin{array}{c}31.17 \\
1.97\end{array}$ & $\begin{array}{c}30.89 \\
2.02\end{array}$ & $\begin{array}{l}0.40 \\
0.07\end{array}$ & $\begin{array}{l}<.06 \\
<0.06\end{array}$ & $\begin{array}{l}<0.06 \\
<0.06\end{array}$ & & \\
\hline SA 631 & 126.50 & & & & 2.12 & & & & 2.28 & & & & $<0.06$ & & & \\
\hline $\begin{array}{l}\text { SA } 783 \\
\text { MC } 908\end{array}$ & $\begin{array}{c}0.97 \\
127.90\end{array}$ & $\begin{array}{c}0.89 \\
140.10\end{array}$ & $\begin{array}{c}0.93 \\
134.00\end{array}$ & $\begin{array}{l}0.05 \\
8.63\end{array}$ & $\begin{array}{c}134.70 \\
3.03\end{array}$ & $\begin{array}{c}194.00 \\
3.16\end{array}$ & $\begin{array}{c}164.35 \\
3.10\end{array}$ & $\begin{array}{c}41.93 \\
0.09\end{array}$ & $\begin{array}{c}1.56 \\
132.60\end{array}$ & $\begin{array}{c}0.98 \\
123.70\end{array}$ & $\begin{array}{c}1.27 \\
128.15\end{array}$ & $\begin{array}{l}0.41 \\
6.29\end{array}$ & $\begin{array}{l}<0.06 \\
<0.06\end{array}$ & $\begin{array}{l}<0.06 \\
<0.06\end{array}$ & & \\
\hline$M C 1026$ & 0.99 & 1.31 & 1.15 & 0.23 & 37.21 & 41.12 & 39.17 & 2.76 & 0.88 & 0.86 & 0.87 & 0.01 & $\infty .06$ & $\$ 0.06$ & & \\
\hline $\begin{array}{l}M C 1510 \\
M C 1515 \mathrm{~A}\end{array}$ & $\begin{array}{l}1.39 \\
1.02\end{array}$ & $\begin{array}{l}2.65 \\
0.71\end{array}$ & $\begin{array}{l}2.02 \\
0.87\end{array}$ & $\begin{array}{l}0.89 \\
0.22\end{array}$ & $\begin{array}{c}0.25 \\
156.10\end{array}$ & $\begin{array}{c}0.86 \\
181.00\end{array}$ & $\begin{array}{c}0.55 \\
168.55\end{array}$ & $\begin{array}{c}0.44 \\
17.61\end{array}$ & $\begin{array}{l}2.65 \\
0.50\end{array}$ & $\begin{array}{l}2.84 \\
0.62\end{array}$ & $\begin{array}{l}2.75 \\
0.56\end{array}$ & $\begin{array}{l}0.13 \\
0.09\end{array}$ & $\begin{array}{l}<0.06 \\
<0.06\end{array}$ & $\begin{array}{l}<0.06 \\
<0.06\end{array}$ & & \\
\hline MC 1873 & 15.93 & 13.41 & 14.67 & 1.78 & 10.98 & 40.62 & 25.80 & 20.96 & 0.88 & 1.25 & 1.07 & 0.26 & $\infty .06$ & $\infty .06$ & & \\
\hline MC 1873 & 7.73 & 2.97 & 5.35 & 3.37 & 48.31 & 23.32 & 35.82 & 17.67 & 0.88 & 0.81 & 0.84 & 0.05 & $<0.06$ & $<0.06$ & & \\
\hline MC 2213 & 64.66 & 24.15 & 44.41 & 28.64 & 61.10 & 93.73 & 77.42 & 23.07 & 1.09 & 0.48 & 0.78 & 0.43 & $\$ 0.06$ & $<0.06$ & & \\
\hline SA $2477-8$ & 6.79 & & & & 0.13 & & & & 5.58 & & & & $<0.06$ & & & \\
\hline $\begin{array}{l}\text { SA } 2730 \\
\text { MC } 2895\end{array}$ & $\begin{array}{c}1010.00 \\
4.09\end{array}$ & $\begin{array}{c}1063.00 \\
2.62\end{array}$ & $\begin{array}{c}1036.50 \\
3.36\end{array}$ & $\begin{array}{c}37.48 \\
1.04\end{array}$ & $\begin{array}{c}2.24 \\
137.90\end{array}$ & $\begin{array}{c}3.44 \\
76.84\end{array}$ & $\begin{array}{c}2.84 \\
107.42\end{array}$ & $\begin{array}{r}0.85 \\
43.11\end{array}$ & $\begin{array}{c}26.42 \\
0.21\end{array}$ & $\begin{array}{c}25.82 \\
0.22\end{array}$ & $\begin{array}{c}26.12 \\
0.21\end{array}$ & $\begin{array}{l}0.42 \\
0.01\end{array}$ & $\begin{array}{l}<0.06 \\
<0.06\end{array}$ & $\begin{array}{l}<0.06 \\
<0.06\end{array}$ & & \\
\hline MC 2918 & 31.53 & 38.43 & 34.98 & 4.88 & 0.50 & 4.98 & 2.74 & 3.17 & 0.89 & 0.98 & 0.93 & 0.07 & $<0.06$ & $<0.06$ & & \\
\hline MC 2818 & 23.61 & 25.63 & 24.62 & 1.43 & 0.35 & 0.62 & 0.48 & 0.20 & 0.91 & 1.08 & 1.00 & 0.12 & $<0.06$ & $<0.06$ & & \\
\hline $\begin{array}{l}\text { MC } 2935 \\
\text { SA } 2946\end{array}$ & $\begin{array}{l}0.79 \\
0.50\end{array}$ & 0.75 & 0.77 & 0.02 & $\begin{array}{l}0.09 \\
0.04\end{array}$ & $\infty .012$ & & & $\begin{array}{l}0.92 \\
0.15\end{array}$ & 0.14 & 0.53 & 0.55 & $\begin{array}{l}<.06 \\
<0.06\end{array}$ & $\$ 0.06$ & & \\
\hline MC 2948 & 40.06 & 31.84 & 36.00 & 5.74 & 4.42 & 11.48 & 7.95 & 4.99 & 0.38 & 0.28 & 0.33 & 0.07 & $\infty .06$ & $\$ 0.06$ & & \\
\hline MC 2969 & $<0.06$ & 0.34 & & & 0.09 & 0.50 & 0.30 & 0.29 & 0.13 & 0.12 & 0.13 & 0.01 & $<0.06$ & $\$ 0.06$ & & \\
\hline MC 3025 & 1.16 & 1.01 & 1.09 & 0.11 & 25.57 & 36.30 & 30.94 & 7.59 & 0.45 & 0.50 & 0.47 & 0.03 & $<0.06$ & $<0.06$ & & \\
\hline MC 3025 & 109.50 & 2.97 & 56.24 & 75.33 & 59.00 & 122.90 & 90.95 & 45.18 & 0.53 & 0.43 & 0.48 & 0.07 & $<0.06$ & $\$ 0.06$ & & \\
\hline$\left|\begin{array}{l}M C 3369-500 \\
M C 4136\end{array}\right|$ & $\begin{array}{l}2.68 \\
5.40\end{array}$ & $\begin{array}{l}5.23 \\
0.87\end{array}$ & $\begin{array}{l}3.96 \\
3.14\end{array}$ & $\begin{array}{l}1.80 \\
3.20\end{array}$ & $\begin{array}{c}0.55 \\
31.70\end{array}$ & $\begin{array}{l}0.18 \\
9.79\end{array}$ & $\begin{array}{c}0.37 \\
20.75\end{array}$ & $\begin{array}{c}0.26 \\
15.49\end{array}$ & $\begin{array}{l}0.21 \\
1.63\end{array}$ & $\begin{array}{l}0.24 \\
1.71\end{array}$ & $\begin{array}{l}0.22 \\
1.67\end{array}$ & $\begin{array}{l}0.02 \\
0.06\end{array}$ & $\begin{array}{l}<0.06 \\
<0.06\end{array}$ & $\begin{array}{l}<0.06 \\
<0.06\end{array}$ & & \\
\hline
\end{tabular}


SDDB Data Entry Chemical Analysis

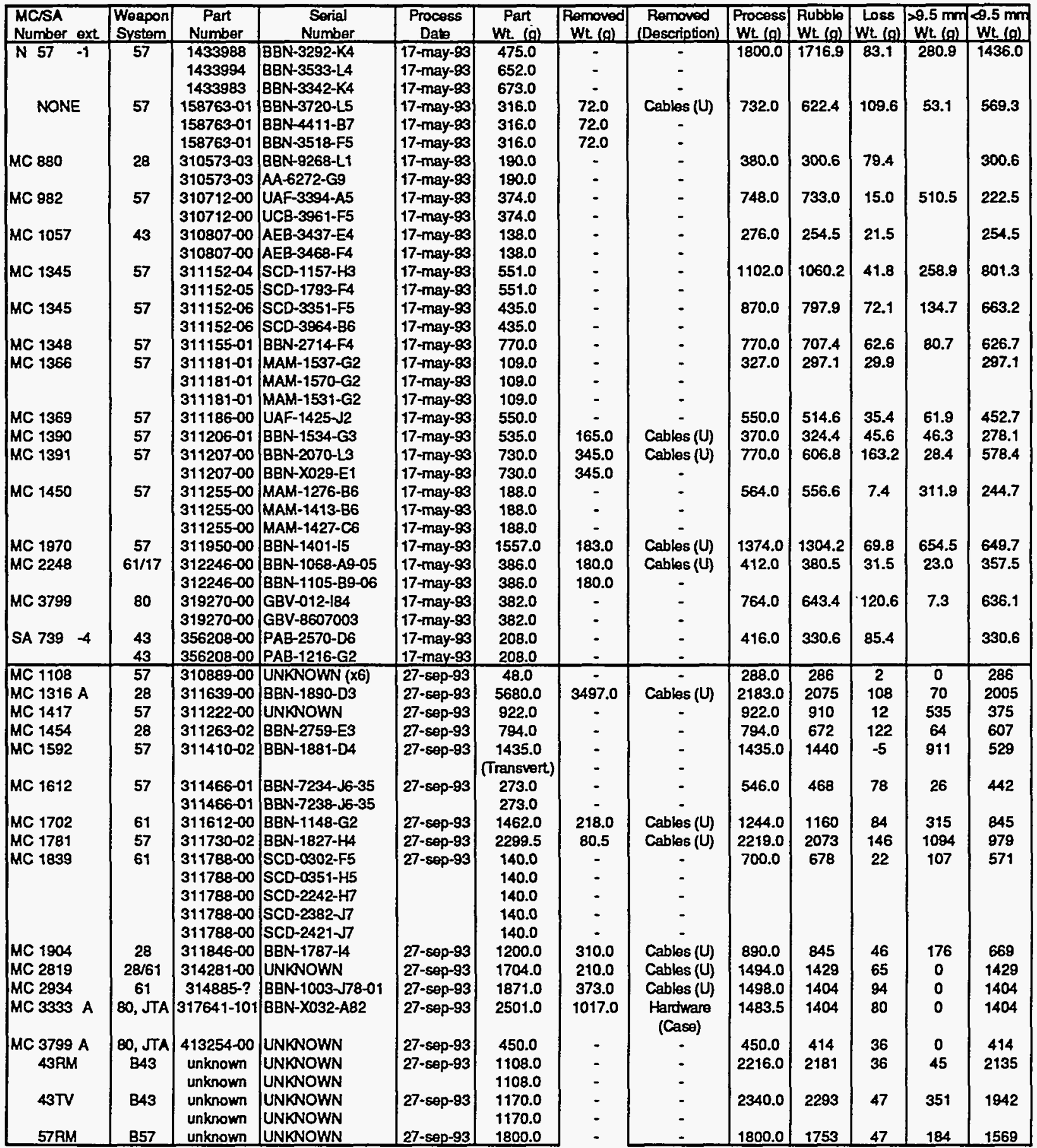


SDDB Data Entry Chemical Analysis

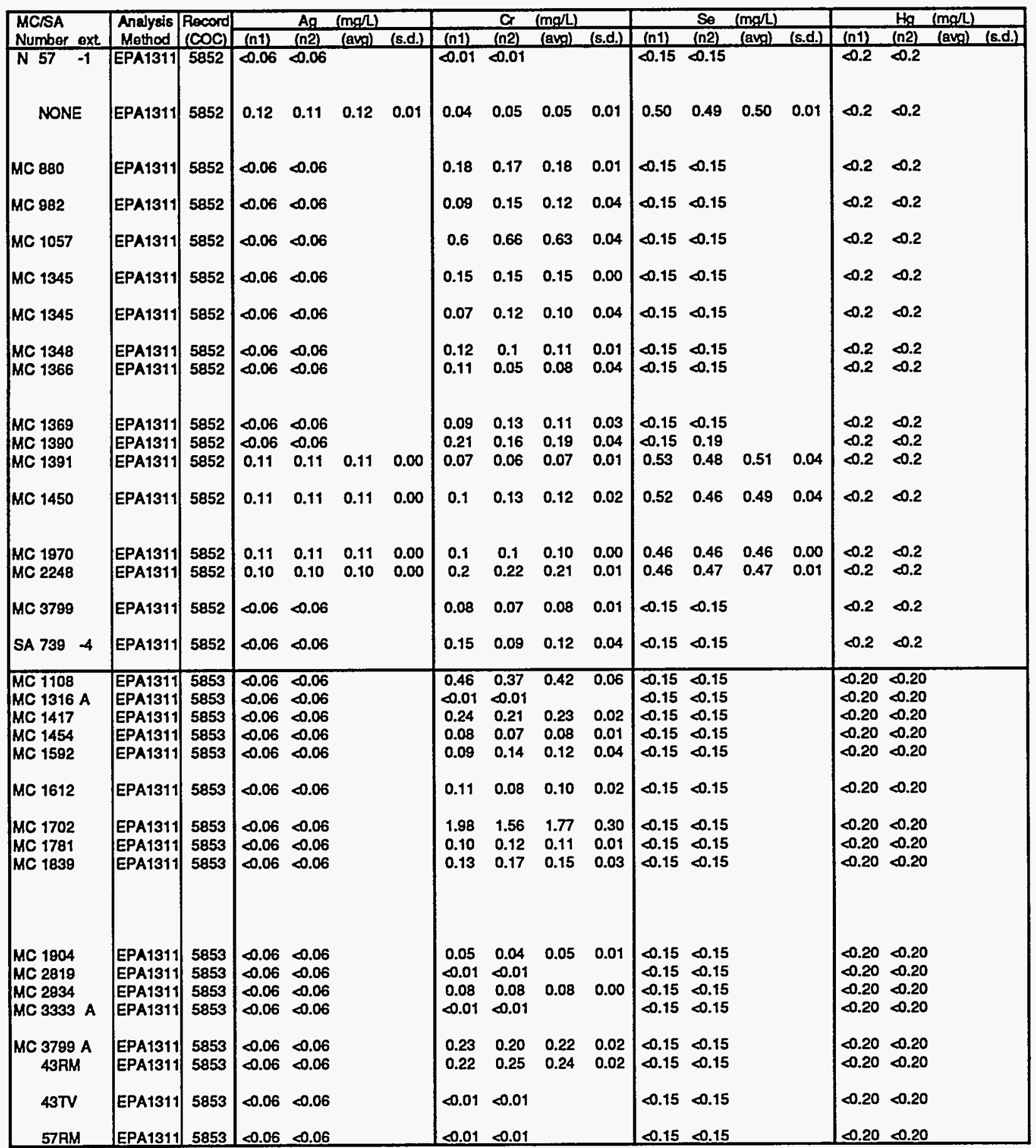


SDDB Data Entry Chemical Analysis

\begin{tabular}{|c|c|c|c|c|c|c|c|c|c|c|c|c|c|c|c|c|}
\hline \multirow{2}{*}{$\begin{array}{l}\text { MCSAA } \\
\text { Number ext. }\end{array}$} & \multicolumn{2}{|r|}{$\mathbf{P b}$} & \multicolumn{2}{|l|}{$(m q /)$} & \multicolumn{4}{|c|}{ Cd $\quad(m g / L)$} & \multicolumn{4}{|c|}{$\mathrm{Ba} \quad(m g / \mathrm{L})$} & \multicolumn{4}{|c|}{ As $(\mathrm{mg} / \mathrm{L})$} \\
\hline & (n1) & (n2) & (avg) & (s.d.) & (n1) & $(n 2)$ & (avg) & (s.d.) & (n1) & (n2) & (avg) & (s.d.) & (nt) & $(n 2)$ & (avg) & $(s, d)$, \\
\hline $\begin{array}{ll}\text { N } 57 & -1\end{array}$ & 4.80 & 6.74 & 5.77 & 1.37 & 2.04 & 0.41 & 1.23 & 1.15 & 1.02 & 1.46 & 1.24 & 0.31 & $<0.06$ & $<0.06$ & & \\
\hline NONE & 58.90 & 78.26 & 68.58 & 13.69 & 7.38 & 14.87 & 11.13 & 5.30 & 1.15 & 1.18 & 1.17 & 0.02 & 0.31 & 0.31 & 0.31 & 0.00 \\
\hline MC 880 & 7.29 & 8.85 & 8.07 & 1.10 & 263.30 & 247.80 & 255.55 & 10.96 & 3.49 & 3.38 & 3.44 & 0.08 & $<0.06$ & 0.09 & & \\
\hline MC 882 & 6.97 & 20.30 & 13.64 & 9.43 & 8.25 & 11.72 & 9.99 & 2.45 & 0.3 & 0.22 & 0.26 & 0.06 & $<0.06$ & $<0.06$ & & \\
\hline MC 1057 & 6.89 & 8.66 & $8.2 B$ & 1.96 & 1.38 & 1.03 & 1.21 & 0.25 & 0.25 & 0.21 & 0.23 & 0.03 & $\infty .06$ & $\infty .06$ & & \\
\hline MC 1345 & 3.30 & 3.18 & 3.24 & 0.08 & 2.94 & 5.19 & 4.07 & 1.59 & 0.18 & 0.21 & 0.20 & 0.02 & $<0.06$ & $<0.06$ & & \\
\hline MC 1345 & 27.32 & 21.70 & 24.51 & & 11.93 & 9.48 & 10.71 & 1.73 & 0.12 & 0.11 & 0.12 & 0.01 & $<0.06$ & $<0.06$ & & \\
\hline $\begin{array}{l}\text { MC } 1348 \\
\text { MC } 1366\end{array}$ & $\begin{array}{c}11.77 \\
1.82\end{array}$ & $\begin{array}{c}57.33 \\
0.72\end{array}$ & $\begin{array}{c}34.55 \\
1.27\end{array}$ & $\begin{array}{c}32.22 \\
0.78\end{array}$ & $\begin{array}{l}1.43 \\
9.32\end{array}$ & $\begin{array}{l}1.20 \\
7.90\end{array}$ & $\begin{array}{l}1.32 \\
8.61\end{array}$ & $\begin{array}{l}0.16 \\
1.00\end{array}$ & $\begin{array}{l}3.08 \\
0.46\end{array}$ & $\begin{array}{l}3.04 \\
0.36\end{array}$ & $\begin{array}{l}3.06 \\
0.41\end{array}$ & $\begin{array}{l}0.03 \\
0.07\end{array}$ & $\begin{array}{l}<0.06 \\
<0.06\end{array}$ & $\begin{array}{l}\infty .06 \\
\infty .06\end{array}$ & & \\
\hline $\begin{array}{l}\text { MC } 1369 \\
M C 1390 \\
M C 1391\end{array}$ & $\begin{array}{c}3.48 \\
21.95 \\
84.72\end{array}$ & $\begin{array}{c}4.24 \\
36.95 \\
89.56\end{array}$ & $\begin{array}{c}3.87 \\
29.45 \\
87.14\end{array}$ & $\begin{array}{c}0.53 \\
10.61 \\
3.42\end{array}$ & $\begin{array}{l}4.85 \\
0.30 \\
0.60\end{array}$ & $\begin{array}{l}12.45 \\
0.35 \\
0.50\end{array}$ & $\begin{array}{l}8.65 \\
0.33 \\
0.55\end{array}$ & $\begin{array}{l}5.37 \\
0.04 \\
0.07\end{array}$ & $\begin{array}{l}0.23 \\
0.31 \\
0.59\end{array}$ & $\begin{array}{l}0.19 \\
0.22 \\
0.51\end{array}$ & $\begin{array}{l}0.21 \\
0.27 \\
0.55\end{array}$ & $\begin{array}{l}0.03 \\
0.06 \\
0.06\end{array}$ & $\begin{array}{l}\infty 0.06 \\
0.09 \\
0.25\end{array}$ & $\begin{array}{l}0.06 \\
0.12 \\
0.27\end{array}$ & $\begin{array}{l}0.11 \\
0.26\end{array}$ & $\begin{array}{l}0.02 \\
0.01\end{array}$ \\
\hline MC 1450 & 2.80 & 6.28 & 4.54 & 2.46 & 9.18 & 2.31 & 5.75 & 4.86 & 0.04 & 0.06 & 0.05 & 0.01 & 0.31 & 0.28 & 0.30 & 0.02 \\
\hline $\begin{array}{l}\text { MC } 1870 \\
\text { MC } 2248\end{array}$ & $\begin{array}{l}17.08 \\
7.31\end{array}$ & $\begin{array}{l}5.80 \\
2.94\end{array}$ & $\begin{array}{c}11.44 \\
5.13\end{array}$ & $\begin{array}{l}7.98 \\
3.09\end{array}$ & $\begin{array}{l}11.67 \\
18.37\end{array}$ & $\begin{array}{l}23.16 \\
26.85\end{array}$ & $\begin{array}{l}17.42 \\
22.61\end{array}$ & $\begin{array}{l}8.12 \\
6.00\end{array}$ & $\begin{array}{l}0.12 \\
1.24\end{array}$ & $\begin{array}{l}0.14 \\
1.23\end{array}$ & $\begin{array}{l}0.13 \\
1.24\end{array}$ & $\begin{array}{l}0.01 \\
0.01\end{array}$ & $\begin{array}{l}0.26 \\
0.30\end{array}$ & $\begin{array}{l}0.24 \\
0.33\end{array}$ & $\begin{array}{l}0.25 \\
0.32\end{array}$ & $\begin{array}{l}0.01 \\
0.02\end{array}$ \\
\hline MC 3799 & 66.67 & 95.54 & 81.11 & 20.41 & 0.36 & 0.36 & 0.36 & 0.00 & 0.36 & 0.36 & 0.36 & 0.00 & $<0.06$ & $<0.06$ & & \\
\hline SA $739-4$ & 0.36 & 1.06 & 0.71 & 0.49 & 0.16 & 0.14 & 0.15 & 0.01 & 0.26 & 0.24 & 0.25 & 0.01 & $<0.06$ & $<0.06$ & & \\
\hline $\begin{array}{l}\text { MC } 1108 \\
M C 1316 \text { A } \\
M C 1417 \\
M C 1454 \\
M C 1592\end{array}$ & \begin{tabular}{|c|}
36.38 \\
112.80 \\
8.76 \\
63.10 \\
8.04
\end{tabular} & $\begin{array}{c}28.32 \\
45.30 \\
7.82 \\
69.69 \\
15.15\end{array}$ & $\begin{array}{c}32.35 \\
79.05 \\
8.29 \\
66.40 \\
11.60\end{array}$ & $\begin{array}{c}5.70 \\
47.73 \\
0.66 \\
4.66 \\
5.03\end{array}$ & $\begin{array}{l}0.49 \\
3.59 \\
0.29 \\
8.98 \\
2.42\end{array}$ & $\begin{array}{c}0.43 \\
18.75 \\
0.33 \\
2.26 \\
3.56\end{array}$ & $\begin{array}{c}0.46 \\
11.17 \\
0.31 \\
5.62 \\
2.99\end{array}$ & $\begin{array}{c}0.04 \\
10.72 \\
0.03 \\
4.75 \\
0.81\end{array}$ & $\begin{array}{l}3.39 \\
0.92 \\
2.87 \\
1.64 \\
1.46\end{array}$ & $\begin{array}{l}2.64 \\
0.81 \\
2.77 \\
1.87 \\
1.86\end{array}$ & $\begin{array}{l}3.02 \\
0.87 \\
2.82 \\
1.76 \\
1.66\end{array}$ & $\begin{array}{l}0.53 \\
0.08 \\
0.07 \\
0.16 \\
0.28\end{array}$ & $\begin{array}{l}\infty 0.06 \\
<0.06 \\
<0.06 \\
<0.06 \\
<0.06\end{array}$ & $\begin{array}{l}\infty 0.06 \\
<0.06 \\
<0.06 \\
<0.06 \\
<0.06\end{array}$ & & \\
\hline MC 1612 & 87.64 & 50.71 & 69.18 & 26.11 & 7.57 & 15.96 & 11.77 & 5.93 & 0.23 & 0.23 & 0.23 & 0.00 & $<0.06$ & $\lessdot 0.06$ & & \\
\hline $\begin{array}{l}\text { MC } 1702 \\
\text { MC } 1781 \\
\text { MC } 1839\end{array}$ & $\begin{array}{c}192.00 \\
3.88 \\
34.46\end{array}$ & $\begin{array}{c}125.20 \\
3.57 \\
62.94\end{array}$ & $\begin{array}{c}158.60 \\
3.73 \\
48.70\end{array}$ & $\begin{array}{c}47.23 \\
0.22 \\
20.14\end{array}$ & $\begin{array}{c}3.81 \\
128.30 \\
1.63\end{array}$ & $\begin{array}{c}14.52 \\
161.90 \\
4.11\end{array}$ & $\begin{array}{c}9.17 \\
145.10 \\
2.87\end{array}$ & $\begin{array}{c}7.57 \\
23.76 \\
1.75\end{array}$ & $\begin{array}{l}6.74 \\
0.44 \\
0.52\end{array}$ & $\begin{array}{l}5.25 \\
0.73 \\
0.64\end{array}$ & $\begin{array}{l}6.00 \\
0.59 \\
0.58\end{array}$ & $\begin{array}{l}1.05 \\
0.21 \\
0.08\end{array}$ & $\begin{array}{l}<0.06 \\
<0.06 \\
<0.06\end{array}$ & $\begin{array}{l}<0.06 \\
<0.06 \\
\infty .06\end{array}$ & & \\
\hline $\begin{array}{l}\text { MC } 1904 \\
\text { MC 2819 } \\
\text { MC 2934 } \\
\text { MC } 3333 \text { A }\end{array}$ & $\begin{array}{c}118.90 \\
56.59 \\
51.81 \\
215.90\end{array}$ & $\begin{array}{l}124.50 \\
66.00 \\
84.82 \\
11.49\end{array}$ & $\begin{array}{c}121.70 \\
61.30 \\
68.32 \\
113.70\end{array}$ & $\begin{array}{c}3.96 \\
6.65 \\
23.34 \\
144.54\end{array}$ & $\begin{array}{c}0.73 \\
0.28 \\
0.24 \\
11.57\end{array}$ & $\begin{array}{c}2.34 \\
0.28 \\
0.24 \\
20.06\end{array}$ & $\begin{array}{c}1.54 \\
0.28 \\
0.24 \\
15.82\end{array}$ & $\begin{array}{l}1.14 \\
0.00 \\
0.00 \\
6.00\end{array}$ & $\begin{array}{l}1.84 \\
0.14 \\
0.33 \\
1.77\end{array}$ & $\begin{array}{l}1.99 \\
0.19 \\
0.33 \\
1.95\end{array}$ & $\begin{array}{l}1.92 \\
0.17 \\
0.33 \\
1.86\end{array}$ & $\begin{array}{l}0.11 \\
0.04 \\
0.00 \\
0.13\end{array}$ & $\begin{array}{l}<0.06 \\
<0.06 \\
<0.06 \\
<0.06\end{array}$ & $\begin{array}{l}<0.06 \\
<0.06 \\
<0.06 \\
<0.06\end{array}$ & & \\
\hline $\begin{array}{c}\text { MC } 3799 \text { A } \\
43 \mathrm{RM}\end{array}$ & $\begin{array}{l}9.62 \\
9.95\end{array}$ & $\begin{array}{c}25.80 \\
6.69\end{array}$ & $\begin{array}{l}17.71 \\
8.32\end{array}$ & $\begin{array}{l}11.44 \\
2.31\end{array}$ & $\begin{array}{l}0.21 \\
4.72\end{array}$ & $\begin{array}{l}0.29 \\
1.75\end{array}$ & $\begin{array}{l}0.25 \\
3.24\end{array}$ & $\begin{array}{l}0.06 \\
2.10\end{array}$ & $\begin{array}{l}0.37 \\
1.17\end{array}$ & $\begin{array}{l}0.31 \\
0.96\end{array}$ & $\begin{array}{l}0.34 \\
1.07\end{array}$ & $\begin{array}{l}0.04 \\
0.15\end{array}$ & $\begin{array}{l}<0.06 \\
<0.06\end{array}$ & $\begin{array}{l}<0.06 \\
<0.06\end{array}$ & & \\
\hline $43 T V$ & 6.23 & 13.07 & 9.65 & 4.84 & 0.44 & 0.61 & 0.53 & 0.12 & 0.92 & 1.57 & 1.25 & 0.46 & $<0.06$ & $<0.06$ & & \\
\hline 57RM & 5.43 & 7.82 & 6.63 & 1.69 & 2.34 & 0.46 & 1.40 & 1.33 & 1.33 & 0.74 & 1.04 & 0.42 & $<0.06$ & $<0.06$ & & \\
\hline
\end{tabular}


Appendix C

SDDB Data Entry Chemical Analysis

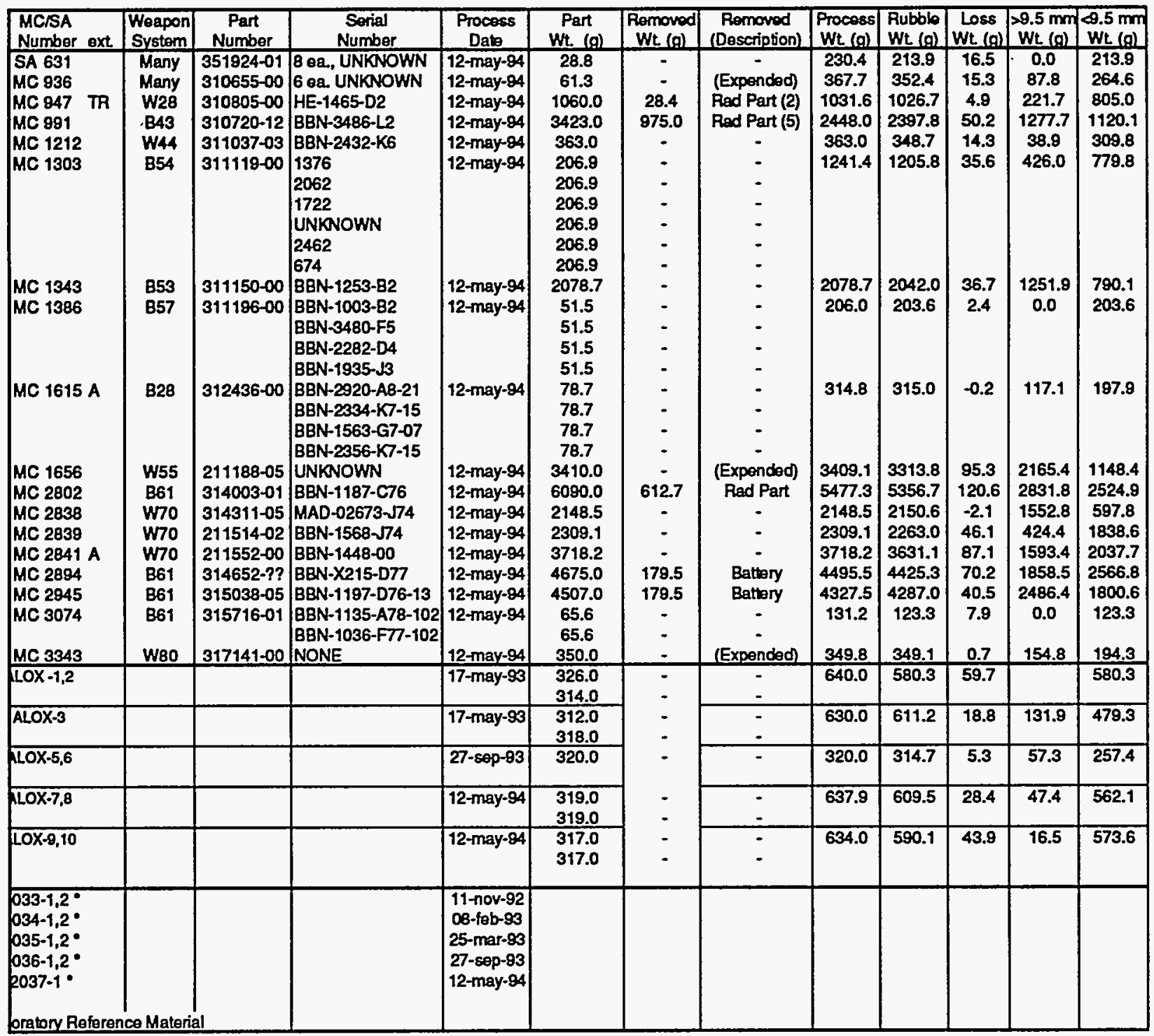


Appendix C

SDDB Data Entry Chemical Analysis

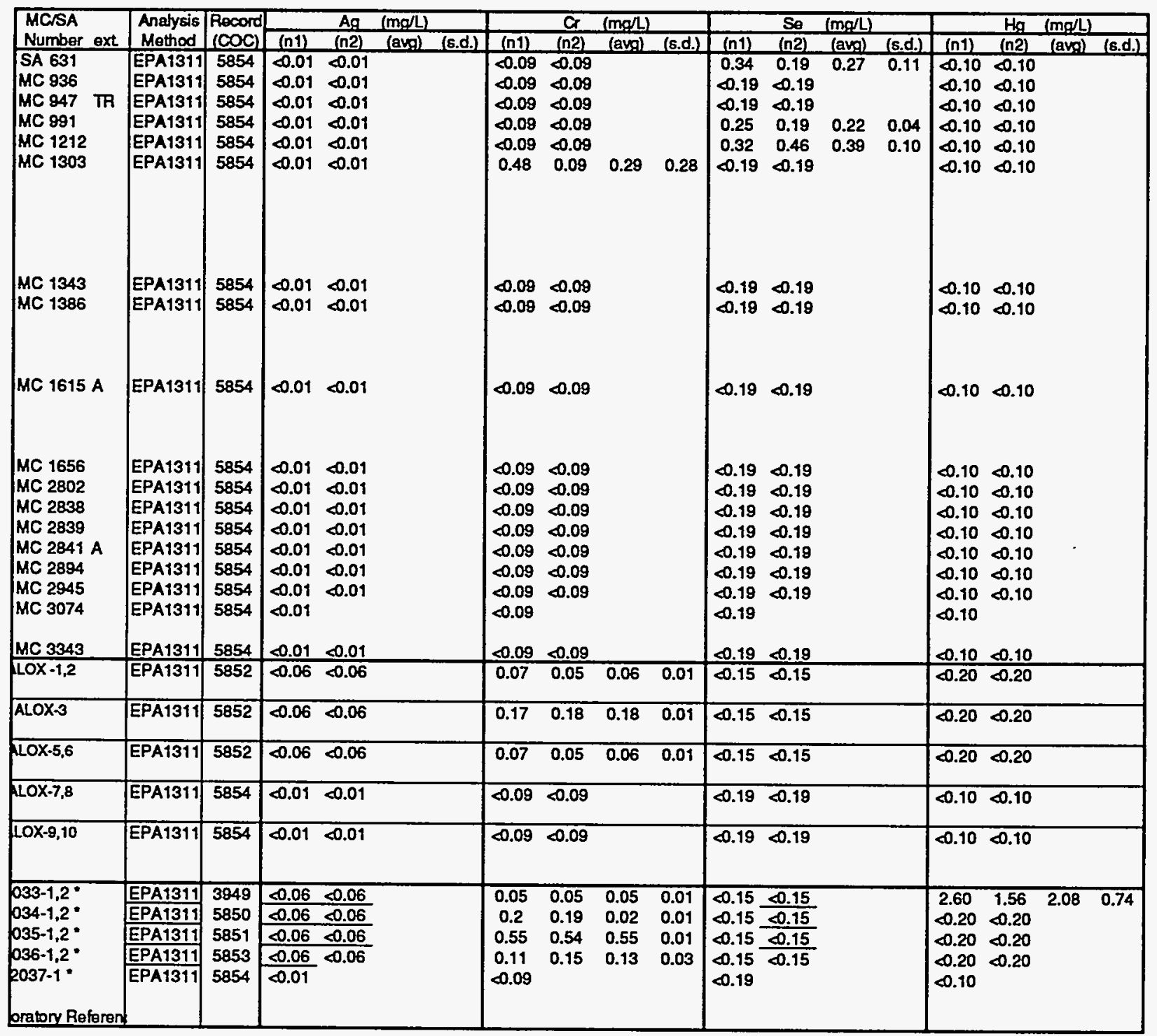


Appendix C

SDDB Data Entry Chemical Analysis

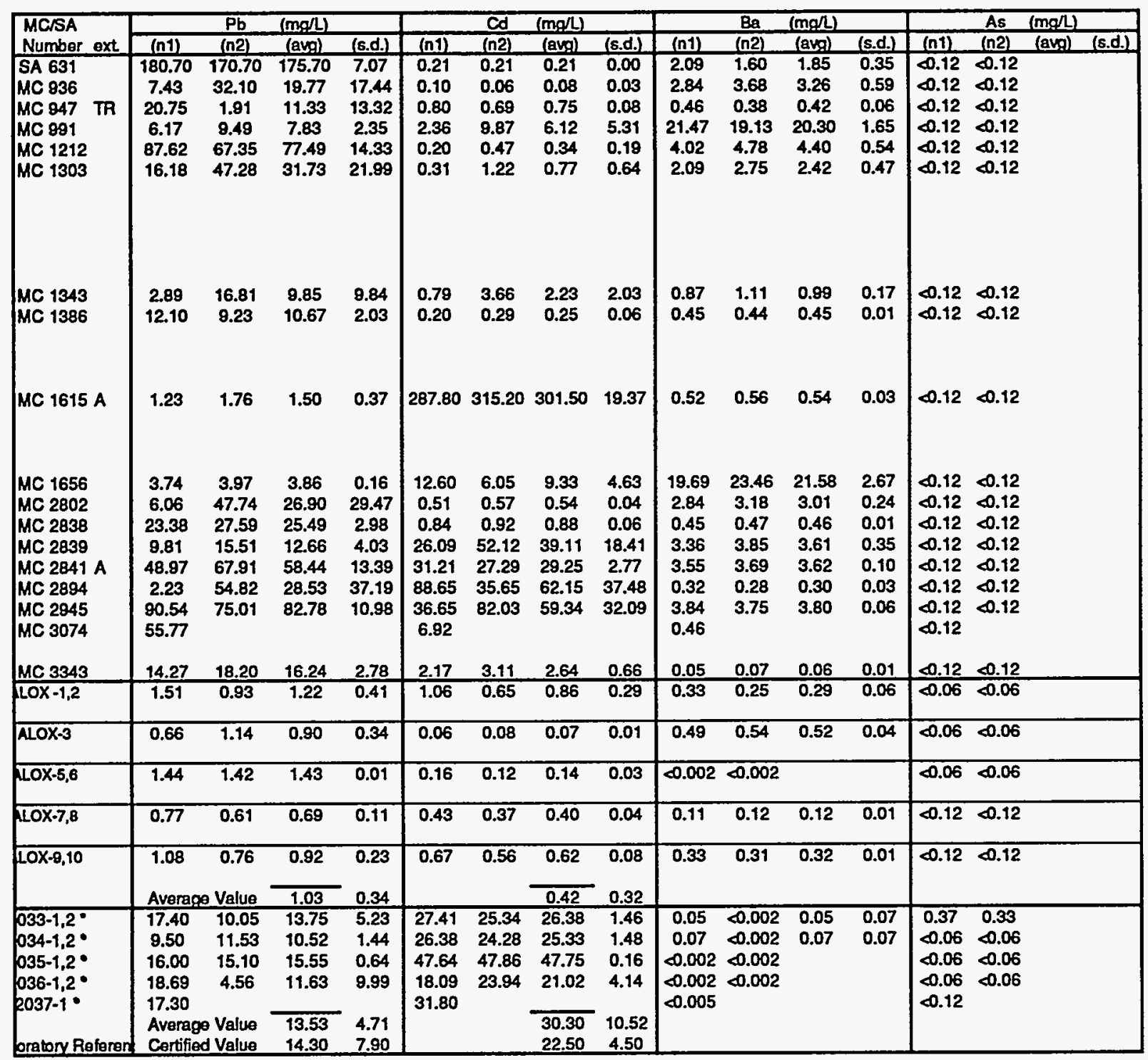


This page intentionally left blank 


\section{Summary of TCLP data on Weapon Component Electronic Hardware}

The attached tables summarize the data for 100 electronic or electromechanical components analyzed by the Toxicity Characteristic Leaching Procedure (TCLP). Nearly all of these components (96 of 100), regardless of design or function, exhibit the Toxicity Characteristic for lead $(\mathrm{Pb})$, cadmium (Cd), or both. The sampling and analysis of these components are described in further detail in Appendices B and C. 
SDDB Chemical Analysis Data TCLP Summary

\begin{tabular}{|c|c|c|c|c|c|c|c|c|}
\hline & MC/SA & & Weapon & Part & Part & Process & TCLP-PD & TCLP-Cd \\
\hline & Number & - - ext. & System & Number & Description & Date & (>5 mg/L) & (>1 mall) \\
\hline & none & & 57 & $158763-01$ & Switch Assembly & 17-May-93 & $x$ & $x$ \\
\hline & none & & 43 & $310608-00$ & Radar Module & 27-Sep-93 & $x$ & $\underline{x}$ \\
\hline & none & & 43 & $310608-00$ & Transverter & 27-Sop-93 & $x$ & \\
\hline & none & & 57 & $300022-? ?$ & Radar Module & 17-May-93 & $x$ & $x$ \\
\hline & none & & 35 & $300922-? ?$ & Radar Module & 27-Sep-93 & $x$ & $x$ \\
\hline SA & 631 & & Many & $351924-01$ & Explosive Bellows & 12-May-94 & $x$ & \\
\hline SA & 739 & -4 & 43 & $356208-00$ & Radar Dolay & 17-Nay-93 & & \\
\hline SA & 783 & & 43 & $3526666-00$ & DC Notor & 8-Fob-93 & & $\bar{x}$ \\
\hline MC & 808 & & 28 & $310414-02$ & Safing Switch & 25-Mar-93 & $x$ & $\bar{x}$ \\
\hline $\mathrm{MC}$ & 880 & & 28 & 310573-03 & Interconnect Box & 17-May-93 & $x$ & $x$ \\
\hline MC & 908 & & Many & $310615-02$ & Rotary Chopper Inverter & 8-Fab-93 & $x$ & $x$ \\
\hline MC & 936 & & Many & $310655-00$ & Explosive Switch & 12-May-94 & $\mathrm{x}$ & \\
\hline MC & 947 & TR & 28 & $310805-00$ & Thyratron Controlled Trigger Ckt & 12-May-94 & $x$ & \\
\hline$M C$ & 982 & & 57 & $310712-\infty$ & Pullout Switch & 17-May-93 & $x$ & $\mathbf{x}$ \\
\hline MC & 991 & & 43 & $310720-12$ & Firing Set & 12-May-94 & $x$ & $\mathrm{x}$ \\
\hline $\mathrm{MC}$ & 993 & & 43 & $310722-09$ & Fuze Switch Pack & 25-Mar-93 & $x$ & \\
\hline $\mathrm{MC}$ & 1026 & & 43 & $310779-01$ & Ready Safe Switch & 8-Feb-93 & & $\bar{x}$ \\
\hline MC & 1057 & & 43 & $310807-00$ & Pressure Switch & 17-May-93 & $\bar{x}$ & $x$ \\
\hline $\mathrm{MC}$ & 1108 & & 57 & $310889-00$ & Dotonator & 27-Sep-93 & $\mathrm{x}$ & \\
\hline $\mathrm{MC}$ & 1187 & & 45 & 211042 & Firing Set & 16-Jun-92 & $\bar{x}$ & $\bar{x}$ \\
\hline $\mathrm{MC}$ & 1212 & & 44 & $311037-03$ & Inertial Switch Pack & 12-Nov-92 & $x$ & \\
\hline $\mathrm{MC}$ & 1212 & & 44 & $311037-03$ & Inertial Switch Pack & 12-May-94 & $x$ & \\
\hline $\mathrm{MC}$ & 1273 & & 57 & $311079-03$ & Sequential Timer & 25-Mar-93 & & $\bar{x}$ \\
\hline $\mathrm{MC}$ & 1303 & & 54 & $311119-00$ & Transducer & 12-May-94 & $x$ & $\bar{x}$ \\
\hline $\mathrm{MC}$ & 1316 & A & 28 & $311639-00$ & Interconnect Box & 27-Sep-93 & $x$ & $\bar{x}$ \\
\hline MC & 1343 & & 53 & $311150-00$ & Transformer & 12-May-94 & $x$ & $x$ \\
\hline $\mathrm{MC}$ & 1345 & & 57 & $311152-04$ & Inertial Switch (Al Housing) & 17-May-93 & & $x$ \\
\hline $\mathrm{MC}$ & 1345 & & 57 & $311152-05$ & Inertial Switch (Al Housing) & 17-May-93 & & $\bar{x}$ \\
\hline $\mathrm{MC}$ & 1345 & & 57 & $311152-06$ & Inertial Switch (Molded Housing) & 17-May-93 & $\bar{x}$ & $\mathrm{x}$ \\
\hline $\mathrm{MC}$ & 1348 & & 57 & 311155-01 & Explosive Switch Pack & 17-May-93 & $x$ & $x$ \\
\hline MC & 1349 & & 57 & $311156-01$ & Strike Select Switch & 25-Mar-93 & $x$ & $\bar{x}$ \\
\hline $\mathrm{MC}$ & 1351 & & 57 . & $311158-04$ & Interconnect Box & 25-Mar-93 & $x$ & $x$ \\
\hline MC & 1352 & & 2957 & $311159-02$ & Ready Safe Switch & 25-Mar-93 & & $\mathrm{x}$ \\
\hline $\mathrm{MC}$ & 1356 & & 57 & $311164-03$ & Sequential Timer & 25-Mar-93 & $x$ & \\
\hline MC & 1366 & & 57 & $311181-01$ & Hydrostatic Switch & 17-May-93 & & $\bar{x}$ \\
\hline $\mathrm{MC}$ & 1369 & & $57 \%$ & $311186-00$ & Motor Driven Switch & 17-May-93 & & $\underline{x}$ \\
\hline MC & 1380 & & 57 & $311188-00$ & Firing Set & 25-Mar-93 & $\bar{x}$ & \\
\hline $\mathrm{MC}$ & 1386 & & 57 & $311196-00$ & Strike Enable Plug & 12-May-94 & $x$ & \\
\hline$M C$ & 1390 & & 57 & $311206-01$ & Explosive Switch Pack & 17-May-93 & $x$ & \\
\hline $\mathrm{MC}$ & 1391 & & 57 & $311207-00$ & Thermal Fuze Pack & 17-May-93 & $x$ & \\
\hline $\mathrm{MC}$ & 1417 & & 57 & $311222-00$ & inducer & 27-Sep-93 & $x$ & \\
\hline MC & 1450 & & 57 & $311255-00$ & Hydrostatic Switch & 17-May-93 & $x$ & $\bar{x}$ \\
\hline MC & 1454 & & 28 & $311263-02$ & Fuse Pack & $27-$ Sep-93 & $\bar{x}$ & $\bar{x}$ \\
\hline$M C$ & 1510 & & 57 & $311299-01$ & Pressure Switch (w/o cover) & 12-Nov-92 & $x$ & \\
\hline $\mathrm{MC}$ & 1510 & & 57 & $311299-01$ & Pressure Switch & 8-Fob-93 & & \\
\hline $\mathrm{MC}$ & 1515 & A & 43 & $311501-00$ & Gravity Switch & 8-Feb-93 & & $x$ \\
\hline$M C$ & 1588 & & 61 & $311397-02$ & Interval Timer & 25-Mar-93 & $x$ & \\
\hline $\mathrm{MC}$ & 1588 & & 61 & $311397-04$ & Interval Timer & $25-$ Mar-93 & $x$ & \\
\hline MC & 1592 & & 57 & $311410-02$ & Transverter & 27-Sep-93 & $x$ & $x$ \\
\hline MC & 1612 & & 57 & $311466-00$ & Switch Pack & 25-Mar-93 & $\mathrm{X}$ & $x$ \\
\hline $\mathrm{MC}$ & 1612 & & 57 & $311466-01$ & Switch Pack & 27-Sep-93 & $x$ & $x$ \\
\hline MC & 1615 & A & 28 & $312436-00$ & Fuse Pack & 12-May-94 & & $x$ \\
\hline$M C$ & 1656 & & 55 & $211188-05$ & Firing Set & 12-Мау-94 & & $x$ \\
\hline $\mathrm{MC}$ & 1702 & & 61 & $311612-00$ & Switch pack & 27-Sep-93 & $\bar{x}$ & $x$ \\
\hline MC & 1781 & & 57 & $311730-02$ & Filter Pack & 27-Sop-93 & & $x$ \\
\hline $\mathrm{MC}$ & 1804 & & 57 & $311751-03$ & Firing Sot & 25-Mar-93 & $x$ & $x$ \\
\hline MC & 1806 & & 43 & $311753-02$ & Firing Sot & 25-Mar-93 & $x$ & $x$ \\
\hline $\mathrm{MC}$ & 1813 & & 57 & $311760-00$ & Interconnect Box & 25-Mar-93 & $x$ & $x$ \\
\hline $\mathrm{MC}$ & 1818 & & 57 & $311767-03$ & Connector Assembly & 25-Mar-93 & $x$ & $x$ \\
\hline
\end{tabular}


Appendix D

SDDB Chemical Analysis Data TCLP Summary

\begin{tabular}{|c|c|c|c|c|c|c|c|c|}
\hline & MC/SA & & Weapon & Part & Part & Process & TCLP-PD & TCLP-Cd \\
\hline & Numbor & -ext. & Systom & Number & Description & Date & $(25 \mathrm{mg} / \mathrm{L})$ & $(>1 \mathrm{mg} / \mathrm{L})$ \\
\hline $\mathrm{MC}$ & 1821 & & 43 & $311770-01$ & Pulse Generator & 12-Nov-92 & & $\bar{x}$ \\
\hline$M C$ & 1838 & A & 61 & $315291-00$ & Signal Programmer & 25-Mar-93 & $x$ & $x$ \\
\hline$M C$ & 1839 & & 61 & $311788-00$ & Inertial Switch & $27-5 e p-93$ & $x$ & $x$ \\
\hline $\mathrm{MC}$ & 1873 & & 61 & $311815-00$ & RF Filter Pack & 8-Fob-93 & $x$ & $x$ \\
\hline MC & 1873 & & 61 & $311815-03$ & RF Filter Pack & 8-Fab-93 & $x$ & $x$ \\
\hline MC & 1874 & & $61 / 28$ & $311816-00$ & Prefilight Controller & 25-Mar-93 & $x$ & $x$ \\
\hline $\mathrm{MC}$ & 1904 & & 28 & $311846-00$ & Pulse Discriminator & 27-Sep-93 & $\bar{x}$ & $\underline{x}$ \\
\hline$M C$ & 1938 & & 57 & $311910-00$ & Firing Sot & 25-Mar-93 & $x$ & $x$ \\
\hline $\mathrm{MC}$ & 1970 & & 557 & $311950-00$ & Filter Pack & 17-May-93 & $x$ & $x$ \\
\hline$M C$ & 2213 & & 61 & $312197-00$ & Pulse Actuator & 8-Feb-93 & $x$ & $x$ \\
\hline $\mathrm{MSC}$ & 2219 & & 57 & $312204-00$ & Explosive Switch Pack & 25-Mar-93 & $\mathbf{X}$ & $x$ \\
\hline $\mathrm{MC}$ & 2248 & & $61 / 28$ & $312246-00$ & Distribution Box & 17-May-93 & $x$ & $x$ \\
\hline $\mathrm{MC}$ & 2248 & & $61 / 28$ & $312246-00$ & Distribution Box & 12-Nov-92 & $x$ & $x$ \\
\hline $\mathrm{MC}$ & 2371 & & 69 & $312454-05$ & Inertial Switch & 25-Mar-93 & $x$ & $x$ \\
\hline $\mathrm{MC}$ & 2477 & -9 & 80, JTA & $316488-00$ & Accelerometer & 8-Feb-93 & $x$ & \\
\hline $\mathrm{MC}$ & 2534 & & 69 & $312834-03$ & Firing Set & 12-Nov-92 & $x$ & $x$ \\
\hline$M C$ & 2534 & & 69 & $312834-09$ & Firing Set & 25-Mar-93 & $x$ & $x$ \\
\hline SA & 2730 & & $80, \mathrm{JTA}$ & $316836-000$ & Encoder & 8-Feb-93 & $\bar{x}$ & $x$ \\
\hline SA & 2747 & -1 & $?$ & $316890-? ?$ & RF Transmitter & $29-\mathrm{Jul}-92$ & $x$ & \\
\hline MC & 2802 & & 61 & 314003-01 & Firing Set & 12-May-94 & $x$ & \\
\hline $\mathrm{MC}$ & 2819 & & $28 / 61$ & $314281-00$ & Resistor & 27-Sep-93 & $\bar{x}$ & \\
\hline$M C$ & 2838 & & 70 & $314311-05$ & Electrical Assembly & 12-May-94 & $x$ & $\bar{x}$ \\
\hline$M C$ & 2839 & & 70 & $211514-02$ & Firing Set Subassembly & 12-May-94 & $x$ & $\mathrm{x}$ \\
\hline MC & 2841 & A & 70 & $211552-00$ & Power Supply & 12-May-94 & $x$ & $x$ \\
\hline MC & 2894 & & 61 & 314652-?? & Prefilight Controller & 12-May-94 & $x$ & $\mathrm{X}$ \\
\hline MC & 2895 & & 80, JTA & 314658-01 & Fuze Switch Pack & 8-Feb-93 & & $x$ \\
\hline $\mathrm{MC}$ & 2907 & & $?$ & $314689-00$ & Coded Switch & 29 Jut-92 & $\bar{x}$ & $x$ \\
\hline $\mathrm{MC}$ & 2918 & & 61 & $314699-02$ & Firing Sot & 8-Fob-93 & $x$ & $x$ \\
\hline $\mathrm{MC}$ & 2934 & & 61 & $314885-00$ & Junction Box & 27-Sep-93 & $x$ & \\
\hline $\mathrm{MC}$ & 2935 & & Many & $314965-00$ & Stronglink Switch & 12-Nov-92 & & \\
\hline MC & 2935 & & Many & $314965-00$ & Stronglink Switch & 8-Feb-93 & & \\
\hline MC & 2945 & & 61 & 315038-05 & Preflight Controller & 12-May-94 & $\bar{x}$ & $x$ \\
\hline SA & 2946 & & Many & $315043-02$ & Output Switch & 8-Feb-93 & & \\
\hline MC & 2948 & & 61 & 315093-00 & TSSG & 8-Fob-93 & $\bar{x}$ & $\bar{x}$ \\
\hline MC & 2969 & & Many & $315225-00$ & Intent Switch & 12-Nov-92 & & \\
\hline MC & 2969 & & Many & $315225-00$ & Intent Switch & 8-Feb-93 & & \\
\hline MC & 3025 & & 61 & $315571-00$ & Signal Select switch & 8-Feb-93 & & $\bar{x}$ \\
\hline MC & 3025 & & 61 & $315571-03$ & Signal Select Switch (w/o case) & 8-Feb-93 & $\bar{x}$ & $\bar{x}$ \\
\hline $\mathrm{MC}$ & 3067 & & 61 & $315698-00$ & RF Filter Pack & 25-Mar-93 & $x$ & $x$ \\
\hline $\mathrm{MC}$ & 3074 & & 61 & $315716-01$ & Circuit Monitor & 12-May-94 & $x$ & $x$ \\
\hline $\mathrm{MC}$ & 3097 & & 28 & $315779-00$ & Power Supply & 12-Nov-92 & $x$ & $x$ \\
\hline $\mathrm{MC}$ & 3268 & & 80 & $316562-? ?$ & TSSG & 29-Jul-92 & $x$ & $x$ \\
\hline MC & 3269 & & 80 & 316563-?? & TSSG & 29 Jul-92 & $x$ & $x$ \\
\hline $\mathrm{MC}$ & 3276 & & 80 & $316590-00$ & Firing Set & 12-Nov-92 & $x$ & $x$ \\
\hline MC & 3289 & A & 80 & 318765-?? & Interconnect Box & 29-Jut-92 & $x$ & $x$ \\
\hline MC & 3333 & A & 80 & $317641-01$ & Signal Conditioner & 27-Sep-93 & $\mathbf{x}$ & $x$ \\
\hline $\mathrm{MC}$ & 3343 & & 80 & $317130-00$ & Neutron Generator & 12-May-94 & $x$ & $x$ \\
\hline $\mathrm{MC}$ & 3369 & -500 & 80 & $317192-00$ & Neutron Tube & 8-Feb-93 & $x$ & \\
\hline $\mathrm{MC}$ & 3371 & & 80 & 317644-?? & Data Analyzer & $29-J u 1-92$ & $x$ & $x$ \\
\hline $\mathrm{MC}$ & 3619 & & 61 & $318359-00$ & Preflight Controller & 25-Mar-93 & $x$ & $x$ \\
\hline MC & 3799 & & 80 & $319270-00$ & Detector & 17-May-93 & $x$ & \\
\hline$M C$ & 3799 & A & 80 & $413254-00$ & Detector & 27-Sep-93 & $\bar{x}$ & \\
\hline $\mathrm{MC}$ & 4067 & & 53 & $411381-00$ & Junction Box & 12-Nov-92 & $x$ & $\bar{x}$ \\
\hline $\mathrm{MC}$ & 4136 & & 61 & $311619-00$ & Preflight Controller & 8-Fob-93 & $\mathrm{X}$ & $x$ \\
\hline
\end{tabular}


Appendix D

This page intentionally left blank. 


\section{Air Gravity Separation Demonstration}

The air/gravity separation demonstration to which the attached data apply, was conducted by Dr. Ibrahim Gundiler at the New Mexico Bureau of Mines (NMBM) in support of the Sandia Weapon Disposal Integrated Demonstration (WeDID) Project.

The material used for the WeDID demonstration consisted of $727 \mathrm{lbs}$. of diverse weapon components as shown on the attached list (List 1.) Table 1 shows the general flow of materials through various size reduction and material separation processes. An initial hand sort and separation of bulk metal was employed to decrease wear and tear on the hammermill. The hammermill and granulator were employed to crush the components and reduce the particle size to effect complete separation of the constituent materials, i.e., metal, epoxy, foam, etc.. The resulting "feed" material (120 lbs., $\leq 0.25$ ") was then sieved to sort the particles into 3 size fractions for more efficient air/gravity separation. The bulk of the material $(90 / 120 \mathrm{lbs}$.) was retained on the 10 mesh screen $(+10$ mesh $=>1.7 \mathrm{~mm})$.

Tables 2 and 3 show the results of air/gravity separation for the various particulate size fractions. The air/gravity separation process employs a vibrating table to separate the metals by density and a stream of air directed across the table to remove light materials such as plastics and foams. As shown in Table 2, the +10 particle size fraction was initially separated into 3 fractions of varying density (Run \#1). The mid-weight fraction was again separated into 3 fractions (Run \#2) which yielded $17.5 \mathrm{lbs}$. of aluminum concentrate. The heavy fraction from Run \#1 was also re-run and separated into 3 fractions which yielded $15.5 \mathrm{lbs}$ of ferrous and non-ferrous metal combined. This material was subsequently magnetically separated (Run \#3). Similar separations were run on the remaining sieve fractions as shown in Table 3.

Table 4 shows the results of compositional analysis of samples of the "heavy" metal concentrates produced by the air/gravity process. Also shown in Table 4, are the results of analysis of a sample of the un-separated ("as is") feed material. The metal content of these samples was determined by inductively coupled plasma-atomic emission spectroscopy (ICP-AES) at Sandia/NM. Only the major elements (>1 wt.\%) are shown in Table 4. As shown, the granulated component material ("as is") contains $60 \%$ metal by weight. The other $40 \%$ consists of lower density organic and inorganic materials including plastic, rubber, epoxy, ceramic, and glass. By comparison, the metal content of the heavy concentrates is, on average, better than $90 \%$ by weight. These analyses show that the metals can be concentrated by separation from lower density ("lite") materials using the air/gravity process. Additionally, as indicated by the "boxed" values in Table 4, aluminum, iron, and copper based metals can be separated for recycling by a combination of air/gravity and magnetic processing. Complete metals analyses of these materials are included in Tables 6-8. 
Table 5 shows the results of precious metal analysis of the concentrates. As indicated by the "boxed" values, the precious metals tend to concentrate in the copper-based fractions which coincidentally enhances their recovery by smelting and refining processes. For purposes of evaluating the potential economic value of reclaimed metals in component hardware, representative values of metals in the "feed" material were obtained by multiplying the analyzed values of the concentrates by the weight fraction of each concentrate (lbs. $/ 120 \mathrm{lbs}$.) and summing those values. Table 5 also includes, for comparison, the precious metals reclaimed in another demonstration where demilitarized component hardware was shipped directly to a refiner for precious metal recovery without material separation (List 2, attached). Good agreement was obtained considering the two demonstrations were conducted with different batches of component hardware. Tables 6,7 and 8 show the elemental content by percent weight for the various fractions of the material that was analyzed. 


\section{List 1. Components for Magnetec Size Reduction - PO\# AF9498}

\begin{tabular}{|c|c|c|c|c|c|}
\hline Pound & MCNo. & Part No. & Component Name & System & Comments \\
\hline 3 & MC880 & 310573 & Interconnect Box & B28 & \\
\hline 62 & MC888 & 310586 & Arming Safing Switch Assy & B28 & \\
\hline 1 & MC908 & 310615 & Rotary Inverter & Many & \\
\hline 6 & MC909 & 310616 & Pressure Switch & B28,43,57 & \\
\hline 7 & MC982 & 310712 & Pullout Switch & B57 & \\
\hline 55 & MC993 & 310722 & Fuze Switch Pack & B43 & Fired \\
\hline 3 & MC1026 & 310779 & Ready-Safe Switch & B43 & \\
\hline 2 & MC1273 & 311079 & Sequential Timer & B57 & Fired \\
\hline 13 & MC1316 & 311135 & Interconnect Box & B28 & \\
\hline 31 & MC1349 & 311156 & Strike Selector Switch Pack & B57 & \\
\hline 12 & MC1352 & 311159 & Ready-Safe Switch & $\mathrm{B} 28,57$ & \\
\hline 8 & MC1356 & 311164 & Sequential Timer & B57 & Fired \\
\hline 2 & MC1454 & 311263 & Fuse Pack & B28 & \\
\hline 2 & $\mathrm{MC1476}$ & 311281 & Pressure Port & B28 & Fired \\
\hline 10 & MC1510 & 311299 & Pressure Switch & B43 & \\
\hline 3 & MC1515A & 311501 & Inertial Switch & B43 & \\
\hline 4 & MC1531 & 311327 & Differential Pressure Inducer & B28,43 & Fired \\
\hline 7 & MC1588 & 311399 & Interval Timer & B28,61 & \\
\hline 54 & $\mathrm{MC} 1592$ & 311410 & Power Supply & B57 & w/o Batteries \\
\hline 62 & MC1813 & 311760 & Interconnect Box & B57 & \\
\hline 7 & MC1818 & 311767 & Breakaway Pulse Connector Assy & B57 & \\
\hline 22 & MC1835 & 311784 & Gas Generator & B61 & Fired \\
\hline 56 & MC1838A & 315291 & Electronic Programmer & B61 & \\
\hline 10 & MC1873 & 311815 & Filter Pack & B61 & \\
\hline 35 & MC1874 & 311816 & Preflight Control Box & B61 & \\
\hline 2 & MC1904 & 311846 & Pulse Duration Discriminator & B28 & \\
\hline 22 & MC1951 & 311932 & Rocket Motor & B61 & Fired \\
\hline 32 & MC1970 & 311950 & Filter Pack & B57 & \\
\hline 7 & MC2213 & 315221 & Pulse Battery Actuator Assembly & B61 & w/o Batteries \\
\hline 1 & MC2895 & 314658 & Switch Pack & W69 & \\
\hline 3 & MC2934 & 314885 & Junction Box & B61 & \\
\hline 14 & MC2935 & 314965 & Strong Link Trajectory Switch & Many & \\
\hline 7 & MC2941 & 315015 & Filter Pack & B61 & w/o Batteries \\
\hline 1 & MC2948 & 315093 & Traiectory Sensing Signal Gen. & B61 & \\
\hline 2 & MC3002 & 315461 & Gas Generator & $\bar{B} 61$ & Fired \\
\hline 21 & MC3066 & 315697 & Interconnect Box & B61 & \\
\hline 2 & MC3067 & 315698 & Filter Pack & B61 & \\
\hline 4 & MC3133 & 315965 & Reefing Line Cutter & $\mathrm{B} 61$ & Fired \\
\hline 4 & MC3269 & 315700 & Trajectory Sensing Signal Gen. & W80 & \\
\hline 43 & MC2538 & 317758 & Interface Adaptor & W85 & \\
\hline 32 & $\mathrm{MC3810}$ & 319332 & AF\&F & W88 & Uncl; NFN-3, -20 \\
\hline 30 & MC4140 & 411624 & Interface Control Unit & B61 & \\
\hline 7 & MC4169 & 411797 & Hermetic Double Layer & B61 & \\
\hline 3 & MC4306 & 412815 & Interface Adaptor & B61 & \\
\hline 3 & & 158761 & Resistor \& Connector & $\overline{\mathrm{B57}}$ & \\
\hline 2 & & 186686 & Electrical Connector Cover & B57 & \\
\hline 1 & & 388149 & Potting Dam, 2, Data Process & & Test Assy \\
\hline 3 & & 421091 & & & \\
\hline 3 & & 1442043 & Bulkhead & & \\
\hline 2 & & & Cu Clad Circuit Boards & & \\
\hline
\end{tabular}

727 Pounds Total Weight of Material Sent to Magnetech 


\section{Table 1. Air Gravity Separation Flowsheet}

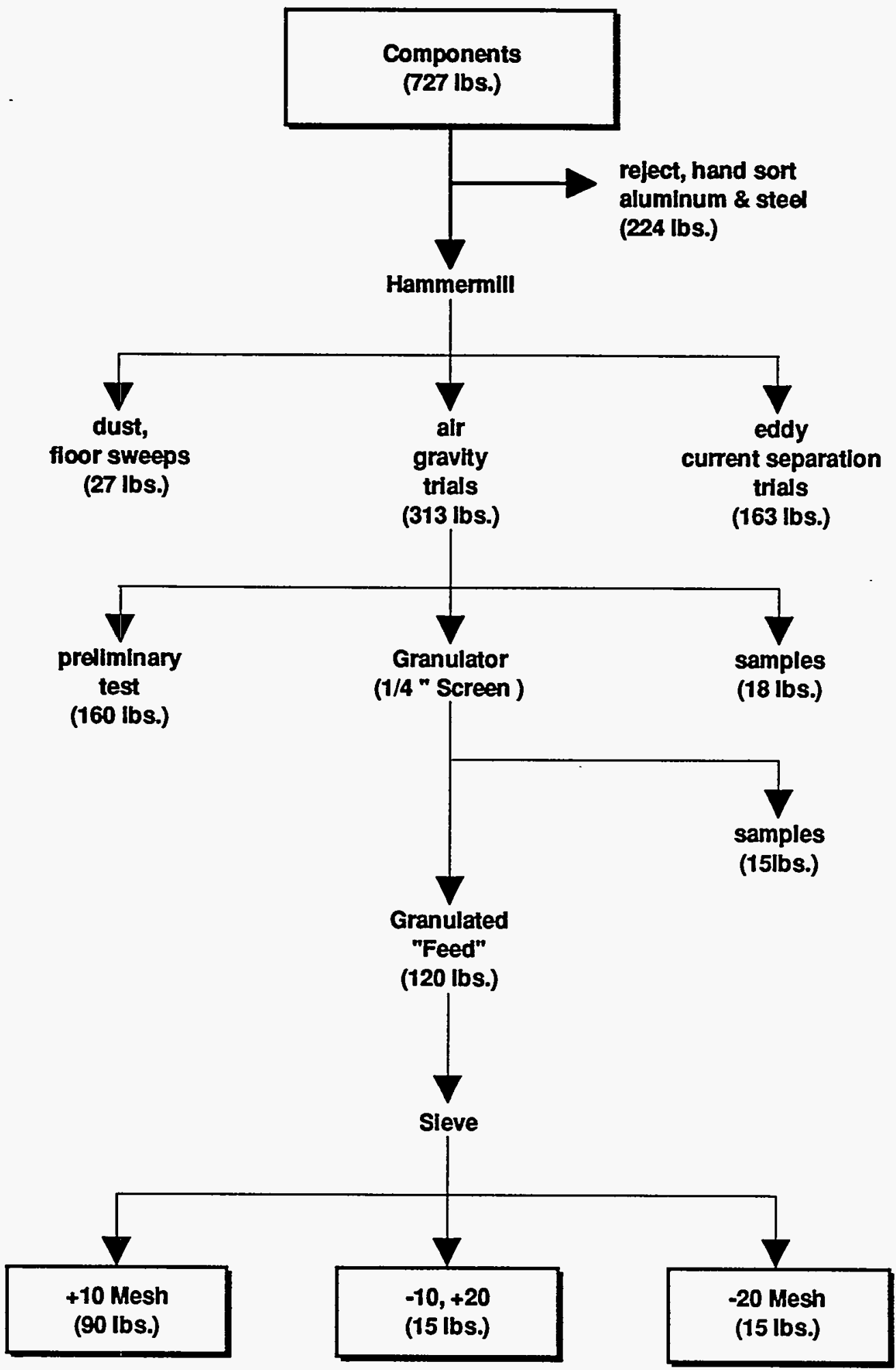




\section{Table 2. Air Gravity Separation of Granulated Components}

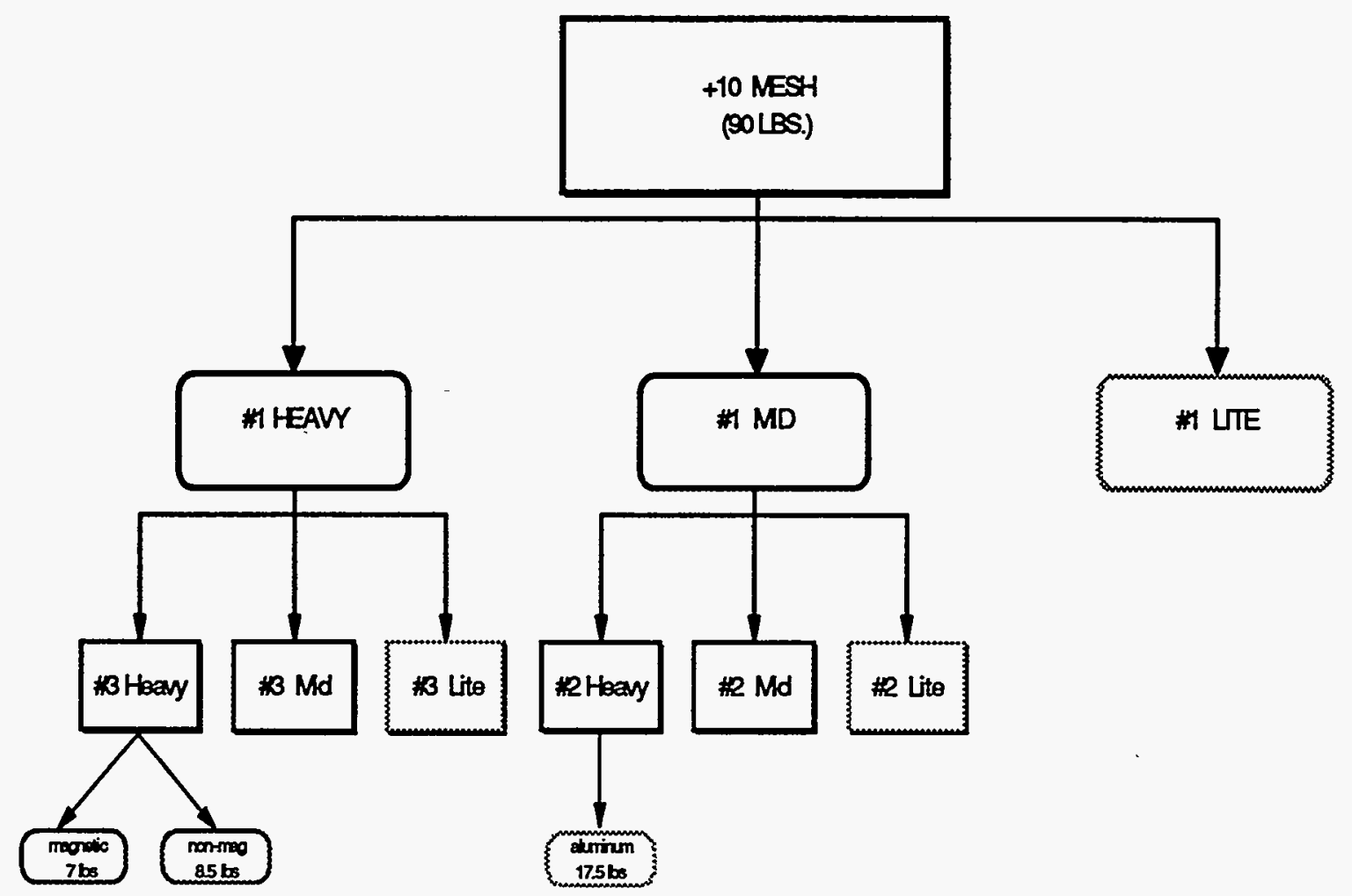

Table 3. Air Gravity Separation of Granulated Components

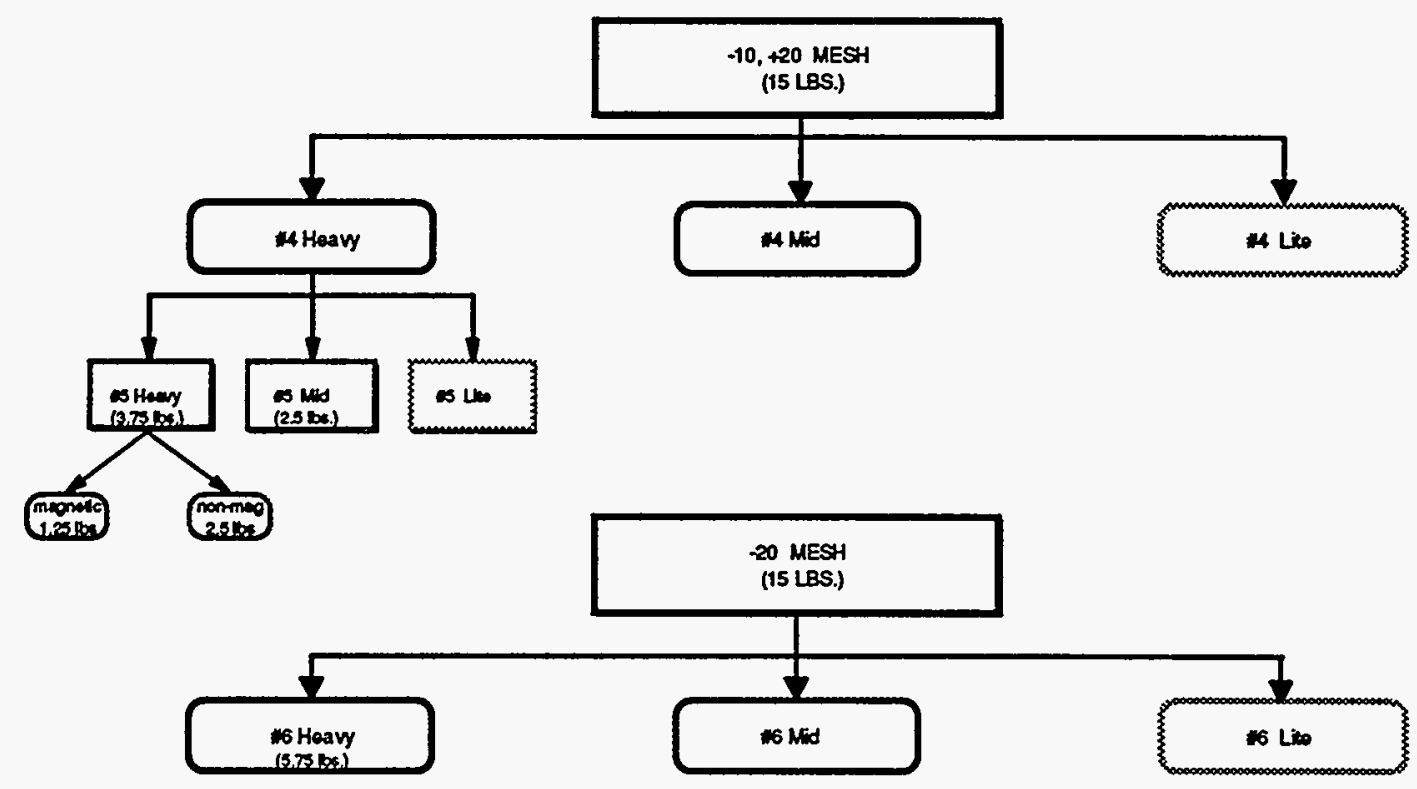


Table 4. Compositional Analysis of Air/Gravity Separation Products

\begin{tabular}{|c|c|c|c|c|c|c|c|c|c|c|}
\hline Granulated Components & $\overline{\mathbf{A}}$ & $\mathrm{Cu}$ & $F_{\theta}$ & $\overline{\mathrm{Ni}}$ & $\overline{\mathrm{Cr}}$ & $\mathrm{Co}_{0}$ & $\mathrm{Zn}$ & $\mathrm{Pb}$ & $S n$ & SUM \\
\hline$\left(1 / 4^{n}\right.$ Fe日d) & (wt.\%) & (wt.\% & (wt.\%) & (wt.\%) & (wt.\%) & (wt.\%) & (wt.\%) & (wt.\% & (wt.\%) & (wt.\%) \\
\hline "As is" sample & 30 & 13 & 10 & 2 & 1 & $<1$ & 2 & 1 & $<1$ & 60 \\
\hline Air/Gravity Separation & & & & & & & & & & \\
\hline (Run \#) & & & & & & & & & & \\
\hline *3 mag heavies & $<1$ & 3 & 70 & 9 & 8 & 6 & $<1$ & $<1$ & 2 & 98 \\
\hline *3 non-mag heavies & $<1$ & 50 & 13 & 8 & 4 & $<1$ & 14 & 3 & 1 & 93 \\
\hline \#5 mag heavies & $<1$ & 10 & 60 & 9 & 8 & 4 & $<1$ & $<1$ & 2 & 93 \\
\hline *5 non-mag heavies & 1 & 70 & 2 & 2 & 1 & $<1$ & 7 & 3 & $<1$ & 86 \\
\hline \#5 mids & 30 & 50 & 6 & 1 & 1 & $<1$ & 1 & 1 & 1 & 91 \\
\hline \#2 heavies & 93 & 4 & 2 & 1 & $<1$ & $<1$ & $<1$ & $<1$ & $<1$ & 100 \\
\hline \#6 heavies & 15 & 45 & 10 & 2 & 1 & 1 & 3 & 2 & 1 & 80 \\
\hline
\end{tabular}

Table 5. Precious Metals Analysis of Air Gravity Separation Products

\begin{tabular}{|c|c|c|c|c|c|c|c|c|c|}
\hline \multicolumn{2}{|l|}{ AirfGravity Separation } & \multicolumn{5}{|c|}{ Analyzed Valuo (Concontrates) } & \multicolumn{3}{|c|}{ Representative Value [As $1 \mathrm{~s}^{\prime}$ ] } \\
\hline Run: & m. fraction & $\frac{A u}{(w . \%)(0 z / 10 n)}$ & \multicolumn{2}{|c|}{$\frac{\mathrm{Ag}}{\text { (wt.\%) (oz/ton) }}$} & \multicolumn{2}{|c|}{$\frac{\mathrm{Pd}}{\text { (wt.\%) (oz/ton) }}$} & $\frac{A u}{(\text { oz/ton) }}$ & $\frac{\mathrm{Ag}}{(0 \mathrm{z} / \mathrm{ton})}$ & $\frac{\mathrm{Pd}}{(\text { ozton) }}$ \\
\hline *3 mag heavies & 0.058 & 0.05 & 0.03 & 9 & & & 1 & 1 & \\
\hline *3 non-mag heavios & 0.071 & 0.1955 & 0.59 & 172 & & & 4 & 12 & \\
\hline "5 mag heavies & 0.01 & $0.07 \quad 20$ & 0.14 & 41 & & & 1 & 1 & \\
\hline H5 non-mag heavios & 0.021 & $0 . 1 0 \longdiv { 2 9 }$ & 1.49 & 435 & 0.14 & 41 & 1 & 9 & 1 \\
\hline 45 mids & 0.0208 & & 0.81 & 236 & & & & 5 & \\
\hline *2 hoavios & 0.1458 & & 0.05 & 15 & & & & 2 & \\
\hline *6 heavies & 0.0479 & 0.06 & 0.67 & 195 & 0.09 & 26 & 1 & 9 & 1 \\
\hline Totals & $\overline{0.3750}$ & & & & & & $\overline{7}$ & $\overline{39}$ & 2 \\
\hline \multicolumn{2}{|c|}{$\begin{array}{l}\text { Smeker/Refiner Recovery } \\
\text { (Serate Shite) }\end{array}$} & & & & & & 12 & 52 & 2 \\
\hline
\end{tabular}




\section{List 2. Components for Recycling - PO\# AF4950}

\begin{tabular}{|c|c|c|c|c|c|}
\hline Ibs & MCNo. & Part No. & Component Name & System & Comments \\
\hline 6 & MC888 & 310586 & Arming Safing Switch Assy & B28 & \\
\hline 4 & MC982 & 310712 & Pullout Switch & B57 & \\
\hline 14 & MC1136 & 310935 & Transducer & B28 & \\
\hline 9 & MC1348 & 311155 & Explosive Switch Pack & B57 & Fired \\
\hline 10 & MC1349 & 311156 & Strike Selector Switch Pack & B57 & \\
\hline 20 & MC1352 & 311159 & Ready-Safe Switch & $\overline{B 28,57}$ & \\
\hline 11 & MC1356 & 311164 & Sequential Timer & B57 & Fired \\
\hline 18 & MC1417 & 311263 & Differential Pressure Inducer & B57 & Fired \\
\hline 17 & MC1510 & 311299 & Pressure Switch & B43 & (Some MC909) \\
\hline 11 & MC1592 & 311410 & Power Supply & B57 & w/o Batteries \\
\hline 3 & MC1702 & 311612 & Explosive Switch Pack & B43 & Fired \\
\hline 4 & MC1781 & 311730 & Filter Pack & B57 & \\
\hline 26 & MC1813 & 311760 & Interconnect Box & B57 & \\
\hline 16 & MC1835 & 311784 & Gas Generator & B61 & Fired \\
\hline 10 & MC1837 & 311786 & Ready Safe Switch & B61 & \\
\hline 22 & MC1838 & 311787 & Electronic Programmer & B61 & \\
\hline 5 & $\mathrm{MC1874}$ & 311816 & Preflight Control Box & B61 & Part for Displays \\
\hline 7 & MC1901 & 311846 & Pulse Duration Discriminator & B28 & \\
\hline 9 & MC1951 & 311932 & Rocket Motor & $\bar{B} 61$ & Fired \\
\hline 10 & MC1970 & 311950 & Filter Pack & B57 & \\
\hline 1 & MC2948 & 315093 & Trajectory Sensing Signal Gen. & B61 & \\
\hline 100 & MC3097 & 315779 & Power Supply & B28 & \\
\hline 8 & MC3897 & 319973 & Junction Box & B61 & \\
\hline & MC4018 & 411084 & Filter Pack & B90 & \\
\hline 5 & $\mathrm{MC} 4027$ & 411136 & Interface Control Unit & $\mathrm{B} 90$ & \\
\hline \multicolumn{6}{|c|}{346 lbs Total Whole and Rubblized (Barrel \# 1) } \\
\hline 15 & & & Brass Plate & W45 & From MC1187 \\
\hline 75 & & 1433994 & Radar Modules $(-3,4,5,6)$ & B57 & CRD; Sanitized \\
\hline 4 & & 352393 & SA739-1 & B43 & \\
\hline 13 & & 158763 & Switch Assembly & B57 & \\
\hline 13 & & $162057 \mathrm{C}$ & Fuse Access & & \\
\hline 8 & & & Fuse Access & & \\
\hline 1 & MC1345 & 311152 & Inertial Switch & B57 & \\
\hline 2 & MC1349 & 311156 & Switch Pack & B57 & \\
\hline 16 & MC1351 & 311158 & Interconnect Box & B57 & Inc XMC1351s \\
\hline 2 & XMC1352 & 311159 & Ready-Safe Switch & B57 & \\
\hline 3 & MC1449 & 311254 & Hydrostatic Switch & B57 & \\
\hline 3 & MC1450 & 311255 & Hydrostatic Switch & B57 & \\
\hline 1 & MC1804 & 311751 & Firing Set & B57 & CRD; Sanitized \\
\hline 1 & MC1813 & 311760 & Interconnecting Box & B57 & \\
\hline 8 & MC1814 & 311761 & Interconnecting Box & B57 & \\
\hline 10 & MC1901 & 311843 & Interconnecting Box & B61 & \\
\hline 1 & MC2213 & 312197 & Actuator/Pulse Battery Assembly & W28, B61 & w/o TB \\
\hline 3 & MC2213A & 315221 & Actuator/Pulse Battery Assembly & B61 & w/o TB \\
\hline 3 & MC2934 & 314885 & Junction Box & B61 & \\
\hline 3 & MC3616 & 318687 & Junction Box & B61 & \\
\hline 52 & MC3897 & 319973 & Junction Box & B61 & \\
\hline 32 & MC4024 & 411133 & Signal Source & $\mathrm{B} 90$ & \\
\hline 95 & MC4027 & 411136 & Interface Control Unit & B90 & \\
\hline 2 & MC4030 & 411142 & Driver & B90 & \\
\hline 2 & MC4136 & 411629 & Preflight Controller & $\mathrm{B} 61$ & $\mathrm{w} / \mathrm{O} \mathrm{TB}$ \\
\hline
\end{tabular}


The following components were rubblized in mixed batches:

\begin{tabular}{|r|l|l|l|l|l|}
\hline \multicolumn{1}{|c|}{ lbs } & MCNo, & Part No. & Component Name & Svstem & Comments \\
\hline 4 & MC4199 & & Strike Enable Plug & B90 & \\
\hline & MC4200 & 412162 & Depth Sensor & B90 & \\
\hline & & & Subassembly & & \\
\hline 10 & MC1970 & 311950 & Filter Pack & B57 & \\
\hline & MC2941 & 315015 & Filter Pack & B61 & w/o TB \\
\hline 10 & MC1349 & 311156 & Strike Selector Switch Pack & B57 & \\
\hline & MC1352 & 311159 & Ready-Safe Switch & B28,57 & \\
\hline & $102 ?$ & & & & \\
\hline 10 & & & Components from Test Unit & & \\
\hline 8 & MC909 & 310616 & Pressure Switch & B28,43,57 & \\
\hline & XMC909 & 310616 & Pressure Switch & B28,43,57 & \\
\hline & MC909TR & 310616 & Pressure Switch & B28,43,53 & \\
\hline & MC1510 & 311299 & Pressure Switch & B43,57 & \\
\hline 8 & & 158761 & Resistor \& Connector & B57 & \\
\hline & MC982 & 310717 & Pullout Switch & B57 & \\
\hline & MC1057 & 310807 & Temp Sensitive Pressure Switch & B43,53, & \\
\hline & MC4200 & 412162 & Depth Sensor & B90 & \\
\hline 6 & & & Switch Assembly & & \\
\hline & MC1531 & 311327 & Differential Pressure Inducer & B28,43 & \\
\hline & MC1766 & 311712 & Breakaway Pulse Conn Assy & B57 & \\
\hline & MC1818 & 311767 & Breakaway Pulse Conn Assy & B57 & \\
\hline 15 & MC1345 & 311152 & Inertial Switch & B57 & \\
\hline & XMC1345 & 311152 & Inertial Switch & B57 & \\
\hline & XMC1418 & 311223 & Hydrostatic Switch & B57 & \\
\hline & MC2969 & 315225 & Unique Signal Switch & Many & \\
\hline & XMC1366 & 311181 & Hydrostatic Switch & B57 & \\
\hline XMC1449 & 311254 & Hydrostatic Switch & B57 & \\
\hline MC1450 & 311255 & Hydrostatic Switch & B57 & \\
\hline MC2895 & 314658 & Switch Pack & W69 & \\
\hline & MC2935 & 314965 & Strong Link Trajectory Switch & Many & \\
\hline & & 158761 & Resistor \& Connector & B57 & \\
\hline & & & \\
\hline
\end{tabular}

$439 \mathrm{lbs}$ Total Rubblized (Barrell \# 2)

\begin{tabular}{|r|l|l|l|l|l|}
\hline 38 & & & Radar Module & B43 & \\
\hline 8 & & & Radar Module & B57 & \\
\hline 6 & MC1273 & 311079 & Temp Sensitive Press Switch & B53 & \\
\hline 26 & MC1348 & 311155 & Explosive Switch Pack & B57 & Fired \\
\hline 3 & MC1349 & 311156 & Strike Selector Switch Pack & B57 & \\
\hline 3 & MC1352 & 311159 & Ready-Safe Switch & B28,57 & \\
\hline 12 & MC1390 & 311206 & Explosive Switch Pack & B57 & \\
\hline 4 & MC1417 & 311222 & Differential Pressure Inducer & B57 & \\
\hline 14 & MC1813 & 311760 & Interconnecting Box & B57 & \\
\hline 15 & MC1814 & 311761 & Interconnecting Box & B57 & \\
\hline 4 & MC2894 & 314652 & Preflight Controller & B61 & \\
\hline 6 & MC2918 & 314699 & Firing Set & B61, W85 & \\
\hline 11 & MC3289 & 316641 & Interconnect \& Control Box & W80 & \\
\hline & MC3619 & 318359 & Preflight Controller & B61 & \\
\hline 2 & MC3679 & 318795 & Fuze & B28 & \\
\hline 20 & MC4017 & 411083 & Preflight Controller & B90 & \\
\hline 38 & MC4023 & 411132 & Weapon Control Unit & B90 & \\
\hline 25 & MC4034 & 411153 & Antenna & B90 & \\
\hline
\end{tabular}


Appendix E

The following components were rubblized in mixed batches:

\begin{tabular}{|c|l|l|l|l|l|}
\hline Ibs & MCNo. & Part No. & Component Name & Svstem & Comments \\
\hline 12 & MC1781 & 311730 & Low Pass Filter Pack & B57 & \\
\hline & MC1970 & 311950 & Filter Pack & B57 & \\
\hline 6 & MC1449 & 311254 & Hydrostatic Switch & B57 & \\
\hline & MC1450 & 311255 & Hydrostatic Switch & B57 & \\
\hline & MC2895 & 314658 & Switch Pack Monitor & W69 & \\
\hline & MC2935 & 314965 & Strong Link Switch & Many & \\
\hline 5 & MC1345 & 311152 & Inertial Switch & B57 & \\
\hline & MC1418 & 311223 & Hydrostatic Switch & B57 & \\
\hline & MC1813 & 311760 & Interconnecting Box & B57 & \\
\hline 8 & SA739-1 & & & B43 & \\
\hline & SA739-4 & 356208 & & B43 & \\
\hline & MC1510 & 311299 & Pressure Switch & B43,57 & \\
\hline & MC1612 & 311466 & Delayed Fuse Switch Pack & B57 & \\
\hline 10 & MC1349 & 311156 & Strike Selector Switch Pack & B57 & \\
\hline & MC1352 & 311159 & Ready-Safe Switch & B57 & \\
\hline & MC1356 & 311164 & Sequential Timer & B57 & \\
\hline & MC1612 & 311466 & Delayed Fuse Switch Pack & B57 & \\
\hline & MC2969 & 315225 & Unique Signal Switch & Many & \\
\hline 5 & MC982 & 310712 & Pullout Switch & B57 & \\
\hline & MC1391 & 311207 & Thermal Fuse Pack & B57 & \\
\hline & MC3268 & 316562 & Trajectory Sensing Signal Gen. & W80 & \\
\hline & MC3269 & 316563 & Trajectory Sensing Signal Gen. & W80 & \\
\hline 281 & 13016 & & \\
\hline
\end{tabular}

281 lbs Total Rubblized (Barrel \# 3) 
Table 6. Analysis Results

\begin{tabular}{|c|c|c|c|c|c|c|}
\hline \multirow{4}{*}{ Element } & \multicolumn{6}{|c|}{ Triple S Dynamics } \\
\hline & \multicolumn{2}{|c|}{ Test \#1 (Granulated) } & \multicolumn{2}{|c|}{ Run \#2 (+10 Heavies) } & \multicolumn{2}{|c|}{ Run \#6 (-20 Heavie } \\
\hline & \multicolumn{2}{|r|}{ As is } & \multicolumn{2}{|c|}{ Al concentrate } & \multicolumn{2}{|c|}{ As is } \\
\hline & wt.\% & $95 \% \mathrm{CL}$ & $w t . \%$ & $95 \% \mathrm{Cl}$ & wt.\% & $95 \% \mathrm{CL}$ \\
\hline $\mathrm{Ag}$ & 0.01 & 0.00 & 0.05 & 0.01 & 0.67 & 0.06 \\
\hline $\mathrm{Al}$ & 29.97 & 2.42 & NA & & 14.99 & 0.86 \\
\hline As & ND & & ND & & ND & \\
\hline As2 & ND & & ND & & ND & \\
\hline $\mathrm{Au}$ & 0.03 & 0.02 & ND & & 0.06 & 0.01 \\
\hline $\mathrm{B}$ & ND & & ND & & 0.05 & 0.02 \\
\hline $\mathbf{B a}$ & 0.05 & 0.00 & ND & & 0.41 & 0.04 \\
\hline Be & ND & & ND & & ND & \\
\hline $\mathrm{Bi}$ & 0.06 & 0.01 & ND & & 0.22 & 0.02 \\
\hline $\mathrm{Ca}$ & 0.56 & 0.11 & ND & & 0.40 & 0.11 \\
\hline Cd & 0.06 & 0.04 & ND & & 0.13 & 0.04 \\
\hline Co & ND & & 0.04 & 0.03 & 0.46 & 0.03 \\
\hline $\mathrm{Cr}$ & 1.18 & 0.58 & 0.18 & 0.40 & 1.20 & 0.17 \\
\hline $\mathrm{Cu}$ & 12.57 & 2.23 & 4.00 & 0.84 & 44.75 & 1.41 \\
\hline$F_{\theta}$ & 9.56 & 1.52 & 1.47 & 0.87 & 9.90 & 0.68 \\
\hline $\mathrm{Hg}$ & ND & & ND & & ND & \\
\hline$K$ & 0.04 & 0.01 & ND & & ND & \\
\hline Li & ND & & ND & & ND & \\
\hline $\mathrm{Mg}$ & 0.34 & 0.09 & ND & & 0.20 & 0.03 \\
\hline$M n$ & 0.14 & 0.07 & 0.02 & 0.03 & 0.21 & 0.02 \\
\hline Mo & 0.08 & 0.03 & ND & & 0.07 & 0.02 \\
\hline $\mathrm{Na}$ & 0.11 & 0.06 & ND & & ND & \\
\hline $\mathrm{Ni}$ & 1.85 & 1.95 & 0.70 & 0.68 & 2.42 & 0.10 \\
\hline$P$ & 0.02 & 0.01 & ND & & ND & \\
\hline $\mathrm{Pb}$ & 0.65 & 0.76 & 0.10 & 0.21 & 1.68 & 0.16 \\
\hline Pd & 0.05 & 0.07 & ND & & 0.09 & 0.02 \\
\hline Pt & ND & & ND & & ND & \\
\hline Sb & ND & & ND & & 0.05 & 0.03 \\
\hline Se & ND & & ND & & ND & \\
\hline Si & ND & & ND & & ND & \\
\hline Sn & 0.36 & 0.14 & 0.05 & 0.08 & 0.93 & 0.96 \\
\hline $\mathrm{Sr}$ & ND & & ND & & ND & \\
\hline $\mathrm{Ti}$ & 0.03 & 0.01 & ND & & 0.09 & 0.05 \\
\hline TI & ND & & ND & & ND & \\
\hline$V$ & ND & & ND & & ND & \\
\hline$W$ & 0.11 & 0.06 & ND & & 0.10 & 0.06 \\
\hline $\mathrm{Zn}$ & 1.76 & 1.59 & 0.08 & 0.13 & 2.73 & 0.68 \\
\hline $\mathrm{Zr}$ & ND & & ND & & ND & \\
\hline SUM & 59.59 & & 6.69 & & 81.81 & \\
\hline
\end{tabular}


Appendix E

Table 7. Analysis Results

Triple S Run \#3 (+10 Heavies)

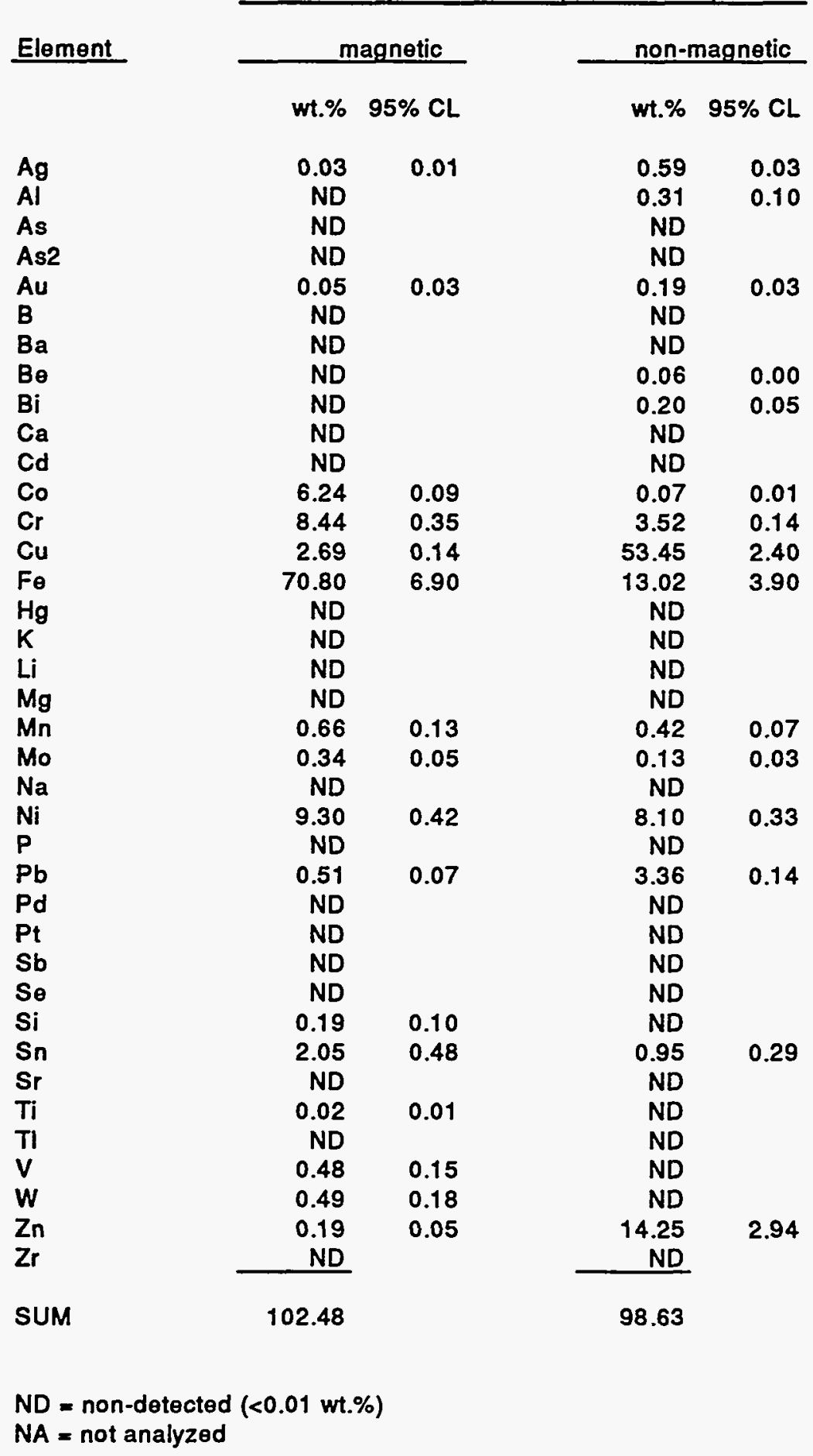


Table 8. Analysis Results

Triple S Run \#5 $(-10,+20$ Heavies $)$

\section{Element}

$\mathrm{Ag}$

Al

As

As2

Au

B

$\mathrm{Ba}$

$\mathrm{Be}$

$\mathrm{Bi}$

$\mathrm{Ca}$

Cd

Co

$\mathrm{Cr}$

$\mathrm{Cu}$

$\mathrm{Fe}$

$\mathrm{Hg}$

K

$\mathrm{Li}$

$\mathrm{Mg}$

$\mathrm{Mn}$

Mo

$\mathrm{Na}$

$\mathrm{Ni}$

$P$

$\mathrm{Pb}$

Pd

Pt

$\mathrm{Sb}$

Se

$\mathrm{Si}$

sn

Sr

$\mathrm{Ti}$

TI

V

W

$\mathrm{Zn}$

$\mathrm{Zr}$

SUM magnetic

wt.\% $95 \% \mathrm{CL}$

$\begin{array}{ll}0.14 & 0.02\end{array}$

$0.42 \quad 0.18$

ND

ND

0.07

ND

ND

0.02

ND

ND

ND

4.42

8.12

10.33

60.50

ND

ND

ND

ND

0.56

0.44

ND

8.95

ND

0.42

ND

ND

ND

ND

ND

1.61

ND

ND

ND

0.27

0.31

0.44

ND

97.01
0.11

0.06

0.41

0.07

0.53

0.13

0.20

0.11 non-magnetic

wt.\% $95 \% \mathrm{CL}$

1.49

0.55

ND

ND

0.10

ND

0.08

0.05

0.28

ND

ND

0.04

0.45

71.57

1.70

ND

ND

ND

ND

ND

ND

ND

1.82

ND

3.10

0.14

ND

ND

ND

ND

ND

ND

ND

ND

ND

ND

7.41

ND

88.78
0.75

0.14

0.29

0.01

0.03

0.06

0.02

1.57

3.02

5.59

1.43

0.69

0.11

1.42

15.13
Run $\# 5(-10,+20 \mathrm{Mi}$

as received

wt.\% $95 \% \mathrm{CL}$

$\begin{array}{rr}0.81 & 0.04 \\ 27.21 & 2.86 \\ \text { ND } & \\ \text { ND } & \end{array}$

ND

ND

$0.02 \quad 0.01$

$0.01 \quad 0.00$

$0.20 \quad 0.05$

$\begin{array}{ll}0.09 & 0.04\end{array}$

ND

$\begin{array}{ll}0.25 & 0.02\end{array}$

$0.66 \quad 0.04$

$52.11 \quad 2.34$

$5.87 \quad 1.28$

ND

ND

ND

$0.27 \quad 0.10$

$0.08 \quad 0.02$

$0.05 \quad 0.03$

$\begin{array}{ll}\text { ND } & \\ 1.36 & 0.07\end{array}$

ND

$0.71 \quad 0.06$

ND

ND

ND

ND

ND

$0.59 \quad 0.29$

ND

$0.02 \quad 0.00$

ND

$0.08 \quad 0.07$

ND

$0.88 \quad 0.19$

ND

91.26

7.49

$N D=$ non-detected $(<0.01 w t . \%)$

$N A=$ not analyzed 